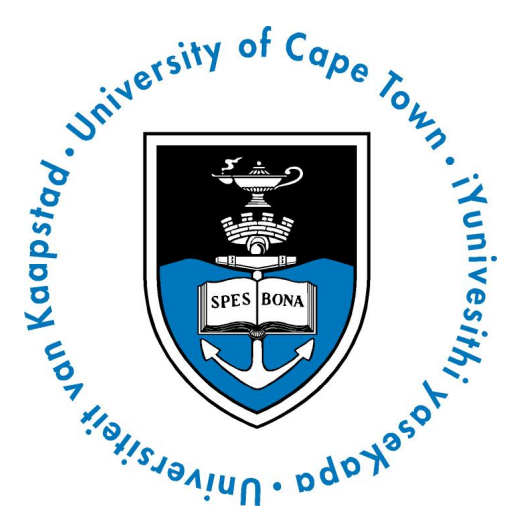

\title{
On the Feasibility of Landing the Dream Chaser Space Vehicle in South Africa
}

\author{
Kyle Luke Colvin
}

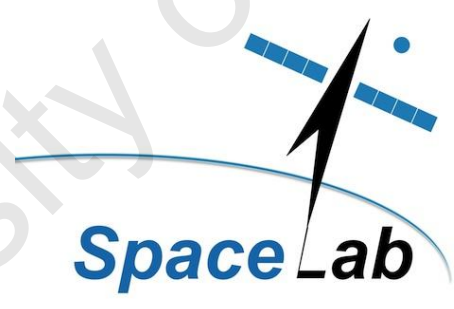

This dissertation is submitted in partial fulfilment of the requirements for the degree of Master of Philosophy in Space Studies

October 29, 2020

SL19-02M 
The copyright of this thesis vests in the author. No quotation from it or information derived from it is to be published without full acknowledgement of the source. The thesis is to be used for private study or noncommercial research purposes only.

Published by the University of Cape Town (UCT) in terms of the non-exclusive license granted to UCT by the author. 


\section{Declaration}

I, Kyle Luke Colvin, hereby:

(a) grant the University of Cape Town free license to reproduce this thesis in whole or in part, for the purpose of research;

(b) declare that:

(i) I know the meaning of plagiarism and declare that all the work in the document, save for that which is properly acknowledged, is my own. This thesis/dissertation has been submitted to the Turnitin module (or equivalent similarity and originality checking software) and I confirm that my supervisor has seen my report and any concerns revealed have been resolved.

I hereby present this dissertation for examination for the degree of MPhil Space Studies.

Signed by candidate

K.L. Colvin

October 29, 2020 


\section{Abstract}

The Dream Chaser is a space vehicle currently under development by the Sierra Nevada Corporation for purposes of carrying humans and cargo to low Earth orbit. In 2016, the United Nations entered into an agreement with Sierra Nevada Corporation to fly experimental payloads on the Dream Chaser. The collaborative UNOOSA-SNC Dream Chaser mission will be approximately two to three weeks in duration, with the Dream Chaser orbiting Earth at an altitude of $500 \mathrm{~km}$ with an inclination of $0-35^{\circ}$. This will be the first space mission dedicated to attaining the Sustainable Development Goals.

In this investigation the South African space and aerospace industry is placed under the microscope for the purpose of studying the feasibility of landing the Dream Chaser Space Vehicle on South African soil. The research dictates possibly having to establish a dualuse airport/spaceport recognised by the South African Space Council under supportive legislation to support this mission. Elements addressed in this investigation range from physical facilities such as the airports, workshops and laboratories through Dream Chaser specific requirements and specifications, right down to space and civil aviation regulations. This dissertation will assess all available infrastructure and supporting entities that will facilitate the safe landing of the Dream Chaser space vehicle in South Africa. However site visits and interviews were not part of this investigation.

This investigation prefaces the University of Cape Town's Space Lab plans to submit a landing proposal for a possible alternative landing site(s) for the Dream Chaser outside of the USA. This report is the first major step in researching and documenting the potential for landing the Dream Chaser or any reusable space vehicle in South Africa and will therefore make the case for South Africa as a suitable and attractive landing destination, not just for the Dream Chaser, but for accompanying scientists and researchers from all over the world involved in the mission. 


\section{Acknowledgements}

My sincere gratitude goes to:

My mother, Karen Colvin and girlfriend, Sara Heneck, for the endless support and guidance they provided when I needed to stay focused and positive in completing this dissertation.

To my two close friends who have been on this journey with me at SpaceLab, Nicholas Ringas and James Wilson. You have been inspirational in your individual ways and I appreciate and admire you both as friends and peers.

To my supervisor, Prof Peter Martinez, for always believing the sky is not the limit and anything is possible. Together with Prof Rene Laufer your creative collaboration bore the idea for this progressive and ambitious project. Your academic advice and guidance has helped me to produce this document that I believe we can all be proud of.

Lastly to my undergrad design lecturer, Dr Ruben Governder, for introducing me to LTEX and providing me with the template for this project. It was not easy at times but I am certainly pleased with the final product. 


\section{Contents}

1 Introduction 1

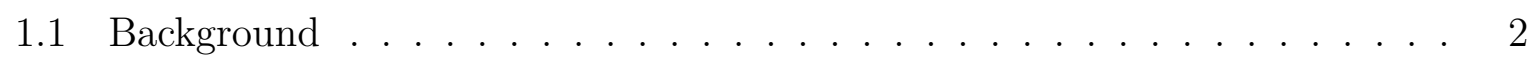

1.1.1 The United Nations and Space . . . . . . . . . . . . . . . . 2

1.1.2 South African Space Heritage . . . . . . . . . . . . . . . . 5

1.1.3 Context: SA Compared to the World . . . . . . . . . . . . . 7

1.1.4 Competitive New Idea . . . . . . . . . . . . . . . . . 8

1.2 Scope and Objectives . . . . . . . . . . . . . . . . . . 8

1.3 Outline and Plan of Development . . . . . . . . . . . . . . . 10

2 Lifting-Body Spaceplanes $\quad 13$

2.1 History . . . . . . . . . . . . . . . . . . . . . . . 13

2.1.1 Dream Chaser Antecedents . . . . . . . . . . . . . . 16

3 Dream Chaser Space Vehicle 23

3.0.1 Dream Chaser studies . . . . . . . . . . . . . . . . . 24

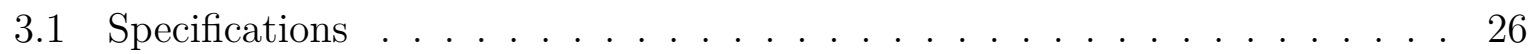

3.1.1 SNC provided specifications . . . . . . . . . . . 26

3.1.2 Payloads and Capabilities . . . . . . . . . . . . . 26

3.1.3 Orbital Options and Parameters . . . . . . . . . . . . 28

3.1 .4 Astrodynamics . . . . . . . . . . . . . . . . 28

3.1.5 Dream Chaser Orbits . . . . . . . . . . . . . . . . . . . 30

3.1.6 Dream Chaser descent \& landing profile . . . . . . . . . . . . . 32 
3.1.7 Dream Chaser Landing Requirements and Constraints . . . . . . . 33

4 South African Infrastructure $\quad 37$

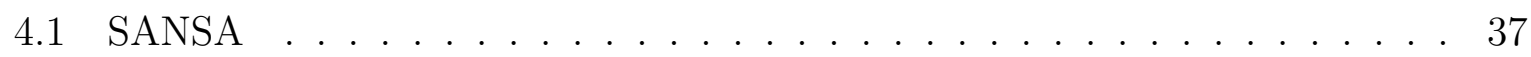

4.1 .1 SANSA Space Science . . . . . . . . . . . . . . . . 38

4.1 .2 SANSA Space Operations . . . . . . . . . . . . . . 39

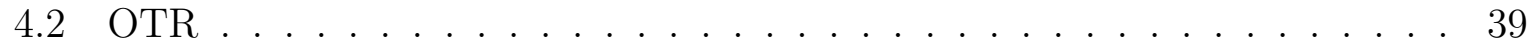

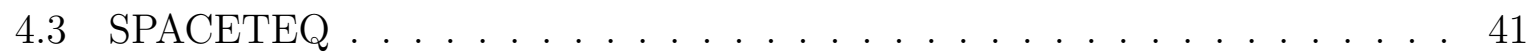

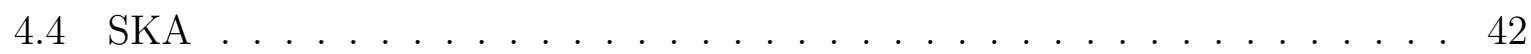

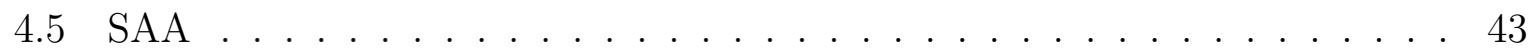

5 Policy \& Regulatory Aspects 45

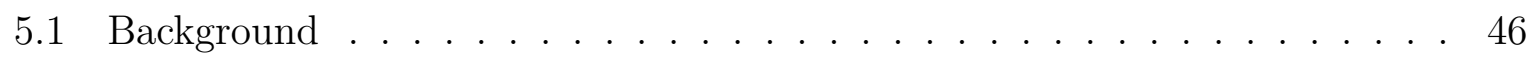

5.2 International Space Law . . . . . . . . . . . . . . . . . . . 47

5.2.1 South Africa's International Obligation . . . . . . . . . . . . . . . . 48

5.2.2 International \& Government Agencies . . . . . . . . . . . . . . . . . 48

5.2 .3 Space Traffic Management . . . . . . . . . . . . . . . . . . . 49

5.3 South African Space Law . . . . . . . . . . . . . . . . . . . . . 50

5.3.1 South African Space Policy and Space Strategy . . . . . . . . . . . 53

5.4 International Spaceport regulations . . . . . . . . . . . . . . . . 54

5.4 Launch and Re-entry guidelines . . . . . . . . . . . . . . 55

5.5 Civil Aviation Regulations . . . . . . . . . . . . . . . . . 57

5.6 Benefits of Strong Legislation _ . . . . . . . . . . . . . . . . . . 59

5.7 South Africa fostering international relations . . . . . . . . . . . . . . 59

$\begin{array}{lll}6 & \text { Analysis } & 61\end{array}$

6.1 Potential Dream Chaser Landing Sites . . . . . . . . . . . . . 63

6.1.1 Site Profiles and SWOT Analysis . . . . . . . . . . . . . . 67

6.1.2 Factors for consideration . . . . . . . . . . . . . . . . 72 
7 Conclusions and Recommendations 75

Appendices 85

A Tailored SME process for this dissertation 85

B Orbital Options 87

C Density comparison 89

D Dream Chaser Mission Overview 91

E African Perspective on Integrated Space and Air Traffic Management 95 


\section{List of Figures}

1.1 The orbital vehicle options in the HSTI program $[4] \ldots . . . . . . .3$

a Chinese Space Station . . . . . . . . . . . . . . . 3

b KiboCUBE - Japanese Experiment Module . . . . . . . . . . . . 3

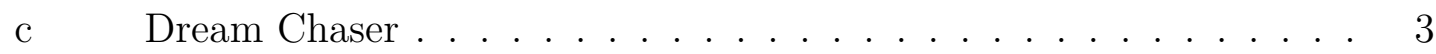

1.2 Sustainable Development Goals. . . . . . . . . . . . . . . . . . . . 4

1.3 Hartebeesthoek Radio Telescope. . . . . . . . . . . . . . . . . . 5

1.4 Helmholtz Coil -The one of a kind, used to calibrate magnetic earth sensors by cancelling the geomagnetic field in real time $[9] \ldots \ldots$. . . . . . 5

1.5 SME Process table and typical flow $[19] \ldots \ldots \ldots \ldots$. . . . . . . 11

2.1 Bill Dana (research pilot) stands along side the HL-10 after a successful test flight over Rodgers Dry Lake. . . . . . . . . . . . . . . . . . . 14

2.2 Left to right: M2-F2, X-20 Dyna-Soar, BOR 4S, Soviet BOR 4. . . . . . . 14

2.3 Artist's impression of the X-20 Dyna-Soar. . . . . . . . . . . . . . . 17

2.4 M2-F1 flown behind R4D plane at Dryden. . . . . . . . . . . . 17

2.5 Lifting Bodies: X-24A, M2-F3, HL-10. . . . . . . . . . . . . . . 18

a BOR-4 [Manufacturer photo]. . . . . . . . . . . . . 22

b Recovery photos by Soviet Navy. . . . . . . . . . . . . . . 22

3.1 Dream Chaser Space Vehicle. . . . . . . . . . . . . . . . . . . . 23

3.2 Dream Chaser aerodynamic control surfaces. . . . . . . . . . . . . 25

3.3 Payload options aboard the UNOOSA Dream Chaser mission. . . . . . . . 27

3.4 Keplerian orbital elements of an orbiting satellite. [braeunig.us] . . . . . . 28 
3.5 Generalised orbit depicting semi-major axis and related basic formulae. . . 29

3.6 Conic sections on planes intersecting a right circular cone. [braeunig.us] . . 29

3.7 STK simulation of ISS orbital ground tracks with orbital data . . . . . . 31

3.8 STK simulation of ISS orbital ground tracks with orbital data . . . . . . . 31

3.9 Dream Chaser re-entry profile[44] . . . . . . . . . . . . . . . . . . . 32

4.1 SANSA and its four major programmes. . . . . . . . . . . . . 38

4.2 Hermanus Space Weather Regional Warning System operates under ISES. . 38

4.3 A few of the antennas operating at SANSA Space Operations. . . . . . . . 39

4.4 Denel OTB Test Range map. . . . . . . . . . . . . . . . . . . . . . . . 40

4.5 Overberg Test Range-Google Earth . . . . . . . . . . . . . . . . . . . . . . 44

5.1 The South African space government framework. . . . . . . . . . . . . . . 52

5.2 U.S. Spaceports. [credits: FAA[65]] . . . . . . . . . . . . . 55

6.1 Dream Chaser landing at the Dryden Flight Research Center runway in the Mojave Desert. . . . . . . . . . . . . . . . . . . . 61

6.2 South Africa Air Traffic Routes as of 2017 - AFB Overberg labelled. . . . . 66

6.3 Model of debris dispersion from a launch vehicle break-up. . . . . . . . . . 66

6.4 Upington International Airport and surrounds . . . . . . . . . . . . . . 67

6.5 Hoedspruit AFB and surrounds. . . . . . . . . . . . . . . . . . 68

6.6 TFDC Bredasdorp and surrounds . . . . . . . . . . . . . . . . . . . . . 69

6.7 King Shaka International Airport and surrounds. . . . . . . . . . . . . . . 70

6.8 Louis Trichardt Airport and surrounds. . . . . . . . . . . . . . . . . . . . . 71

6.9 Potential suborbital Space Traffic routes for passenger (orange) and cargo transportation $($ red) $[61] \ldots \ldots \ldots$. . . . . . . . . . . . . . . 72

B.1 In this image the DC is in a slightly inclined orbit requiring lower energy and passing over both Florida and South Africa, the take-off and potential landing site respectively. . . . . . . . . . . . . . . . . 87

B.2 In this image two potential ground-stations are shown for the Dream Chaser, one in Guam and the other at HartRAO . . . . . . . . . . . . . . . . . . . . 88 
B.3 In this image the Dream Chaser is in a polar orbit, another potentially desirable orbit also covering take-off and landing sites. . . . . . . . . . 88

C.1 Lanseria International Airport, NW of Randburg and Sandton surrounded by sparse farmland and owned privately. . . . . . . . . . . . . . . . 89

C.2 Waterkloof AFB surrounded by dense civilian population. . . . . . . . . . . 90

C.3 King Shaka International Airport, surrounded by mostly sugar-cane fields and nucleated settlements. . . . . . . . . . . . . . . . . . 990 90

D.1 Comparisons for our common knowledge to help grasp features for the Dream Chaser. . . . . . . . . . . . . . . . . . . . . . . . 93 


\section{List of Tables}

2.1 Flight count of NASA's lifting body fleet. . . . . . . . . . . . . 19

6.1 Condensed list of Dream Chaser Specifications . . . . . . . . . . . . . . . 62

6.2 Shortened list of SA Airports [Fallinggrain software] reduced with Excel filters. . . . . . . . . . . . . . . . . . . . . 64

6.3 Potential Dream Chaser landing sites in South Africa. . . . . . . . . . . . . 65

6.4 Potential Dream Chaser landing sites in South Africa. . . . . . . . . . . . 65 


\section{Acronyms}

AFB - Air Force Base

ALAIRP - As low as is reasonably practicable

AMSL - Above Mean Sea Level

ARMC - African Resource Management Constellation

ATC - Air Traffic Control

ATM - Air Traffic Management

CAASA - Civil Aviation Authority of South Africa

CFI - Call For Interest

CNES - Centre National D'etudes Spatiales /French National Center for Space Studies (Space Agency)

CNSA - Chinese National Space Agency

CONUS - Contiguous United States

COPUOS - Comity On Peaceful User of Outer Space

CRS - Commercial Resupply Services

CSLAA - Commercial Space Launch Amendment Act

DARPA - Defence Advanced Research Projects Agency

DCSS - Dream Chaser Space System

DOTR - Denel Overberg Test Range

EO - Earth Observation

ESA - European Space Agency

FAA - Federal Aviation Administration

FAA-AST - FAA's Office of Commercial Space Transportation 
FE - Future European

GNSS - Global Navigation Satellite System

GSE - Ground Support Equipment

HSE - Health and Safety Executive

HSL - Health and Safety Laboratory

IAA - Inernational Aeronautic Association

IAASS - International Association for the Advancement of Space Safety

IAF - International Astronautical Federation

ICAO - International Civil Aviation Organisation

ICP - Informed Concent Protocol

ITU - International Telecommunication Union

MCC - Mission Control Center

MPS - Main Propulsion System

NAS - National Airspace System

NAS - Nationa Airspace System

NASA - National Aeronautics and Space Administration

NMUSAF - National Museum United States Air Force

ORV - Orbital Return Vehicle

OTR(OTB) - Overberg Test Range (Overberg Toetsbaan)

OV - Orbital Vehicle

PCM - Phase Change Material

PLS - Personal Launch System

RPS - Reaction Propulsion system

SACAA - South African Commercial Aviation Authority

SARP - Standards and Recommended Practices

SCS - Space Commercial Services 
SDG - Sustainable Development Goals

SFAIRP - So far as is resonably practicable

SGAC - Space Generation Advisory Council

SMAD - Space Mission Analysis and Design

SME - Space Mission Engineering

SNC - Sierra Nevada Corporation

STM - SpaceTraffic Management

STS - Space Transportation System

TCS - Thermal Control System

TFDC - Test Flight Development Center

UKSA - United Kingdom Space Agency

UN - United Nations

UNOOSA - United Nations Office for Outer Space Affairs

USAF - United States Air Force

VTHL - Vertical Take-off Horizontal landing

msl - Mean Sea Level

\section{Units \& Conventions}

$\begin{array}{ll}1 \text { inch }=2.54 \text { centimetres } & \text { FL100, 10,000 ft above msl } \\ 1 \text { foot }=30.48 \text { centimetres } & \text { FL180, 18,000 } f t \text { above msl } \\ & \text { FL340, 34,000 ft above msl } \\ & \text { FL450, 45, 000 ft above msl } \\ & \text { FL600, 60, } 000 \mathrm{ft} \text { above msl }\end{array}$




\section{Chapter 1}

\section{Introduction}

In 2016 a partnership was established between the United Nations Office for Outer Space Affairs (UNOOSA) and a private American company, Sierra Nevada Corporation (SNC), to collaborate on utilising space technology to support capacity building in the emerging space nations as well as the attainment of the UN's Sustainable Development Goals. The SNC spaceplane, the Dream Chaser, will be utilised to fly experimental payloads from UN member States in an orbital mission, particularly aimed at facilitating developing nations' space capabilities. The mission will be approximately two to three weeks in duration, with the Dream Chaser orbiting Earth at an altitude of $500 \mathrm{~km}$ with an inclination of $0-35^{\circ}[1]$. This will be the first space mission dedicated to supporting the Sustainable Development Goals (SDGs)[2].

The University of Cape Town's (UCT) SpaceLab responded to UNOOSA's call for interest (CFI) with a notice of intent to participate by developing a payload in an international collaboration. Furthermore, the SpaceLab plans to submit a landing proposal for a possible joint UNOOSA-SNC call for landing sites outside of the USA. This dissertation is the first major step in researching and documenting the potential for landing the Dream Chaser in South Africa and will therefore look to make the case for South Africa as a suitable and attractive landing site. This work may later become the background study to the SpaceLab's landing site proposal.

Underpinning this work is the South African Space policy, which recognises the far reaching and multidisciplinary nature of space activities. The policy also recognizes the importance of appreciating our space heritage. Space is now integrated into our daily lives and is key in uplifting the economy while supporting sustainable development of the country and its people.

The remainder of this chapter aims to bring to the foreground the relevance of this project and the proposal it precedes, while making reference to the major stakeholders and key role players which may be involved in carrying this idea forward. And at the end of this 
chapter a plan of development for this dissertation is addressed, drawn from the scope and objectives in the form of an outline and summary.

\subsection{Background}

In this section we will provide an overview of how the SpaceLab has come to be involved in such a multinational project by briefly discussing the stakeholders of the UNOOSASNC collaboration before shedding light on South Africa's often underestimated space capabilities.

\subsubsection{The United Nations and Space}

Space activities are by their very nature international in scope and character. The United Nations has served as an international forum to discuss space activities since the dawn of the Space Age in 1957. The United Nations Committee on the Peaceful Uses of Outer Space (UNCOPUOS) was set up in 1959 by the UN General Assembly (GA). It fills the need for a cooperative intergovernmental platform based on maintaining the peaceful exploration and use of outer space. It has always stood for international cooperation in human space flight and space related activities among its Member States. UNOOSA, as the secretariat to COPUOS, "services international discourse and dialogue against a backdrop of law and diplomacy, conducts capacity building activities that harness space tools for development and promotes awareness through the celebration of space achievements and milestones"[3]. In 2010 UNOOSA launched the Human Space Technology Initiative (HSTI) aimed at involving more countries in activities related to human space flight and space exploration [4]. All activities under the initiative are based upon three pillars:

\section{- International Cooperation}

\section{- Outreach}

\section{- Capacity building}

Under the HSTI initiative are events, workshops and activities aimed at providing experimental platforms and orbital opportunities. UNOOSA has established key partnerships with both private and public member state organisations to provide access to a variety of orbital opportunities into Low-Earth-Orbit (LEO) (100 km-2000 km altitude). These opportunities are as follows and can be viewed in more detail on the official UN-HSTI website:

(a) In collaboration with the Chinese National Space Agency (CNSA) - Flying experiments, astronauts/payload engineers aboard the Chinese Space Station CSS. 
(b) KIBOCUBE - In Collaboration with Japan, using their experimental module, KiboCube, to launch CubeSats from the ISS.

(c) Free Flyer Orbital Mission - In collaboration with Sierra Nevada Corporation (SNC), UN member states can participate in an orbital space mission using the Dream Chaser space vehicle.

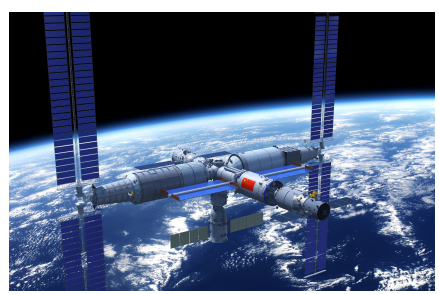

(a) Chinese Space Station

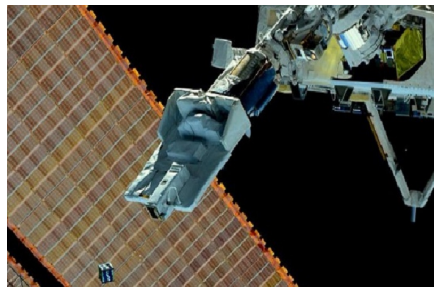

(b) KiboCUBE - Japanese Experiment Module

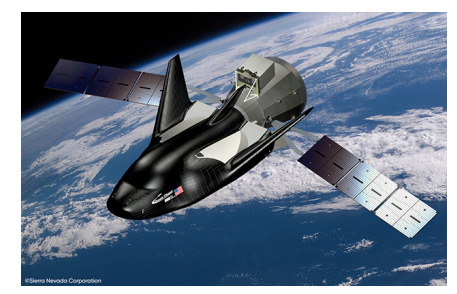

(c) Dream Chaser

Figure 1.1 The orbital vehicle options in the HSTI program [4]

This project is concerned with the SNC Dream Chaser space vehicle, seen in Figure 1.1c. The Dream Chaser is a multi-mission space utility vehicle designed to deliver cargo and crew into LEO, to destinations such as the International Space Station (ISS). The Dream Chaser was partially developed under NASA's Commercial Crew transportation Capacity (CCtCap) funding program, but, due to lack of project maturity in final rounds, SNC lost out to further projects. Another phase of NASA funding was introduced to add robust redundancy to the present ISS services, the Commercial Resupply Service 2 (CRS-2) contract. Through this contract SNC now has funding to deliver food and water as well as provide waste removal at least six times from the ISS beginning in 2021 [5].

The signing of the Memorandum of Understanding (MoU) between UNOOSA and SNC took place on the 28th of June 2016[6]. The MoU marked the beginning of the exploration into the collaboration which will see the Dream Chaser host experimental payloads from UN member countries into a 3-week long mission orbiting Earth, with a particular focus on encouraging the involvement of developing countries.

\subsubsection{SNC to use ESA developed Docking Station}

It is worth mentioning that in 2017 ESA and a team of industrial contractors finalised an agreement with SNC to use Europe's International Berthing Docking Mechanism (IBDM) on the Dream Chaser spaceplane. The IBDM is a "contact force-sensing, low impact docking system". The IBDM is in line with the International Docking System Standards (IDSS) and was developed in cooperation with NASA for replacing the docking system for space vehicles visiting the ISS post the retirement of the Space Shuttle [7]. 


\subsubsection{The UN Sustainable Development Goals (SDGs)}

The SDGs, are a focal point in the UNOOSA and SNC collaborative mission as this will be the first space mission dedicated to the SDGs (Figure 1.2 below). The UN with 190 member States has developed the Agenda 2030 to tackle global societal challenges of the day in the fields of the SDG's with 169 associated targets. The importance of space in achieving these goals and targets cannot be overestimated. For example, disaster management, a major challenge with climate change and overpopulation in low-lying coastal regions, is reliant on space systems from beginning to end; weather mapping, earth observation (EO) and global navigation satellite services (GNSS), to name but a few of the space services and technologies required[8]. In the announcement around the MoU signing, the owner and President of SNC, Eren Ozmen said, "This is about scientific discovery, and about opening space to organizations that may not have access to it otherwise. We're thrilled to provide the vehicle that will make this happen." Simonetta Di Pippo, director of UNOOSA said, "We expect our efforts in building industry capacity to have long-term impacts, especially in space-related science, technology, engineering and mathematics (STEM) education programs, and that these results will flow to the wider economy as a whole. We are here to support developing and emerging countries and institutions so that this mission can really enable inclusive access to space for all and contribute to the attainment of the Sustainable Development Goals."

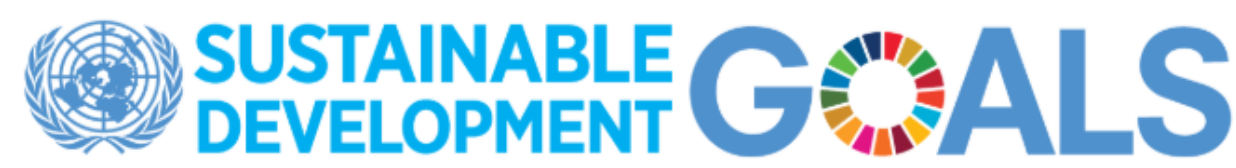

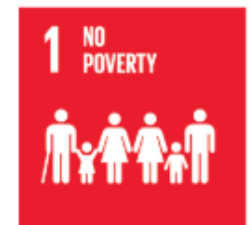
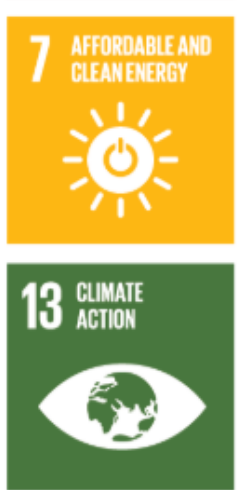
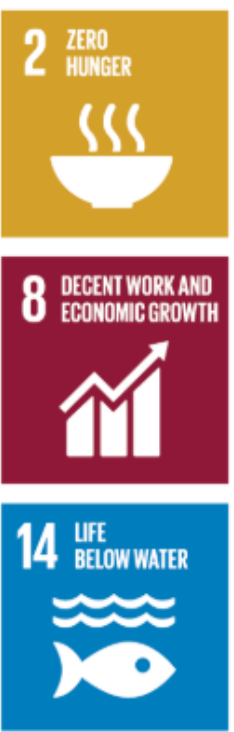

Figure 1.
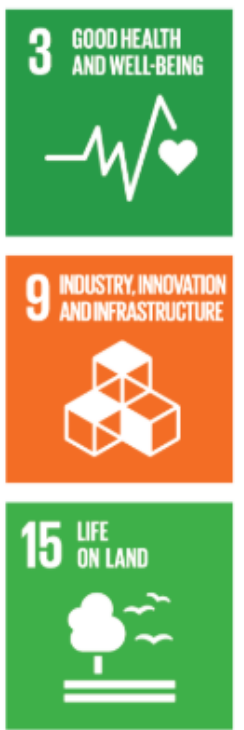
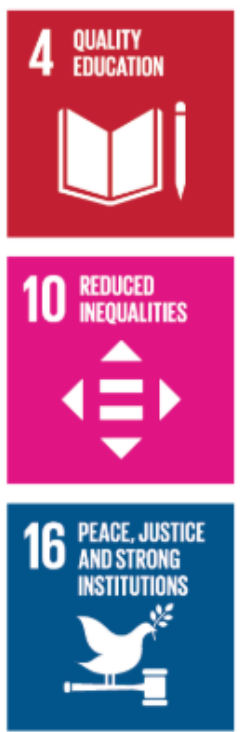
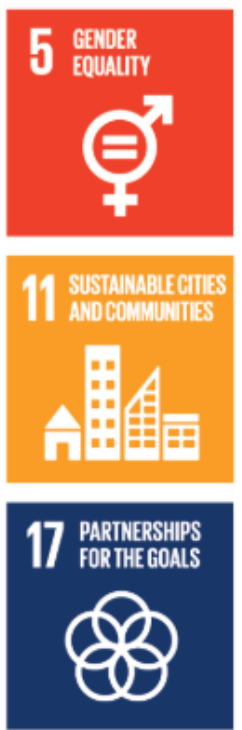
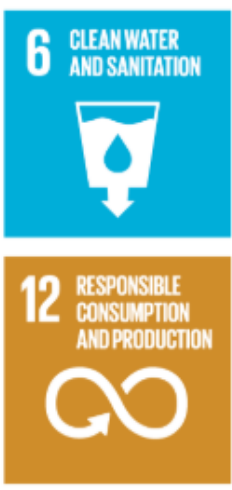

(89) SUSTAINABLE DEVELOPMENT GALS 


\subsubsection{South African Space Heritage}

South Africa has long been involved in space research and the global space industry. Some of the oldest space related programmes and facilities in the world originated in South Africa, some even before the Space Race which took place during the years of the Cold War. It was only in 2010 however, that the South African National Space Agency (SANSA) was established, following the 2008 SANSA Act, in order to house all space related activities under one roof.

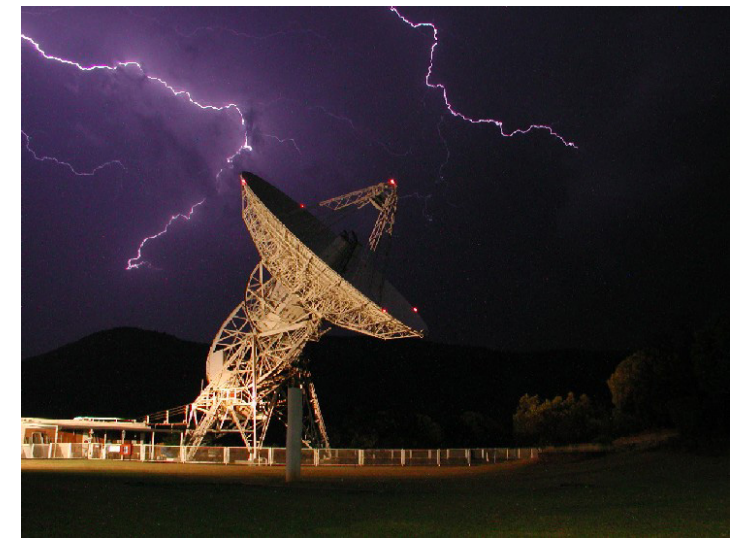

Figure 1.3 Hartebeesthoek Radio Telescope.

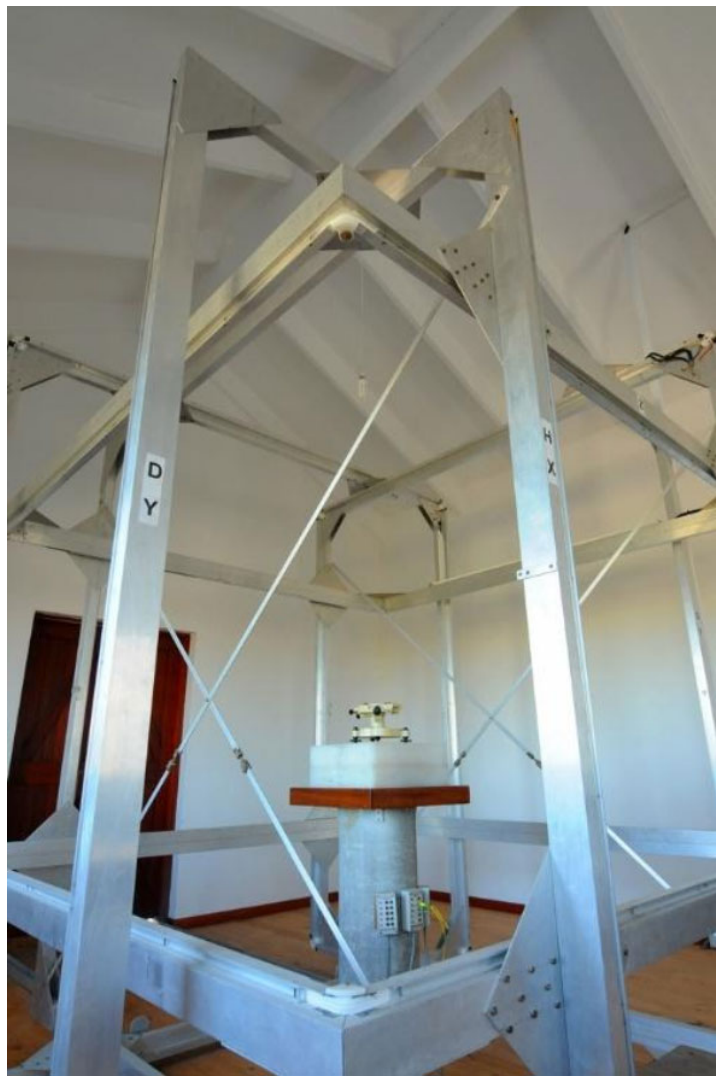

Figure 1.4 Helmholtz Coil -The one of a kind, used to calibrate magnetic earth sensors by cancelling the geomagnetic field in real time[9]

In 1960, a series of events and research carried out by a global observatory network, including the SA Magnetic Observatory (based in Hermanus since 1940), culminated in the first South African Antarctic Expedition (SANAE 1). The Magnetic Observatory had previously been operating from UCT, since 1841. Due to the introduction of the electric railway system in Cape Town, the observatory had to be moved. During the same year that SANAE 1 took place, the United States National Aeronautics and Space Administration (NASA) built a tracking station at Hartebeesthoek, located $50 \mathrm{~km}$ North West of Johannesburg[10]. It was crucial to maintain radio contact with their satellites from the ground when they were not visible from the USA ground stations. Many American lunar and interplanetary space missions were supported by the Hartebeesthoek facility. South Africa's unique position at the bottom of Africa meant it was in sight of the second stage separation for rockets launched from Cape Canaveral, Florida.

The original antenna built for NASA is still in use today, adapted for radio astronomy purposes. Due to political pressure, resulting from the apartheid regime and sanctions placed on SA, the USA pulled out of operations in Hartebeesthoek in 1974. The site became known as HartRao, a world class Radio Astronomy Observatory, headed by Dr. 
George Nicolson. The SANSA Space Operations Centre is adjacent to the old NASA facility and is used for Telemetry, Tracking and Command $(\mathrm{TT} \& \mathrm{C})^{1}$ purposes. Today the site is home to many nations' and private organisations radio equipment. It also serves the last point of downlink before polar orbiting satellites go over the South Pole. According to SANSA, hundreds of launches have been overseen and the site has provided continuous TT\&C services to satellites belonging to international space agencies and companies. This station was also responsible for receiving the first-ever images of the far side of the Moon and later, close-up images of Mars, downlinked from the Mariner IV on a Mars flyby in 1968[11]. HartRAO, a SANSA Space Ops. facility, represents technological maturity and expertise required for key elements of the Dream Chaser mission. It also provides options as there are many radio telescopes from which the mission planners and engineers can choose in one well established area.

South Africa is one of Africa's eight space faring nations with satellites in orbit. It has the most satellites launched to date; 8 out of the total 35 satellites launched from Africa. Ahead of Algeria and Nigeria with 6 satellites launched and Egypt which has launched 7 satellites[12]. South Africa was the second African country to launch a satellite. Just one year after Egypt launched the NILE-Sat1. South Africa launched its SUNSAT multi spectral EO satellite in 1999. The continent has seen rapid growth in the space industry in the last few years, with 15 of the 35 satellites being launched in just the last four years according to the 2019 annual report on the African Space Industry [13]. The annual report goes on to say that Africa's Space Market is now worth US\$7 billion annually and is expected to grow by $40 \%$ in the next 5 years to reach over US\$10 billion. South Africa is also the most advanced country in Africa in terms of its ability to manufacture a satellite with local facilities, suppliers and indigenous technologies. The Houwteq facility in Grabouw, which was built in 1985, hosts: clean rooms, thermal vacuum ovens, anechoic chambers, mechanical and acoustic vibration testing areas and designated client areas encompassing secure access enclosed areas with open-plan offices, conference rooms, small laboratory spaces and fast, secure internet connection[14]. South Africas' unique combination of geographic location, the already exisitng and well-established ground facilities and its space heritage along with operational expertise gained in national, foreign and international space missions factor into putting South Africa in a prime position to host the first landing site for the Dream Chaser in Africa.

Security for the Dream Chasers' landing options is a key area of interest for this dissertation, therefore the South African defence industry must be considered. South Africa's defence industry is well renowned, with large parastatal counterparts that service both local and international customers - elaborated on in Chapter 4.

\footnotetext{
${ }^{1}$ Communicating with spacecraft, providing uplink commands from operators on Earth and receiving downlinked data
} 
Less well known is the South African civil aerospace industry, represented by the Commercial Aviation Manufacturing Association of South Africa (CAMASA), founded in 2016. CAMASA has over 50 members, boasts export revenue of $R 3$ billion annually and collectively employs over 3000 staff. CAMASA plans to boost annual exports of locally produced aerospace equipment by $100 \%$ over the next 5 years. The Commercial Aviation Association of South Africa (CAASA) is the oldest of the aviation groups in the country. It was established in 1944 and recently celebrated its 75th birthday. These establishments bode well for the Dream Chaser in South Africa as the mission requires aviation infrastructure and furthermore concerns aviation policy to accommodate the landing.

One of the major issues faced in South Africa today is that of corruption within government and the mismanagement of resources and funds. Notably however, the director of Civil Aviation Authority in South Africa (SACAA), Ms Poppy Khoza, was awarded Top Empowered Business Leader of the year in April 2018. According to reports, her brilliance permeated across the organisation, achieving 100\% against set targets and receiving the Auditor-General's Award 5-years in a row since her appointment in 2013 [15]. Many industry experts believe the industry is primed for expansion[16].

\subsubsection{Context: SA Compared to the World}

The US-based Space Foundation's 2018 annual report found that the global space economy was worth $\$ 383.5$ billion in total, up from $\$ 329$ billion in 2017 . This massive year-on-year growth is mostly attributed to the commercial space sector, which made up $76 \%$ of global space activities in 2017. South Africa in contrast continues to suffer from an underfunded space program, even relative to African competitors; projects such as EO-Sat1 sit in stagnation largely because the SA government does not recognise the importance and value of the Space Sector. "The South African space economy is very small" says Khatri of SANSA in the annual report[17]. According to the online magazine, Space in Africa only around $\$ 3$ billion has been spent on space projects across Africa since NILEsat 101 was launched in 1998[13]. This is a tiny figure in contrast to the value of the global space economy. "Space is essential for South Africa's economic and social development," Val Munsami writes in SANSA's yearly report. Budget constraints continue to affect the agency, making it hard to achieve the agency's strategic mandate. He adds however, that despite having constraints the SANSA staff continue to be motivated to achieving excellence. Consequently SANSA has been clever in its use of funding and is seriously looking at leveraging international collaborations to enhance SANSA's capacity to reach its mandate with the limited resources at its disposal. If South Africa is going to become a globally recognised contributor to the global space industry in the next decade, new collaborations will need to be forged.

The proposed landing of the Dream Chaser space vehicle in South Africa has great potential to bring renewed infrastructure and energy to the South African Space community. 
This project will be the greatest US-SA space collaboration since the Hartebeesthoek tracking station (turned Astronomical observatory site). If the infrastructure and worldclass radio astronomy facilities that remained after the US withdrew from Hartebeesthoek in the 1970's, is anything to go by it is safe to say that this new project should be pursued for its long-term benefits by all available means. Section 4.4 is dedicated to the benefits stemming from the Square Kilometre Array (SKA). The arrival of the Dream Chaser space vehicle in South Africa along with SNC know-how brings Engineering and other STEM related disciplines to the fore in a country that needs this stimulus.

\subsubsection{Competitive New Idea}

Prior to conducting research and writing this dissertation, the idea for proposing South Africa as a potential landing site for SNC's Dream Chaser space vehicle had not been publicly discussed, therefore it is being considered here as a competitive new idea. Competitive, as the proposal will follow a CFI which may be issued by UNOOSA or SNC once there is a decision to land the Dream Chaser outside of America to further the benefits of a joint private and governmental mission aimed at bettering skills and technology in developing countries[18].

The idea originated through discussions between professors at the UCT Space Lab, namely: Professor Peter Martinez and Professor Rene Laufer. When the call for interest came from UNOOSA-SNC for a mission to take experiments from member states of UNOOSA aboard the Dream Chaser space vehicle, the Space Lab was quick to propose an experiment of it's own. Following the proposal and recognising UNOOSA's continued initiatives aimed at uplifting developing countries as well as SNC's need for building a network of landing sites around the world for nominal and contingency (emergency) situations, the idea behind this project materialised.

The challenge now is bringing together all the elements that provide a basis from which future groups can carry this work forward successfully and without having to re-work this document.

This new idea brings together some of South Africa's strongest technological experience; historic world-class facilities; dedicated agencies and best-in-class companies. These elements as well as the dedicated SDGs mission will be elaborated on in the chapters to follow.

\subsection{Scope and Objectives}

As mentioned in the previous Section 1.1.4 there are many elements that must be identified and understood in order to produce a successful background study. Mapping 
a comprehensive and coherent project plan is imperative and this begins here with the scope and corresponding objectives of this project:

(1) Introduction and initial literature research (literature survey, possible landing sites and infrastructure in South Africa, legal and regulatory, technical issues, stakeholders) - Literature discussed throughout.

(2) Identification, recognition, compilation and assessment of requirements and constraints as well as additional boundary conditions (technical and non-technical) for a Dream Chaser landing campaign in South Africa.

- Brought forward in Chapter3, further reviewed in Chapter6.

(3) Identification and assessment of necessary infrastructure, facilities, ground and space segments and its respective operators and stakeholders.

- Discuss relevant South African Infrastructure in Chapter 4.

(4) Identification and assessment of institutions, organisations as well as governmental and non-governmental bodies to be involved in preparing for a Dream Chaser landing campaign in South African and the involved regulatory processes.

- Chapter 4 discusses policy and related institutions and organisations.

(5) Preliminary mission design of a Dream Chaser landing campaign in South African.

(6) Documentation in preparation of a planned landing site proposal.

Leading on from the six items in the scope, a paired list of objectives has been generated below to further develop the project plan:

(1) Identify all useful websites, articles, reports pertaining to the relevant sections of this report, with particular focus on South African infrastructure (airports, space segments), the Dream Chaser (technical and not), other stakeholders and legal documentation)

(2) Through identified literature successfully build parameters and outlines for the preliminary mission design of the Dream Chaser Landing campaign in South African.

(3) Generate a complete profile/catalogue of the institutions and organisations that are most definitely required to be involved in such a mission assessing as many as necessary but keeping it to a minimum before expanding into the additional groups that may be nice to have involved.

(4) Generate a clear assessment of all possibly feasible infrastructure, facilities, ground and space segments and respective operators and stakeholders to fully understand the options. 
(5) Outline and discuss Space Mission Ananlysis and Design/Space Mission Engineering, building a foundation from which others can build on this project in the future.

(6) Prepare a reasonable guide to helping future group/s prepare for the Dream Chaser landing in South Africa.

\subsection{Outline and Plan of Development}

The investigation for this dissertation is inherently multidisciplinary as it concerns an orbital space mission; one which brings together groups from different nations. This dissertation therefore lends itself to the classical Space Mission Analysis and Design (SMAD) and the Space Mission Engineering (SME) approach. Successful space missions should adhere to these guidelines as they have been developed through the analysis of many case studies and past missions. The models are ever changing although the underlying theory holds true. As this report is mainly concerned with the background research and not developing the full mission only the relevant elements of the SMAD \& SME approaches will be addressed.

The objective of SME is refining the requirements and definition of mission parameters to meet the broad objectives of a space mission in a timely manner at minimum risk and cost[SME: 2011]. This dissertation will analyse the Dream Chaser and its antecedents in order to best refine its requirements and mission parameters before attempting to match these requirements with the necessary infrastructure and capabilities of South Africa. Time and risk are not greatly concerned here although detail where available will be utilised in refining airport and other facility selections - Feasibility Analysis see Chapter 6 .

There are many other relevant elements of the SME Process for this investigation as well. The table below is taken from the classical SME textbook (SMAD:2011)[19], it summarises the SME process grouping them into subsections. These subsections can be tailored to this report for a more detailed break down and have been placed in the Appendix A (up to and including point 7 ).

Continuing on, SME has evolved from the classical SMAD process (SMAD:1991)[20], by including stakeholders and project timescales. The process is iterative, therefore returning to the objectives regularly, reviewing and documenting revisions is important. No single process can cover all contingencies.

The structure of the dissertation is as follows: Firstly this, Chapter 1, introduces the relevance of the project through reflecting on past collaborations and endeavours in South Africa as well as briefly discussing the major stakeholders. Chapter 2 discusses the history of a long line of lifting-body spacecraft before Dream Chaser, in order to fully understand the vehicle. Dream Chaser builds on a legacy of previous Lifting Bodies as 


\begin{tabular}{|c|c|c|c|}
\hline $\begin{array}{l}\text { Typical } \\
\text { Flow }\end{array}$ & \multicolumn{2}{|l|}{ Step } & Where Discussed \\
\hline \multirow{4}{*}{ 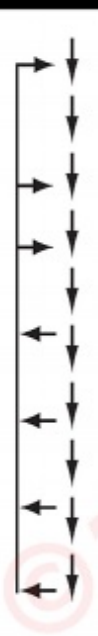 } & $\begin{array}{l}\text { Define Objectives and Constraints } \\
\text { 1. Define the Broad (Qualitative) Objectives and Constraints } \\
\text { 2. Define the Principal Players } \\
\text { 3. Define the Program Timescale } \\
\text { 4. Estimate the Quantitative Needs, Requirements, and Constraints }\end{array}$ & \multirow{3}{*}{ 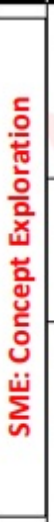 } & $\begin{array}{l}\text { 03: Space } \\
\text { Mission } \\
\text { Engineering }\end{array}$ \\
\hline & $\begin{array}{l}\text { Define Alternative Mission Concepts or Designs } \\
\text { 5. Define Alternative Mission Architectures } \\
\text { 6. Define Alternative Mission Concepts } \\
\text { 7. Define the Likely System Drivers and Key Requirements }\end{array}$ & & $\begin{array}{l}\text { 04: Mission } \\
\text { Concept } \\
\text { Definition }\end{array}$ \\
\hline & $\begin{array}{l}\text { Evaluate the Alternative Mission Concepts } \\
\text { 8. Conduct Performance Assessments and System Trades } \\
\text { 9. Evaluate Mission Utility } \\
\text { 10. Define the Baseline Mission Concept and Architecture } \\
\text { 11. Revise the Quantitative Requirements and Constraints } \\
\text { 12. Iterate and Explore Other Alternatives }\end{array}$ & & $\begin{array}{l}\text { 05: Mission } \\
\text { Analysis } \\
\text { and } \\
\text { Mission Utility }\end{array}$ \\
\hline & $\begin{array}{l}\text { Define and Allocate System Requirements } \\
\text { 13. Define System Requirements } \\
\text { 14. Allocate the Requirements to System Elements }\end{array}$ & 山 & $\begin{array}{c}\text { 06: Formal } \\
\text { Requirements }\end{array}$ \\
\hline
\end{tabular}

Figure 1.5 SME Process table and typical flow [19]

well as the Space Shuttle (135 STS missions and the lessons learnt from them).Chapter 2 discusses the history of a long line of lifting-body spacecraft before Dream Chaser, in order to fully understand the vehicle. Dream Chaser builds on a legacy of previous Lifting Bodies as well as the Space Shuttle (135 STS missions and the lessons learnt from them). Chapter 3 will go into depth regarding the Dream Chaser Space Vehicle and its history before outlining the important requirements and specifications. The chapter will end with a comprehensive discussion detailing what the Dream Chaser requires in preparation for Chapter 4, South Africa's Space Infrastructure. Chapter 4 describes South Africa's rich space observation history and its strategic position that has seen global investors seeking to place their assets here. Furthermore South Africa's historic space program, its achievements and remaining facilities will be discussed in light of the previous chapter and how South Africa can provide a feasible landing site for the Dream Chaser. Chapter 5 will address the policy and regulations surrounding the landing of the Dream Chaser in South Africa while considering the position of South Africa as a budding space faring nation still far behind in technological and regulatory development. Chapter 6 will consider the previous chapters in a all-inclusive summary, with comparative tables and discussions comprising a feasibility study. Chapter 7 presents the conclusion and recommendations distilled from this research project. Throughout the far reaching benefits of previous and future space related projects in South Africa with regards to integrating South Africa into the global space community while addressing the lack of high calibre jobs in the STEM fields in South Africa will be addressed. 


\section{Chapter 2}

\section{Lifting-Body Spaceplanes}

The Dream Chaser is a lifting-body ${ }^{1}$, reusable spaceplane. In this chapter many of the Dream Chaser's antecedents are discussed, to gather information that ensures a more complete understanding of the Drear Chaser. Like the Dream Chaser, many of its antecedents were also lifting-bodies and so this chapter sheds light on the vast array of lifting-body vehicles that came before it, such as the Figure 2.1 seen below after a test flight, research pilot Bill Dana stands alongside the HL_10 after a successful flight. Flying overhead is the modified B-52 launch aircraft that lifted him in the HL-10 to a height of 45, $000 \mathrm{ft}$ before releasing them over Rodgers Dry Lake adjacent to the now Armstrong AFB.

Figure 2.2 shows some of a long list of antecedents that pre-date the Dream Chaser's existence. Some resemble its general shape, like the Soviet BOR (third and fourth frame from the left) while others have their own unique 'rocketplane' body-shape. Although current designs house the Dream Chaser inside of a fairing atop of the launch vehicle, previously the Dream Chaser was mounted atop, fully exposed, like the second image of the Boeing X-20 Dyna-Soar. The oldest direct influencer of the Dream Chaser (part of the original lifting body program) is the Northrop companies M2-F2, built and delivered for testing at Edwards AFB in 1956. All of the previous rocketplanes listed in the next Section 2.1.1 had some influence whether direct or indirect. The similarities and differences are important to identify and discuss in order to gain a full understanding of the Dream Chaser.

\subsection{History}

The most notable feature of the Dream Chaser and the common characteristic across the antecedents is that it is a lifting body spaceplane or rocketplane with small winglets

\footnotetext{
${ }^{1} \mathrm{~A}$ lifting-body uses its fuselage to provide the lift unlike a winged aircraft that gets most of its lift from the wings.
} 


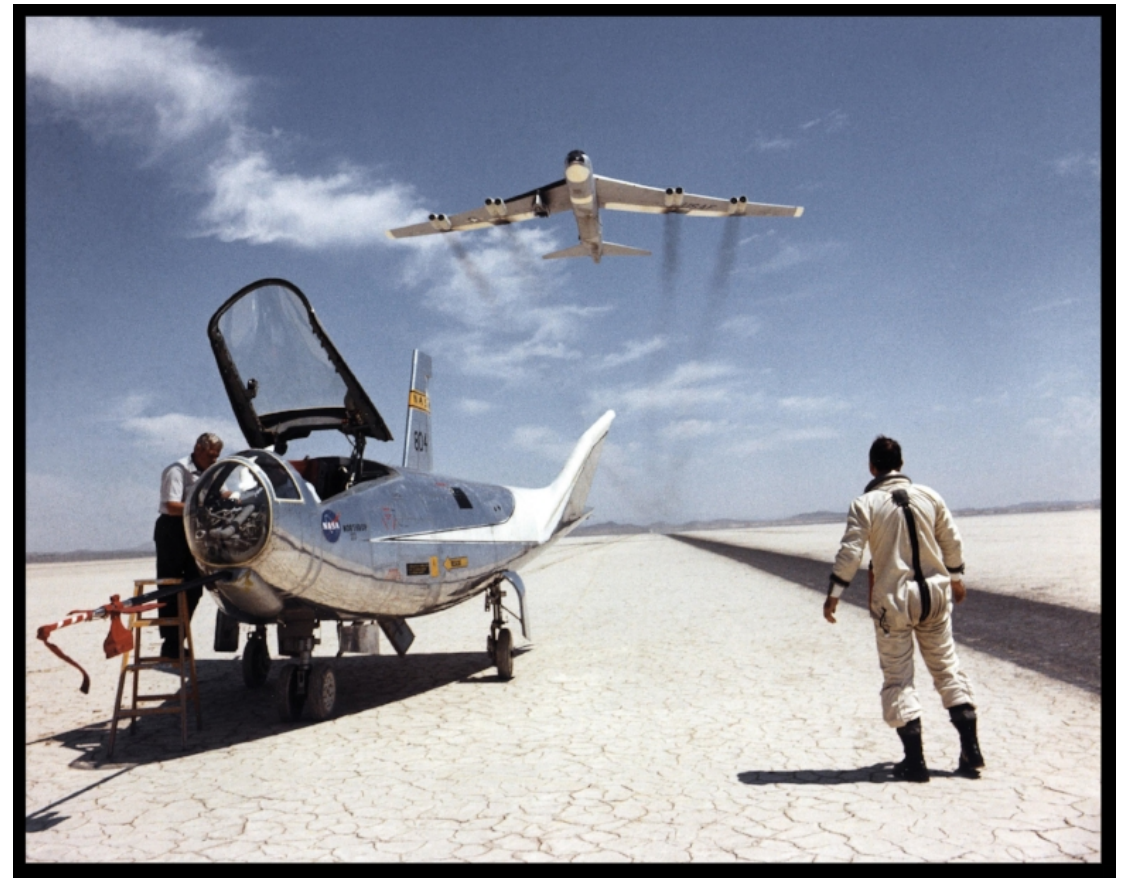

Figure 2.1 Bill Dana (research pilot) stands along side the HL-10 after a successful test flight over Rodgers Dry Lake.
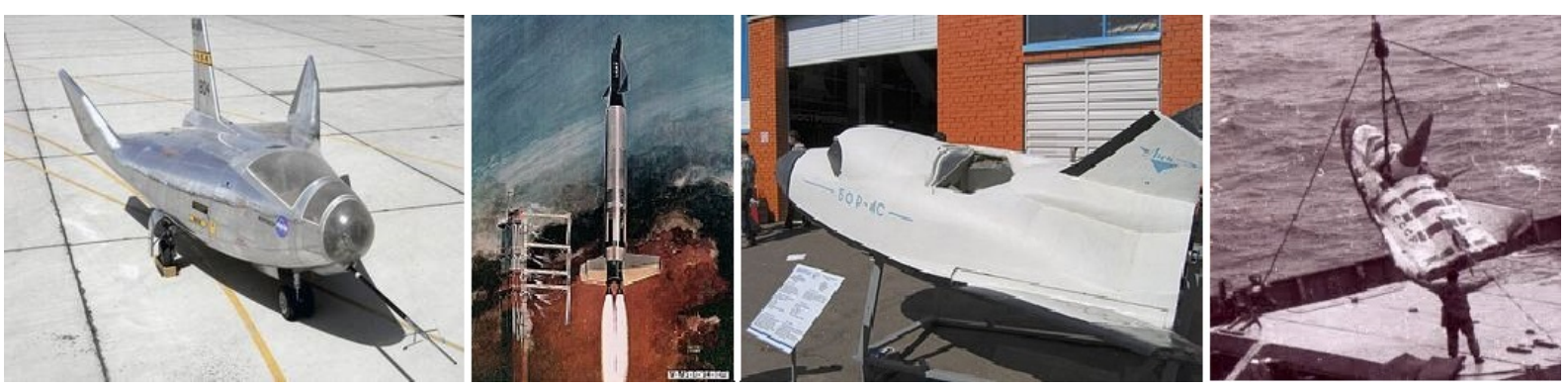

Figure 2.2 Left to right: M2-F2, X-20 Dyna-Soar, BOR 4S, Soviet BOR 4.

known as airfoil fins and a broader shaped fuselage than normal winged aircraft. The first patent for a lifting body craft was issued 1917 to Roy Scroggs [21] and the first example was built in 1929, although it experienced limited success due to its inefficiencies and the vehicle never made it to production. Like many great inventions, the lifting body was ahead of its time.

Lifting body spaceplanes and re-entry vehicles were researched during the height of the space race, in the 1960's-1970's and developed for aerospace purposes as alternative reentry vehicles[22]. The concept is attractive for two major reasons: a propelled spaceplane with cross-range capability ${ }^{2}$ provides higher versatility and a considerably larger landing envelope than conventional re-entry vehicles, such as the Apollo capsule, which have little or no control over where they land, whereas a lifting body craft can make a controlled

\footnotetext{
${ }^{2}$ Cross-range capability means to the ability of a spaceplane to manoeuvre off its re-entry glide-path and 'glide' on a new trajectory[23].
} 
landing on a predetermined runway. The other major advantage of lifting body craft is that they provide a solution to re-entry vehicles that may experience very high, even supersonic, speeds where a winged craft would tear apart under the high stresses. However at lower speeds lifting body craft are notoriously hard to control and have posed major challenges to engineers and pilots with regards to design and flight control[24]. This is one of the reasons why over the years most examples of lifting body rocket plane programmes have been terminated.

By the 1970's the end of the first phase of rocket planes was due to a declining interest from the US Air Force in manned missions and the beginning of the Space Shuttle research program, which made use of the data generated by the lifting body research[22]. The last lifting body spaceplane to fly in the lifting body program (1963-1975)was the X-24B, on September 2nd 1975[25].

The Dream Chaser Space Program is the latest lifting body program to become public knowledge. In 2004 it was first publicly announced that NASA and SpaceDev (founded and owned by Jim Benson), had signed a MoU outlining the collaboration on new "small piloted launch vehicles"[26]. SpaceDev, under Benson, coined the name Dream Chaser and the craft was to be designed in the light of the NASA HL-20 lifting body experimental spacecraft. The HL-20 had its roots deep in the early lifting body program however it took on a radically new look from the subsequent HL-10 after shots of the USSR BOR craft reached the Langley Research Center[23]. When Benson stepped down and passed away in October 2008 SpaceDev agreed to be bought by SNC for $\$ 38$ million[27].

So the Dream Chaser's line of historical antecedents dates back to the mid-20th century and later designs came about in the early 90's during the Space Shuttle era. The original lifting body designs originated from the NASA Ames Research Center, conceived by assistant director of Research and Development Analysis and Planning, Dr Alfred J. Eggers Jr[28]. Since then the line of antecedents has passed through government (NASA and the Air Force) and private (SpaceDev and SNC) ownership and development to get to where they are today and the program is an example of a space mission that has gone though multiple phases of development. Presently the Dream Chaser Space Vehicle is under ownership and development by the Sierra Nevada Corporation (SNC), a privately owned American company that among other things provides "high performance, innovative space components and systems for space utilisation and exploration".

When SpaceDev agreed to be bought by SNC in 2008 it had already signed an agreement with NASA on the collaborative development of the Dream Chaser. SNC bought a majority share (between $68-72 \%$ ), effectively taking over the agreement with NASA and the Dream Chaser Space System (DCSS)[29]. SNC continued to receive funding from NASA 
through various Commercial Crew Development (CCDev) programs ${ }^{3}$. Most notably SNC has received funding for the DCSS through the Commercial Resupply Service (CRS-2 specifically) program. SNC proposed the Dream Chaser in 2014 for CRS-2 and in 2016 NASA announced that SNC had been awarded one of the contracts promising to purchase a minimum of 6 ISS resupply missions from SNC alongside SpaceX and Orbital Sciences Corp.

Despite original developments through prior CCDev programs since 2009 in 2014 the SNC's Dream Chaser was not selected for the CC integration Capacity (CCiCap) program funding due to lack of maturity. This sequence of events lead to the need for SNC to broaden its market opportunity and stimulate further development of the Dream Chaser. During the same period the German Aerospace Center (DLR) conducted a study on the potential of the Dream Chaser providing orbital services to Europe. The project was called the Dream Chaser for European Utilisation (DC4EU). ESA took an interest and agreed to join the DC4EU research by finding whether the Dream Chaser was compatible with existing ESA fairings and technology[31]. The success of this research lead to SNC launching the Dream Chaser Global Project Spaceflight program in September 2014. The SNC Global Project provides, "for the first time in history, an unprecedented and unique set of spaceflight opportunities for clients around the world," said John Roth, vice president of business development for SNC's Space Systems[32]. UNOOSA choosing the Dream Chaser to carry out its first dedicated space mission was therefore a result of these events.

\subsubsection{Dream Chaser Antecedents}

Like the Dream Chaser, most of its antecedents were also lifting-body craft and some delta-winged or delta-based hybrids, like the X-20 Dyna-Soar. This section runs through a few predecessors of the Dream Chaser and briefly describes their programmes and key characteristics. Their occurrence is given in a sequential order below, starting with the oldest $^{4}$ :

1. Kicking-off with the oldest lifting-body antecedent, Boeing's military spaceplane project:

\footnotetext{
${ }^{3}$ Since the final Space Shuttle flight, in 2011 NASA has changed its approach seeking commercial options to transport supplies, equipment and science research to and from the International Space Station (ISS) $[30]$

${ }^{4}$ The NASA lifting-bodies occur in two major eras, before and after the period of the Soviet BOR program.
} 
- X-20 Dyna-Soar - This program ran from 1957 - 1963 and cost around \$660 million, reaching mock-up stage with assembly tools being prepared but no craft ever flew[33]. The X-20 had a low-wing-body design with fins or winglets on the wing ends rather than a tail. Planned for aerial reconnaissance, bombing, space rescue, satellite maintenance and enemy satellite sabotage, the X-20 would have flown atop the Titan III launch vehicle. The program ended due to lack of viable military missions. The craft used an all-skid, tricycle arrangement landing gear[34]. The

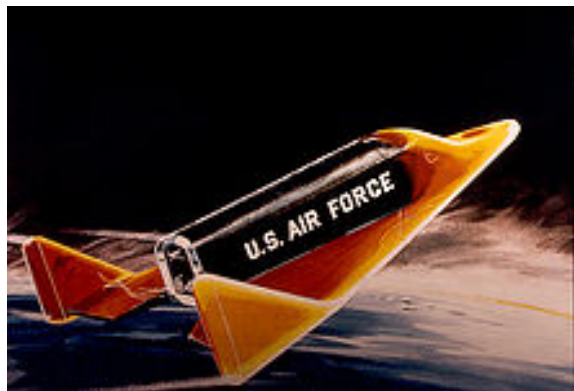

Figure 2.3 Artist's impression of the X-20 Dyna-Soar. reason for skids is because maintaining gas filled tyres in space is problematic.

2. Designs by NASA's Dryden Flight Research Centre (FRC) Lifting-Body program ${ }^{5}$. The project ran from 1963 - 1975. The summaries here are developed mostly from a NASA Armstrong fact sheet: Lifting Bodies, where all flight tests of NASA's lifting bodies took place[28] and American X-Vehicles Book. Below, ' $\mathrm{M}$ ' is for manned and ' $\mathrm{F}$ ' for flight, 'HL' for Horizontal Landing and ' 10 ' for the tenth lifting body design to be investigated by NASA. At the end of this section Table 2.1 sums up all the flights.

- M2-F1 - This was the first lifting body design to be tested (first model completed in 1963). Made from wood, M2-F1 had a modified half-cone (flat on top round on the bottom nose design) and twin fins for control. The unmanned and unpowered (glider) was considered a lightweight lifting body design. Nicknamed "the bathtub" which had not yet been given a tail. It was first towed aloft behind a modified Pontiac convertible before flying behind NASA's R4D plane.

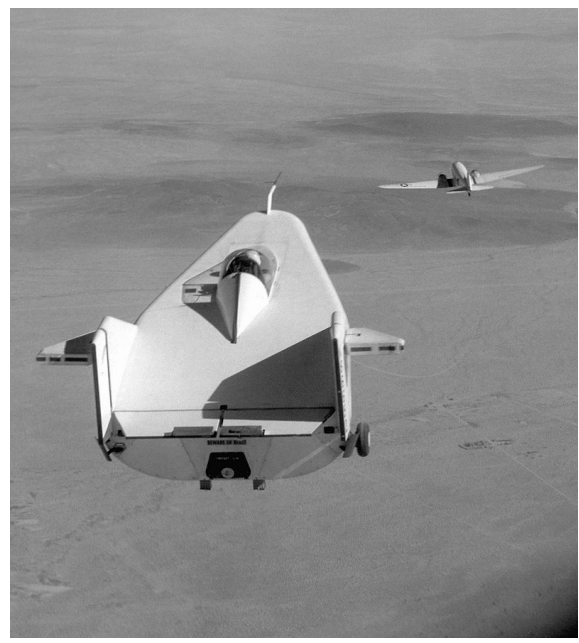

Figure 2.4 M2-F1 flown behind R4D plane at Dryden.

- M2-F2/3 - The next two models were built by Northrop under the first liftingbody contract. These were now considered 'Heavy lifting-body vehicle' and

\footnotetext{
${ }^{5}$ US Air Force (USAF) gained interest and projects overlapped eg. NASA and AF PILOT program.
} 
were powered by XLR-11 rockets from the Bell X-1 although they were released from the modified wing of NASA's NB-52B "mothership" launch plane at 45,000 ft before igniting the rocket engines and accelerating to 1,100 mph and an altitude of 70,000 ft. A serious crash of the M2-F2 led to improvements on the M2-F3 including a vertical tail fin for improved control of lateral movement.

- Northrop HL-10 - A follow-on design from the M2-Fs, HL-10 had three vertical fins and the wing-fins slanted outwards to eliminate air flow separation problems. A tall center fin gave increased control and horizontal stability.

Program records: Feb 181970 HL-10 reached 1,228 mph (Pilot: Maj. Peter Hoag -USAF), Feb 27 HL-10 flown to 90,303 ft (Pilot: Bill Dana -NASA). Validated landing a craft unpowered and without wings.

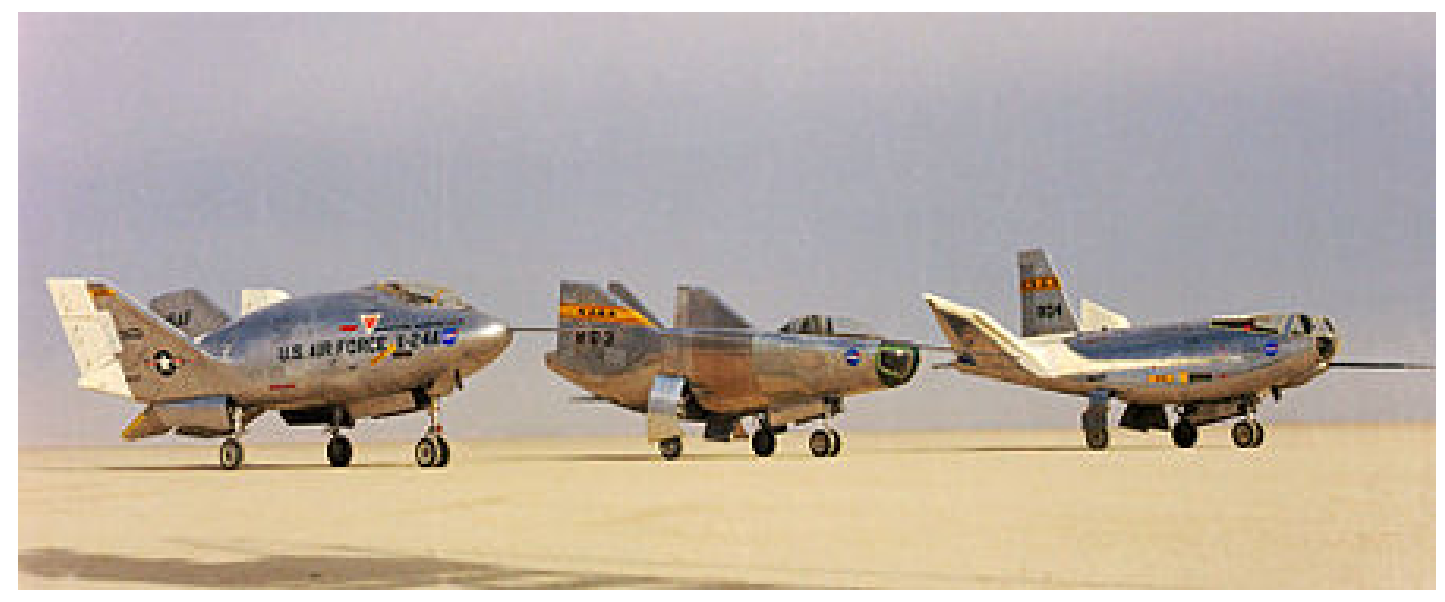

Figure 2.5 Lifting Bodies: X-24A, M2-F3, HL-10.

- Martin X-23 Prime - This research aircraft was primarily testing precision reentry including manoeuvring re-entry by the USAF. A small lifting-body $(2.04 \mathrm{~m})$ spaceplane developed to test manoeuvring during re-entry and cross-range. X-23 was launched atop an Atlas launch vehicle 3 times between 1966-1967 to demonstrate or simulate various capabilities. Only the third was successfully recovered and is now on display in National Museum of USAF (NMUSAF). The rest sank into the pacific ocean.

- Martin-Marietta X-24A/B - This was a USAF-NASA joint mission to test Lifting body Craft for unpowered re-entry - under PILOT program. The X-24A (Figure $2.5)$ was a short chunky aircraft, $24 \mathrm{ft}$ long and $14 \mathrm{ft}$ wide. The $\mathrm{X}-24 \mathrm{~B}$ was simply the X-24A with a new exterior shape by Martin used to test the body DFL-7 (a more advanced lifting body being planned) and save the USAF money. The X-24B's final flight on the 9 September 1975 marked the end of the rocket plane research[35] and further helped write the Space Shuttle's flight plan. 


\begin{tabular}{|c|c|c|c|c|c|c|c|c|}
\hline Craft & M2-F1 & M2-F2 & HL-10 & HL-10 mod & M2-F3 & X-24A & X-24B & Total \\
\hline Total flights & 77 & 16 & 37 & 36 & 27 & 28 & 36 & 257 \\
\hline
\end{tabular}

Table 2.1 Flight count of NASA's lifting body fleet.

Observation: A change seen from the M2-F's to the HL-10 was the vertical fins on older antecedents were now splayed out to prevent unwanted roll effects, producing a V-tail which also included a small vertical tail fin. By splaying the fins out they essentially become winglets producing some of the lift. It is therefore noted that although the Dream Chaser is considered a lifting body vehicle its winglets actually produce about $50 \%$ of the vehicle's lift on descent.

3. Soviet efforts to create an orbital spaceplane between 1966 - 1978. The information presented here after has been derived from a translated version of the Soviet Buran Website[36] and Encyclopedia Astronautica [37] and the Russian acronyms are not always directly translatable.

- MiG 105 - Named after the company that designed it, Mikoyan-Gorevich, it was part of the Spiral Aerospace System program. -This was a response to Boeing X-20 Dyna-Soar spaceplane by America.

- BOR-4 - After consecutive failures of BOR-1/2/3 (tested in late 1970's) which were a result of extensive laboratory testing of multiple orbital plane designs then led to the much improved design of the BOR-4 (called Cosmos in USSR). The MiG 105 first flew a suborbital flight in 1980 then took its first orbital flight 1982. Primarily used to test reusable thermal barrier coating (HRC) required for Buran. MiG 105 launched on Kosmos-3M RN (K65M-RB5) from the Kapustin Yar cosmodome. Cosmos-1374 completing 1.25 orbits before landing in the Indian Ocean several hundred kilometres south of the Cocos (Keeling) Islands off the west coast of Australia. The dispatch of the USSR navy and recovery ships attracted the attention of the Australian navy and a R-3C Orion reconnaissance aircraft circled closely overhead photographing the scene.

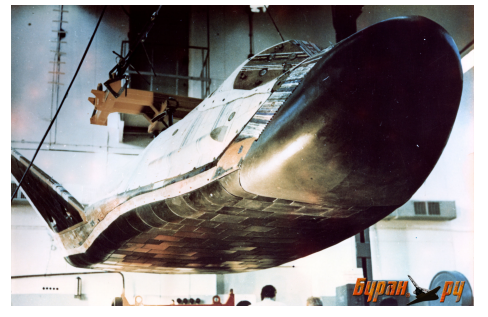

(a) BOR-4 [Manufacturer photo].

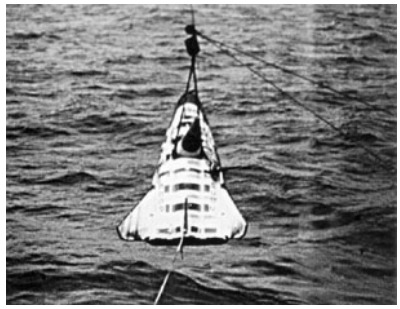

(b) Recovery photos by Soviet Navy.

- Bor-5 - Unmanned 1:8 model of Buran Space Shuttle. It was used to study aerodynamics, thermal, acoustic and stability characteristics. BOR-5 used 
gas-jet nozzles for out of atmosphere manoeuvring and air craft like surfaces in atmosphere. Due to scaling, the nose-cone and wings were provided extra heat protection due to sharper edges experiencing increased heat flux. The "hot" parts of the vehicle were covered in MSP-K material (operating temperature up to $1800^{\circ} \mathrm{C}$ ) based on quartz fibre and chrome-aluminium-phosphate binder (mineral fibreglass).

- Buran Soviet Space Shuttle program (1975 - 1992) - Buran was 35, 4 m long $16,5 \mathrm{~m}$ tall and had a $24 \mathrm{~m}$ wing span. It was capable of carrying 2-4 crew and 6 passengers and weighed 105 tons on take off. Buran was protected with 38,600 heat retarding tiles the structure was built to last 100 orbits. On 15 November 1988 Buran took its first and final flight, launched with its custom Energia rocket system, then orbited Earth twice before landing autonomously. It was the only Shuttle to ever fly unmanned and land automatically (missing its mark by only centimetres. It was destroyed in its hanger along with the Energia rocket when the hanger it was stored in collapsed due to strong winds.

4. NASA-tested vehicles, post the Soviet BOR vehicles.

- HL-20 Personal Launch System (PLS) - Using a Cherrywood model the HL-20 was reverse-engineered from photos taken from an Australian Navy spy plane of the Soviet BOR-4 being retrieved in the Indian Ocean. This ironically set the lifting-body research back in motion as the Space Shuttle era came to a close. The HL-20 was researched by NASA's Langley Centre around 1990, but no hardware was ever produced. Multiple simulation and model studies were conducted with substantial data generated using modern technology. Designed to carry up to 10 people but little cargo. A lifting-body once again chosen for cross range capabilities while keeping re-entry temperatures down[38]. Observation: Similarities to the BOR craft and modern Dream Chaser are apparent while differing substantially from the HL-10 and other earlier NASA-AF exterior designs.

- Boeing X-37B - "One of the world's newest and most advanced re-entry spacecraft .. first since the Space Shuttle with the ability to return experiments to Earth". Known as the Orbital Test Vehicle (OTV). NASA began the X-37 project with Boeing in 1999 before transferring it over to the Department of Defence (DOD), more specifically Defence Advanced Research Project Agency (DARPA) in 2004 not long after the Challenger Shuttle disaster[39]. DOD had the project classified so not a lot is known about this vehicle although it is not a typical lifting-body, OTV features aerodynamic characteristics similar to that of the Space Shuttle. There had been no hardware built prior to the transfer, however now the AF has developed X-37B which is on its fifth orbital mission. The OTV-1 flew in April 2010 and the most recent, OTV-5 flew in 
September 2017 and is currently still in orbit[40]. OTV is a $120 \%$ scale model of the Boeing X-40 precursor built for the USAF Space Manoeuvre Vehicle program. OTV is primarily developed to demonstrate 41 technologies aimed at cutting the cost of space flight[39].

- X-38 - This was a small prototype emergency decent vehicle, planned for the ISS. Its first flight was planned for 1999, but was postponed to 2002. It would have been a joint international venture and possibly flown on the Ariane 5 launcher. It inherited much data collected from the HL-20.

5. Europe has also designed its own versions of a spaceplane. These are Europe's attempts to gain an independence from the other two major space faring nations.

- Hermes - Originally Hermes was developed by CNES and later advanced by ESA. Development started in 1975 and ended in 1992.

- Hopper - The Hopper was an ESA-proposed reusable orbital spaceplane under the FESTIP program. The Germans built a 1:7 scale version called the Phoenix which was drop tested in 2004 providing an affordable field experiment producing highly useful data.

- Intermediate eXperimental Vehicle (IXV) - Designed by the Italian space agency, IXV is a suborbital spaceplane prototype ahead of the future Space Rider spacecraft. Launched atop the Vega rocket in February 2015 it successfully completed a 100-minute suborbital flight making it the first lifting-body to complete full atmospheric re-entry from orbital speeds.

6. USA Space Shuttle Four times the size of the Dream Chaser and very similar to its Russian cousin, measured $122.2 \mathrm{ft}$ long, $56.67 \mathrm{ft}$ high, with wingspan of 78.06 feet. The height of the full shuttle stack, including the external fuel tank, was a whopping $184.2 \mathrm{ft}$. The Space Shuttle and the Buran featured a low delta wing design and a large vertical tail fin. The Space Shuttle measured Delta-shaped wings named after the Greek upper-case letter delta, like that found on fighter jets, has a high structural integrity which was known to be easier to control at low or high speeds, cheaper to produce and provided plenty fuel storage space[41]. In many ways the Space Shuttle and Dream Chaser share similar mission objectives, whether it be ISS services, scientific discovery or on orbit delivery and maintenance.

\section{Observations}

Like many of its antecedents, although with much higher precision thanks to a researcher at the Utah State University who developed the Flush Air Data System (FADS), the Dream Chaser effectively glides through the atmosphere at high speeds in order to shave 
off speed before descending, performing atmospheric flight path manuvours to the desired runway.

Another modern feature of the Dream Chaser is its ability to land anywhere with no additional ground supporting infrastructure. The following section will go into greater detail regarding these advantages as well as many others of the Dream Chaser.

It now becomes clear how vast the background is to the Dream Chaser Space Program. Through all of these prior and overlapping projects, similarities to the Dream Chaser in function and design can be seen other than the lifting body characteristic, such as: demonstrating reusable space technologies (RST), servicing satellites, providing versatility of landing opportunities and so on. It's clear that some of these technologies have been copied and reworked by competing nations, nonetheless there is now vast amount of data and information regarding lifting body spacecraft, making it a mature body of study. The timing of SNC taking over the Dream Chaser is therefore strategic, enough background studies have been completed for a modern lifting body vehicle to be a viable candidate for a practical space mission as well as being financially viable for a commercial company such as SNC to develop the project successfully. 


\section{Chapter 3}

\section{Dream Chaser Space Vehicle}

The Dream Chaser lifting-body spaceplane is the tip of an ice-berg or historic research and innovation, which will launch vertically atop an Atlas V, Ariane 5 or Falcon 9 rocket and land horizontally on a commercial runway ${ }^{1}$. It is being designed and developed by a private American Defence company with over 25 years of experience in the space industry, Sierra Nevada Corporation (SNC). On December 182018 SNC announced it had passed the Integrated Review 4 milestone in its Commercial Resupply Services 2 (CRS-2) contract with NASA, allowing them to go forward with full-scale production of the Dream Chaser[42].

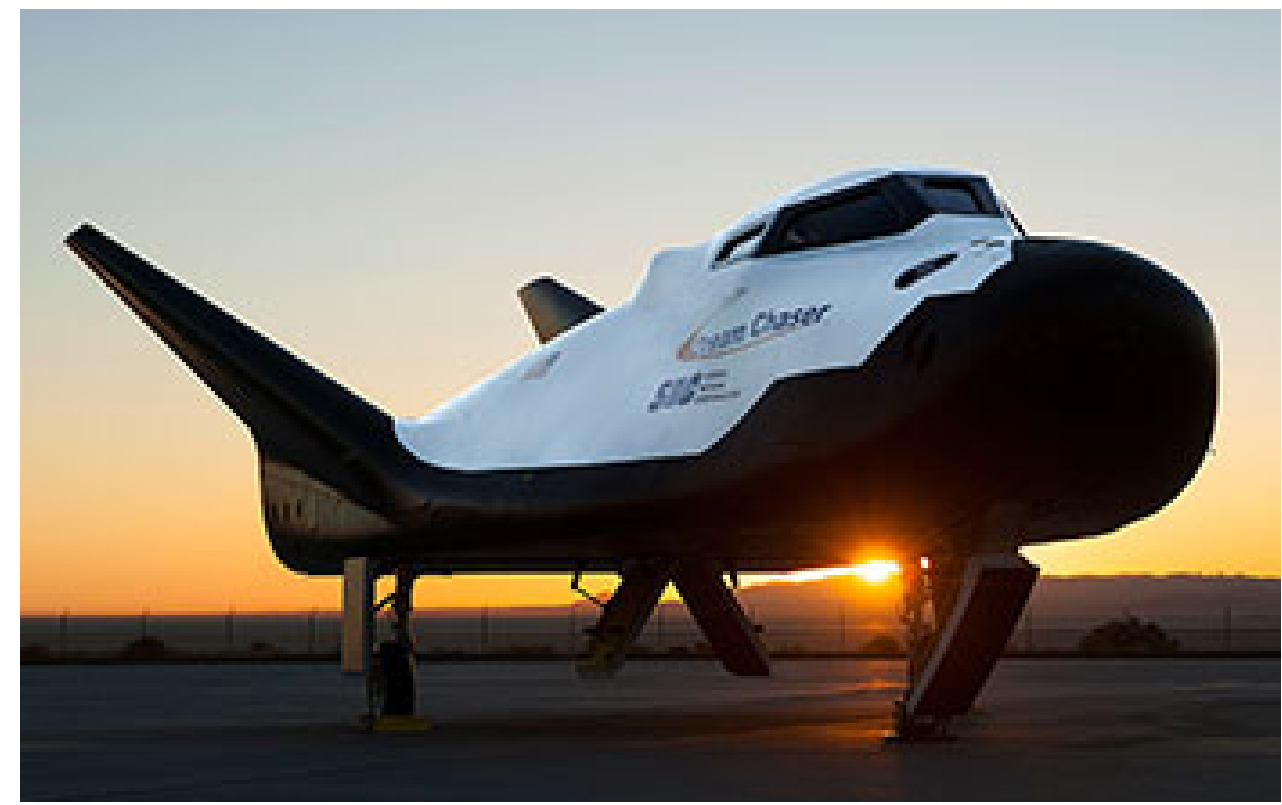

Figure 3.1 Dream Chaser Space Vehicle.

\footnotetext{
${ }^{1}$ Craft of this type are sometimes referred to as VTHL -Vertical Takeoff and Horizontal Landing.
} 
Much of the success of this investigation will rely on properly uncovering the important information regarding the requirements and specifications of the Dream Chaser Space vehicle. It is therefore important that all the available information on the Dream Chaser is gathered and understood in preparation for the proposal from the UCT Space Lab, particularly that pertaining to the airspace, airfield, airport and support requirements for the safe landing of the Dream Chaser and the support thereafter regarding the experimental payloads.

There are publications available on public platforms regarding the Dream Chaser, albeit not for all aspects of the vehicle, and few are very recent. The documents available will be analysed and reviewed in this chapter. However, the Dream Chaser owes a lot to its many predecessors, which combined have a far greater collection of resources available. For a complete understanding of this highly specialised vehicle, information will be drawn from literature on these other historical vehicles in Chapter 2.

The Dream Chaser is constantly evolving under rigorous iterative tests and analyses. Many advanced, innovative systems and have been developed by SNC for Dream Chaser and have enabled the team to pass the agreed NASA CCDev milestones. The Dream Chaser is likely to continue to be adapted until its first successful Earth orbit. Therefore continuous adjustments will need to be made to the information on the Dream Chaser contained within this dissertation.

\subsubsection{Dream Chaser studies}

There are a number of dedicated Dream Chaser studies publicly available that reveal important information about the vehicle. A summary of this information and data will be presented below. Some of the details in these studies have changed and will continue to change after further testing. As further studies come out updates to the details presented here will need to be addressed.

\subsubsection{Landing challenges and opportunities}

One of the advantages of a lifting body, reusable space vehicle is the ability to offer frequent landing opportunities. With the Main Propulsion System (MPS) the Dream Chaser maintains a $1100 \mathrm{nmi}$ landing radius or cross-range capability, this is an improved performance from the larger Space Shuttle and ensures that the Dream Chaser can land on a suitable runway every orbit in contiguous United States (CONUS). The Reaction Propulsion System (RPS) is coupled with the MPS and shares fuel and oxidiser, radically reducing weight and increasing mission flexibility. Furthermore the RPS can perform the MPS de-orbit burns and nominal ascent burns providing better fault tolerance for the Dream Chaser. 
Maintaining a stable and precise re-entry of a craft with virtually no wings requires computer controlled movement of all body flaps (or control surfaces). Figure 3.2 shows these control surfaces viewing the Dream Chaser from the rear. Also shown is the primary propulsion engine, which would be used in the case of needing to change path on re-entry.

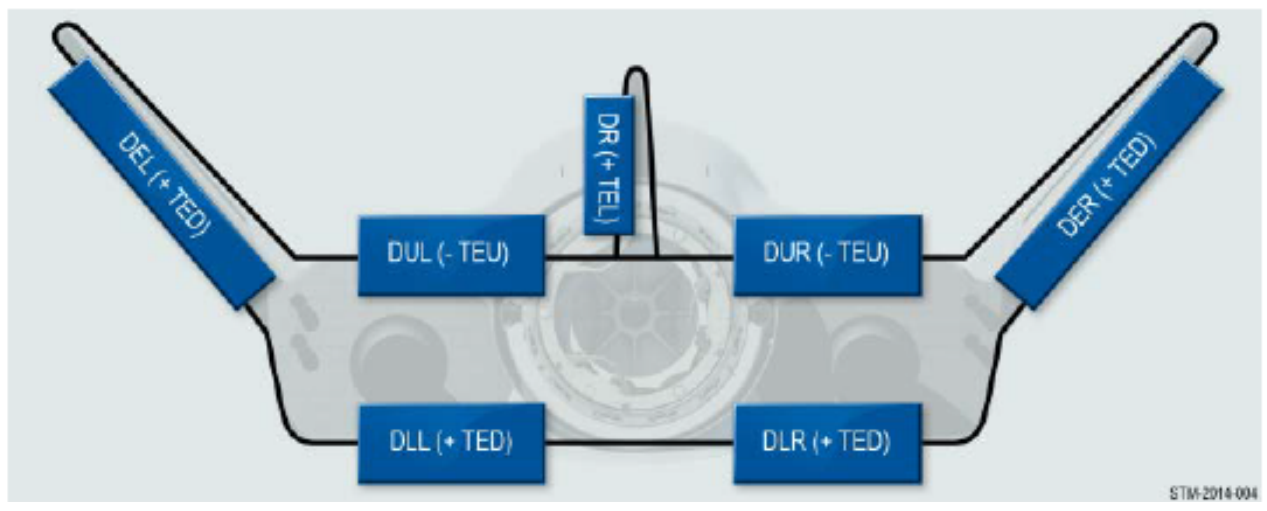

Figure 3.2 Dream Chaser aerodynamic control surfaces.

The Federal Aviation Administration (FAA) maintains collaborative dialogue with the Dream Chaser programme and assists SNC in pre-coordinating emergency landings. Together SNC and the FAA will distribute Dream Chaser Systems Operation Documentation (SOD) to identified emergency landing sites to familiarise airport personnel on the vehicle.

The Dream Chaser's use of non-toxic propellent and oxidiser as well as its user friendly design means it can be accessed quickly after landing and removed from the runway within minutes, crucially allowing nominal flights to continue after an emergency Dream Chaser landing.

The Dream Chaser has a manned version and a cargo (unmanned) version, both are equipped with autoland functionality although the primary way for the manned crew to land is through pilot control. In some scenarios, such as 'crew abort' descent, where the crew may experience up to $6 g^{\prime} s$, it is safer to allow the craft to autoland rather than to attempt a crew-controlled landing. SNC has already proven its autoland technology aboard the X-47 military aircraft for which the company received the prestigious Collier Trophy.

Like the propulsion system, the Thermal Control System (TCS) uses non-toxic fluids to allow for quick access to the vehicle upon landing. The primary system while in space uses water $\left(\mathrm{H}_{2} \mathrm{O}\right)$ as a working fluid through an evaporator to control the temperature. While in the atmosphere two $\mathrm{N}_{2} \mathrm{O}$ boilers and a Phase Change Material (PCM) control the temperature throughout the vehicle. The PCM can be cooled by the primary thermal control system while in space and reused on re-entry. The boilers and PCM allow for thermal control through landing and after stopping on the runway, thus providing the option of the Dream Chaser being removed from the runway with the crew is still on board.[43] 


\subsection{Specifications}

The Dream Chaser's technical and performance specifications will come from a combination of literature already mentioned in the previous two Sections, 2.1.1 \& 3.0.1 as well as Section 3.1.1 below. It may be useful to tabulate the information gathered here to clearly represent the details gathered in the research. To help with further understanding please refer to Appendix B for orbital options created in STK and additional details.

\subsubsection{SNC provided specifications}

The Sierra Nevada's web page on the Dream Chaser provides the important functionalities and specification for the vehicle and it is possible to derive the landing requirements of the Dream Chaser space vehicle from these. It also promotes the ethos of collaboration and minimal additional facilities required to service the vehicle upon landing, which has clear benefits when landing outside of the USA, for example. Some of the most important features of the Dream Chaser are explicitly listed on the web page and repeated below:

- Lifting-body spacecraft (50\% lift from winglets)

- Autonomous launch, flight and landing capabilities

- High reusability, $15+$ times

- Low atmospheric entry, at $1,5 g^{\prime} s$

- Gentle commercial runway landing, compatible with runways worldwide

- Immediate access to crew or cargo upon landing

- $5500 \mathrm{~kg}$ pressurised and unpressurised cargo to ISS

\subsubsection{Payloads and Capabilities}

The Dream Chaser Space System (DCSS) was originally built for carrying up to seven astronauts to and from the ISS and other LEO destinations. Much of this development occurred under NASA's commercial crew development (CCDev) programme. There are environmental control and life support systems as well as windows for crew visibility. An integrated Thermal Control System (TCS) uses $\mathrm{NO}_{2}$ with the primary propulsion system allowing immediate access to cargo and crew upon landing. The TCS uses a phase change material (PCM) that can be reused and $\mathrm{H}_{2} \mathrm{O}$ is the working fluid while in space. The system maintains stable temperatures of all systems including crew during the mission and even after wheel stop, allowing time for ground support crew to safely hitch and tow the Dream Chaser off the runway. 
In early 2016 (as explained in Section 2.1) SNC was selected by NASA to provide supplies and waste removal services to the ISS under the CRS-2 contract. Refer to Appendix D for the mission overview of the ISS CRS-2 contract. An unmanned fully autonomous version was then developed to transport $5500 \mathrm{~kg}$ of pressurised and unpressurised cargo. Breaking this volume down, there is $1925 \mathrm{~kg}$ of pressurised cargo returnable, $3250 \mathrm{~kg}$ pressurised cargo disposed and $1500 \mathrm{~kg}$ unpressurised and disposed. The Dream Chaser Cargo System (DCCS) hosts a cargo module which increases the carrying capacity and payload opportunities. The cargo module has expandable solar panels providing power to the powered payloads. There are five different payload opportunities aboard the Dream Chaser Cargo System:

1. Internal powered (pressurised, protected, returned)

2. Internal powered (pressurised, protected, disposed)

3. Internal unpowered (pressurised, protected, returned)

4. CubeSat and MicroSat Deployment capabilities

5. External Cargo powered (Not protected, disposed)

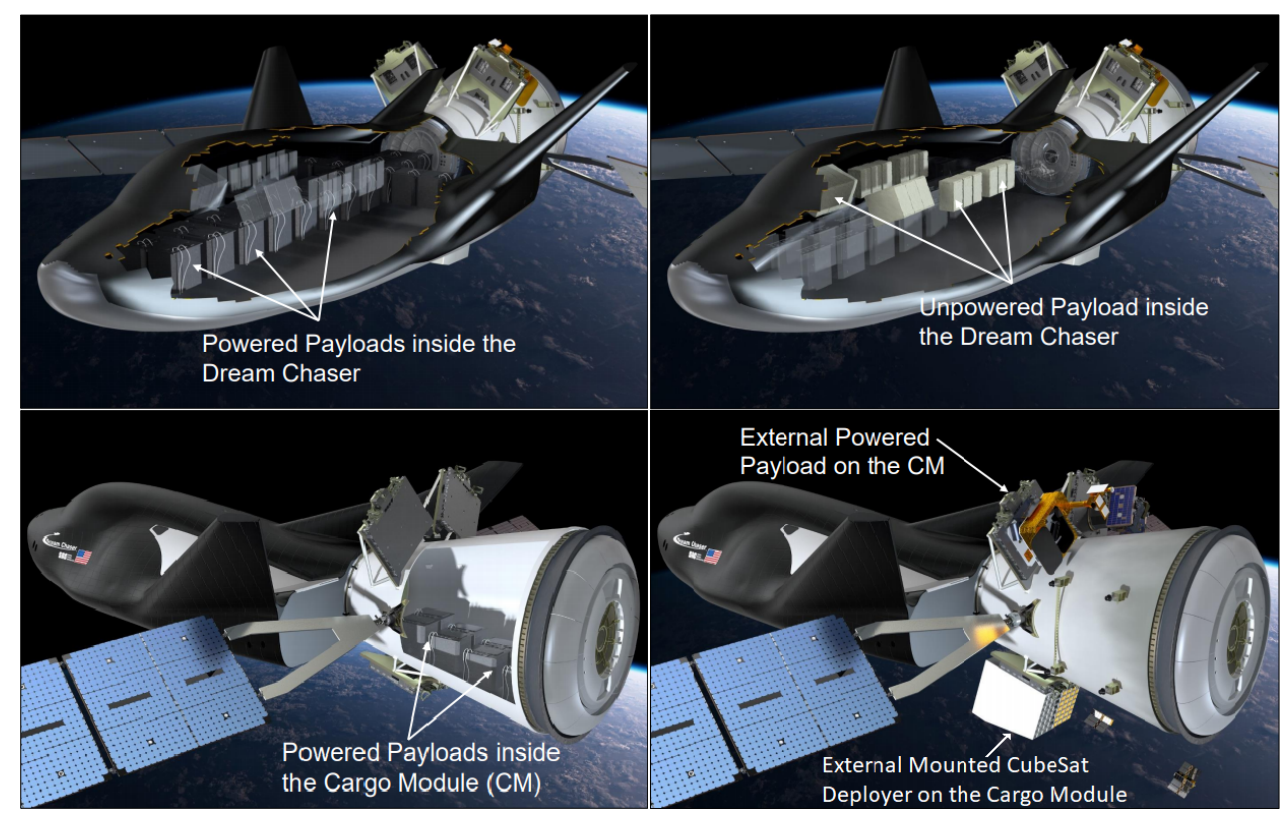

Figure 3.3 Payload options aboard the UNOOSA Dream Chaser mission.

Possible additional payload type suggested being subdivided locker space for multi-specimen or plant experiments. 


\subsubsection{Orbital Options and Parameters}

The Dream Chaser is an inherently versatile space vehicle, with a range of orbital options available to its users. The orbital path will therefore be defined by the mission requirements. This section will briefly analyse the various LEO orbital missions available for the Dream Chaser before detailing the future UN SDG-dedicated mission with a potential landing site in South Africa. First we commence with an astrodynamics overview.

\subsubsection{Astrodynamics}

In order to describe an orbital trajectory mathematically there are six values that need to be known, these values are orbital elements also called Keplerian elements - after the German astronomer, Johannes Kepler (1571-1630).

- Semi-Major axis, a

- Eccentricity, e (given as major-axis/focal separation)

- $\operatorname{argument}$ of Periapsis, $\omega$

- Inclination, $i$

- Time of Periapsis passage, $T$

- Longitude of Ascending Node, $\Omega$

These elements are portrayed in Figure 3.4, excluding $a$ and $e$, which are shown in the following Figure 3.5.

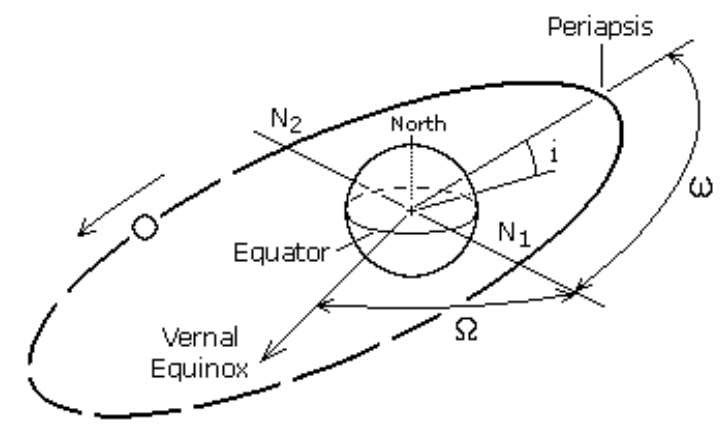

\footnotetext{
i = Inclination

$\omega$ = Argument of Periapsis

$\Omega=$ Longitude of Ascending Node

$N_{1}=$ Ascending Node

$\mathrm{N}_{2}=$ Descending Node
}

Figure 3.4 Keplerian orbital elements of an orbiting satellite. [braeunig.us]

These Keplerian elements will completely describe an orbit. Orbits or trajectories can be in any of four conical sections as seen in Figure 3.6. Each conic is determined by the 


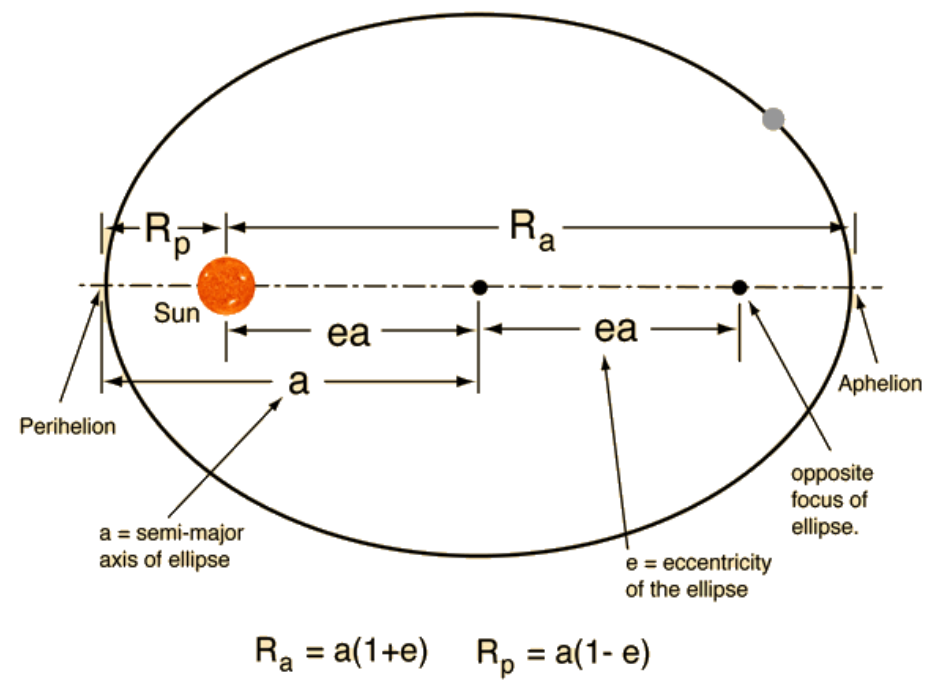

Figure 3.5 Generalised orbit depicting semi-major axis and related basic formulae.

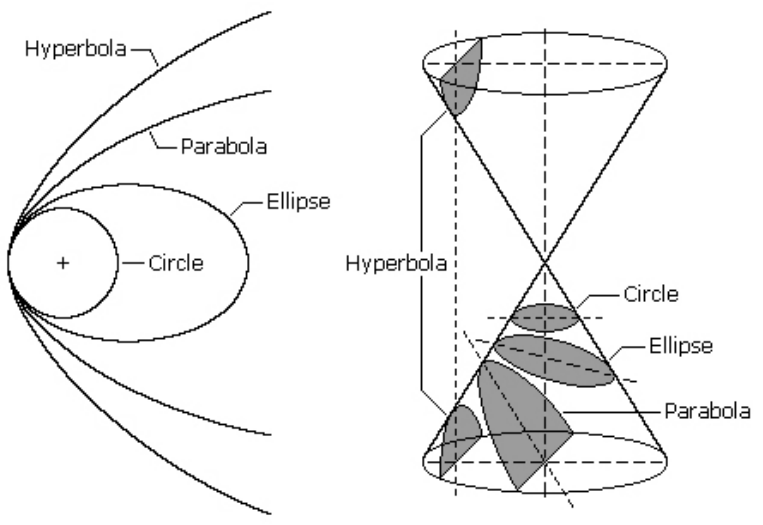

Figure 3.6 Conic sections on planes intersecting a right circular cone. [braeunig.us]

angular orientation of the planes with respect to the cone.

Issac Newton's (1642-1727) laws of motion and universal laws of gravity can be used to explain the phenomenon of an orbit and derive the orbital speed of a satellite quite simply, by equating centrifugal forces to gravitational forces.

$$
\begin{array}{r}
F_{c}=F_{g} \\
\frac{m v^{2}}{r_{p}}=\frac{M m G}{\left(r_{p}\right)^{2}} \\
v=\sqrt{\frac{m G}{r}}
\end{array}
$$


Newton's equations can be used to derive Kepler's third law of harmonics, confirming Keplers' empirical calculations with theory, with T being orbital period.

$$
\begin{array}{r}
v=\sqrt{\frac{m G}{r}}=\frac{2 \pi r}{T} \\
\frac{m G}{r}=\frac{4 *(\pi)^{2} * r^{2}}{T^{2}} \\
\frac{r^{3}}{T^{2}}=\frac{m G}{4 \pi^{2}}=\text { constant } \\
\therefore T^{2} \propto r^{3}
\end{array}
$$

\subsubsection{Dream Chaser Orbits}

With the fundamentals of orbital mechanicals having been explained above, the various options that are available to the Dream Chaser can now be discussed. The Dream Chaser is designed for LEO, more specifically to rendezvous with the ISS. This provides some indication of a typical orbital trajectory that the Dream Chaser mission designers will be planning. STK is a powerful tool used to simulate orbital missions, it is likely that SNC uses a commercial version of the software to plan the mission in detail. For purposes of this analysis an educational version of STK was used to simulate the potential missions. One of the advantages STK has is the vast database of places, ground-stations and satellites which can easily be imported into a scenario.

The basic orbits available in LEO are as follows:

- Equatorial orbit - As it is suggested by its name, this orbit lies in the equatorial plane. This is a very energy efficient orbit as the Earths rotation can be used to its maximum potential. However the ISS follows an inclined orbit and South Africa lies between $22 \mathrm{deg}$ and $33 \mathrm{deg}$ South of the Equator rendering this orbit unnecessary to consider.

- Polar or Sun-Synchronous orbit - This orbital option stands in contrast to the Equatorial orbit as it flies with a maximum inclination or around $90 \mathrm{deg}$ and allows a satellite on this orbit to view the Earth with nearly the same conditions every orbit. As you can see in Figure 3.8 this orbit does indeed allow the Dream Chaser to fly over South Africa at certain times.

- The options of orbits in between these two major categories range between the inclinations, see Figure 3.7 of the ISS orbit.

The first basic orbit that is depicted in Figure 3.7 is that of the ISS. It can be seen that the ISS does pass over South Africa. Note too that it is sometimes ascending and 
sometimes descending. These details can be used by mission planners to make the deorbiting procedure as simple as possible.

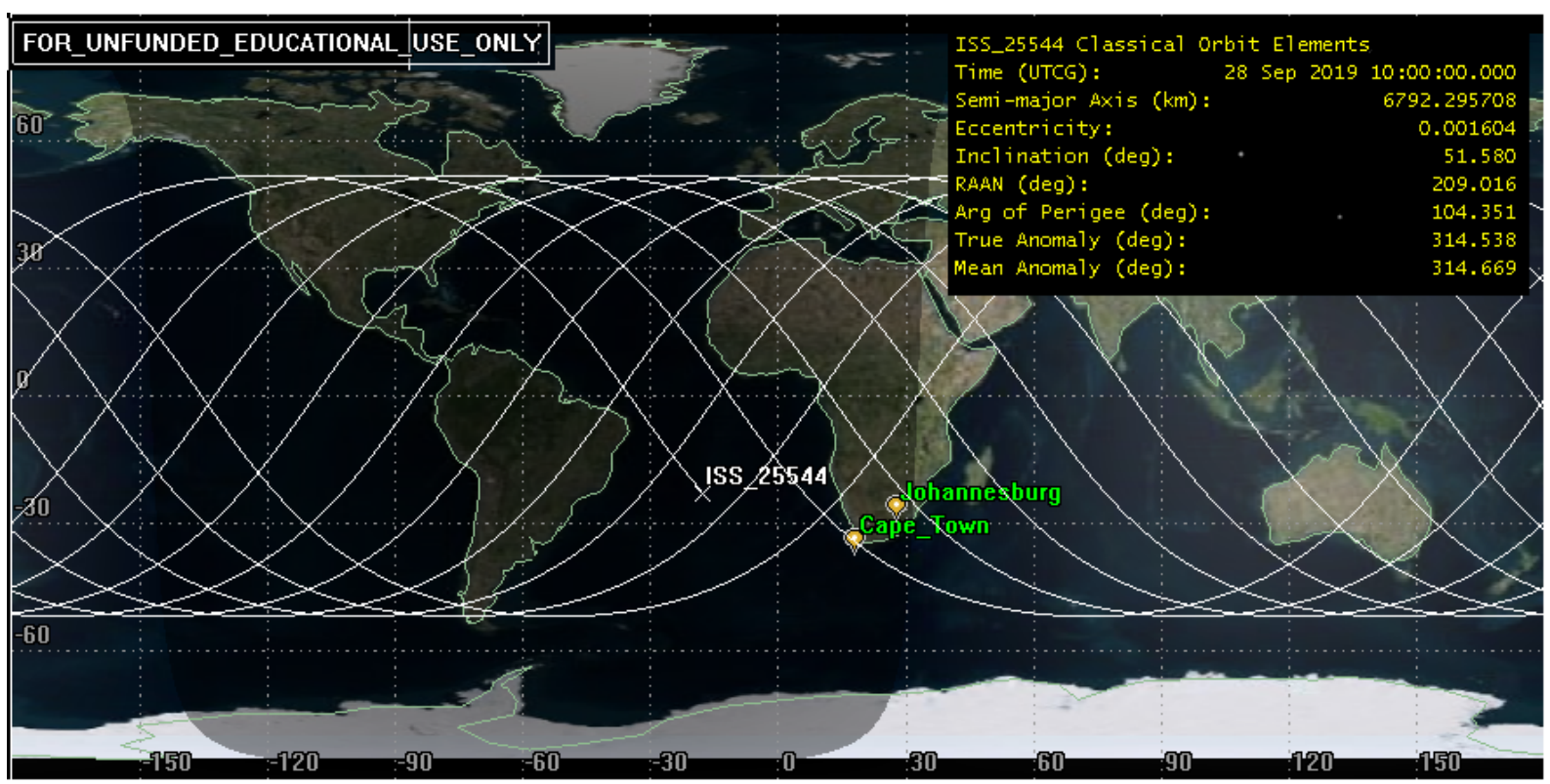

Figure 3.7 STK simulation of ISS orbital ground tracks with orbital data

The second basic orbit that is depicted in Figure 3.8 below is that of RadarSat2, a satellite that has such a high inclination it actually orbits in reverse to the ISS around the Earth.

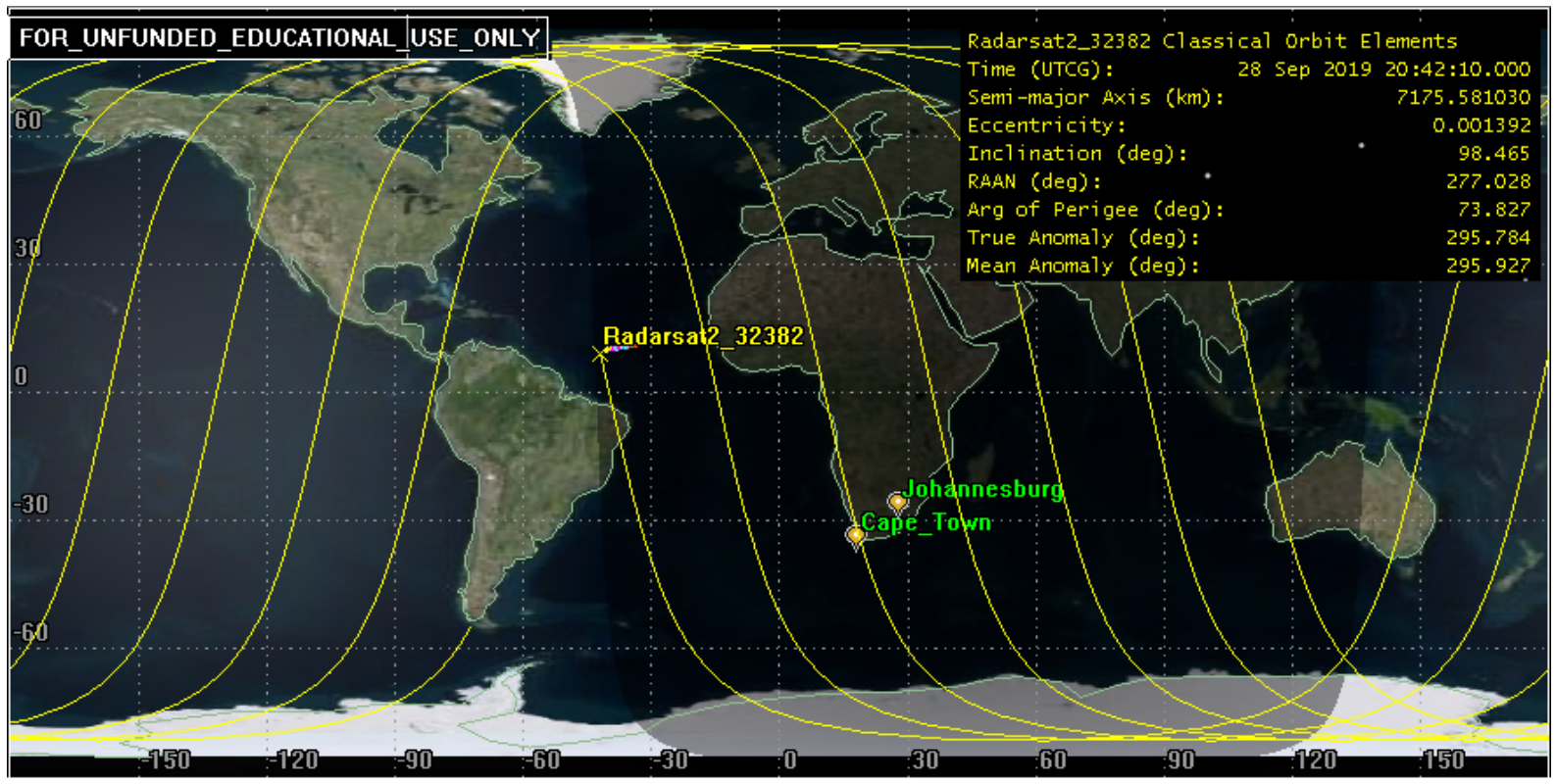

Figure 3.8 STK simulation of ISS orbital ground tracks with orbital data

In the Appendix B possible orbits of the Dream Chaser including ground stations have been included for reference. 


\subsubsection{Dream Chaser descent \& landing profile}

The Dream Chaser descends from orbit with both a very high velocity and a very high sink-rate, this is unlike any aircraft and therefore considerations for the Dream Chaser are unlike any others. Generally aircraft between 18,000 ft above mean sea level (msl) (FL180) and 60,000 ft above msl (FL600) need to be in contact with air traffic control and abide by Instrument Flight Rules (IFR). Below 18,000 ft many aircraft will use a mixture of IFR and Visual Flight Rules (VFR) and may or may not be in contact with control towers depending on the area [43]. Figure 3.9 below depicts this transition from the upper National Airspace System (NAS) limit to the Earth's surface.

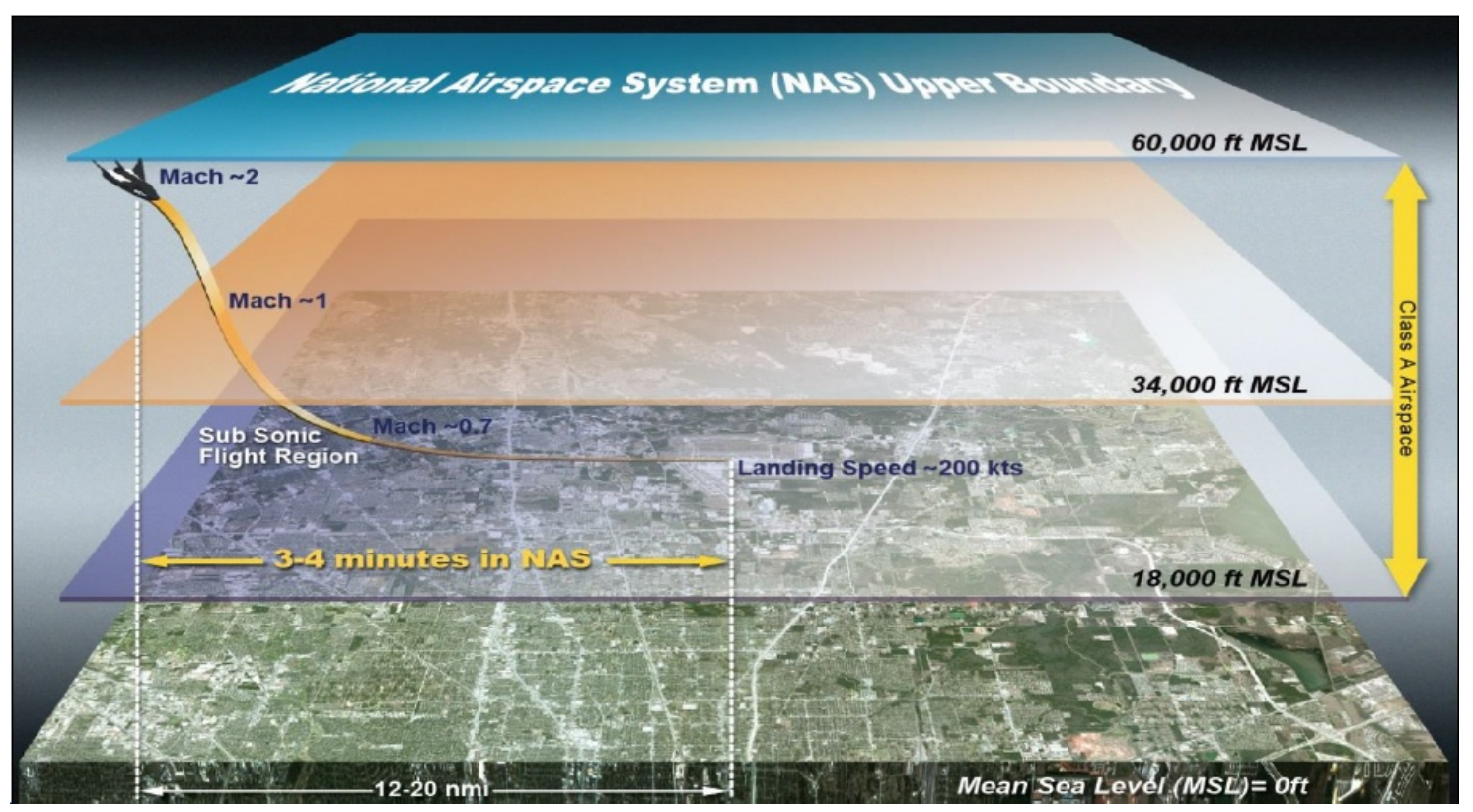

Figure 3.9 Dream Chaser re-entry profile[44].

Figure 3.9 does not depict the skip-glide manoeuvre which must commence in advance of the in-atmosphere manoeuvres (depicted above) which will orientate the Dream Chaser for landing.

The Dream Chaser is a high-tech machine which uses multiple systems for its controlled autoland capabilities. SNC does not disclose the exact technology used to land the Dream Chaser, however the primary technology developer for Guidance Navigation and Control is The Charles Stark Draper Laboratory Inc. Specialising in the design, development, and deployment of advanced technology solutions to problems in national security, space exploration, health care and energy. Technologies the laboratory has developed can be found on the Draper website as they have been invloved in every manned space mission and many other suborbital flight missions. In 2016 the Draper Lab begun developing solutions for the Dream Chaser landing system. 
Another contributor, the professor of mecahnical and earospace engineering from Utah State University USU, Prof. Tony Whitmore developed the Flush Air Data System or FADS which " represents one of the most complex non-linear, real-time estimation schemes ever flight tested," said Whitmore, who patented an algorithm that makes the FADS technology possible. "Dream Chaser is a multi-use spacecraft designed to glide back to Earth after re-entry, similar to the unpowered landings of the now-retired space shuttle. Accurate air speed information is critical for Dream Chaser to glide through the atmosphere on its approach to the runway. FADS generates air speed data using multiple flush-mounted sensors located on the nose of the spacecraft. By comparing air pressure values at multiple points, the autonomous Dream Chaser can calculate its air speed and adjust its flight path." [45]

\subsubsection{Dream Chaser Landing Requirements and Constraints}

Leading into the next chapter on South African infrastructure and particularly Chapter 6's feasibility study a list of categorising features of the Dream Chaser will now be outlined. These will need to be extended by further research into supporting the Dream Chaser post landing including how to fly the Dream Chaser back to the USA. Partly requirements defined here are for selection and elimination of airports in Chapter 6.

1. Length, width and type of Runway:

- Length: $10000 \mathrm{ft}$ or $3000 \mathrm{~m}$

- Width: $150 \mathrm{ft}$

- Type: Based on drag tests at Edwards AFB, concrete is the prefered surface material as the drag-pad on the front landing gear has a high-friction surface which may cause "unusual wear and degradation" on flexible airport runway pavements. However SNC says the Dream Chaser can land on any runway "capable of handling a typical large aircraft (eg. Boeing 737 or Airbus a320)". Having said that provisions for returning the Dream Chaser to Kennedy Space Center for launch will need to be considered. This may require ability to land lager aircraft like the military cargo plane.

2. Runway availability:

- As the Dream Chaser does not have an onboard method for taxiing, it will continue to access the runway for approximately $10-20$ min post landing while being safed ${ }^{2}$ and hitched to be taken to a designated area.

3. Location:

\footnotetext{
${ }^{2}$ Term used for inboard procedure to vent excess fuel or anything hazardous for ground support crew
} 
- Access to hangar space for safe storage of the Dream Chaser between turn around.

- Access to international transport routes for return of the Dream Chaser to the United States.

- Or ability to land large cargo aircraft that could fly the Dream Chaser back to the United States.

4. Airspace Coordination.

- The Dream Chaser descends from space orbit as a glider with both high velocity and high sink-rate, requiring special consideration by Air Traffic Control authorities.

5. Climate.

- Inappropriate weather eg. extreme weather variations, sudden storms such as monsoons experienced at certain times of year in tropical regions, should be avoided at all cost for the safety of the spacecraft and its cargo.

6. Compatibility with existing airport operations.

- Unique Airport operations i.e. the ability of airport to accommodate the special Dream Chaser requirements.

- Type of airport classification

- Existing airport capacity

- Sensitivity of local population to noise (Sonic boom considerations)

- Geopolitical Climate

- Unpiloted landing considerations

- Airport management acceptance of landing Orbital Spacecraft

Further recommendations and requirements:

- Appropriate separation after landing from active runway. In the case of unvented oxidiser/fuel explosive hazards require vehicle to be safely away from public areas.

- Security of temporary parking

- Processing hangar

- Ground support equipment (GSE): tug, taxi vehicle, tow-bar, cooling carts. These facilities will be pre-verified or temporarily deployed as necessary. 
For the purpose of this investigation the primary reference regarding Dream Chaser's specifications was the article Challenges and Opportunities Related to Landing the Dream Chaser Reusable Space Vehicle at a Public Use Airport. We also gleemed some information from the Dream Chaser pages on the SNC website. Of course some antecedent documentation will suffice to augment certain unknowns. Ultimately SNC must be involved in the planning and release of more detailed specifications regarding the Dream Chaser's unique requirements in preparation for a nominal landing in SA. 


\section{Chapter 4}

\section{South African Infrastructure for the Dream Chaser Space Vehicle}

The South African space and aerospace infrastructure along with other facilities currently in place within South Africa, whether in full or partial operation, will be documented in this chapter. By all means not everything, but what might be most relevant. There are many smaller companies and groups that could be included in a more detailed report of the stakeholders. Personnel are also of utmost importance to the overall success of the project, they will therefore be reported on in conjunction with their respective fields of expertise. This research will compliment the previous chapters' findings as the Dream Chaser space vehicle's requirements will define the parameters to which the facilities and personnel must provide support.

Although the Dream Chaser is a well equipped spaceplane with autonomous landing capabilities, to ensure its mission success from vertical launch through to horizontal landing requires a combination of ground and space segment support, as do most space missions. Particularly on re-entry the Dream Chaser requires additional support from the landing state. As discussed previously, the Dream Chaser performs a high atmosphere skip-glide manoeuvre and more than one orbit of the Earth, passing over the proposed South African landing site before beginning its final approach. Sending and receiving information while tracking the Dream Chaser on its approach are critical elements of the mission. Air Traffic Control (ATC) must also be aware of the whereabouts and decent path of the Dream Chaser and any deviations from its planned path to ensure safety in civilian airways by restricting aeroplanes in the area.

\subsection{South African National Space Agency}

Figure 4.1 below shows a breakdown of the government space agency SANSA's programmes, all of which play a role to some degree in the expertise required to host the 
Dream Chaser. Private and military infrastructure is also discussed. All space activities

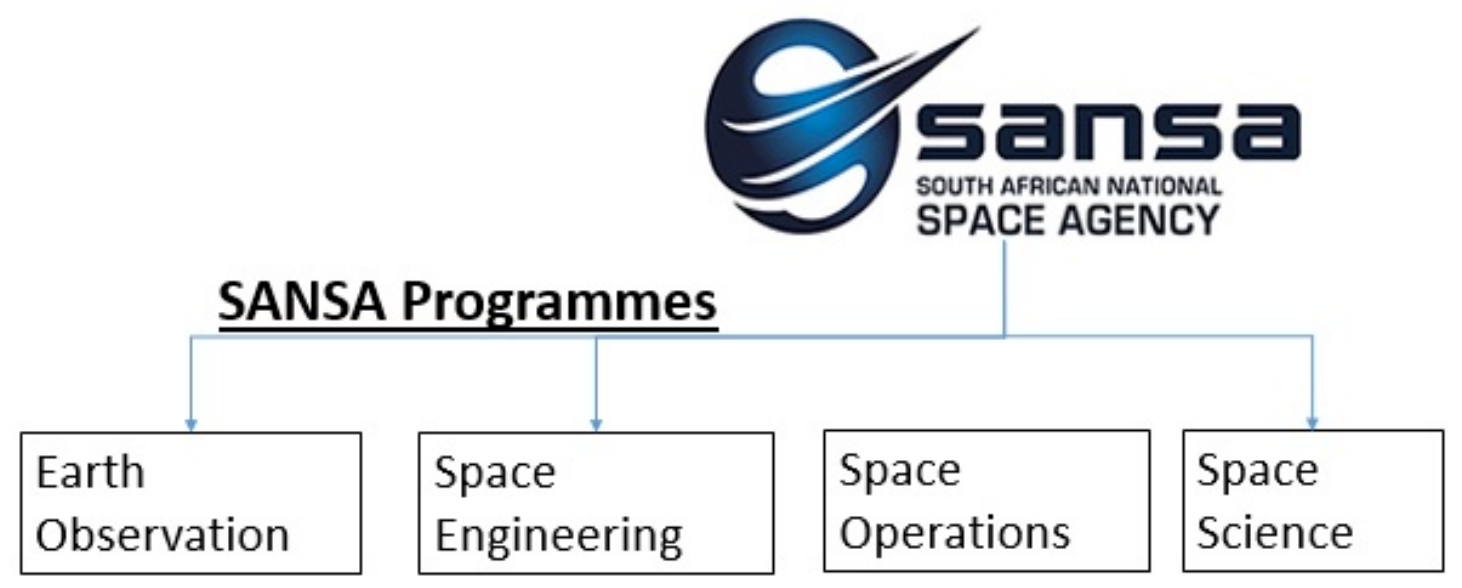

Figure 4.1 SANSA and its four major programmes.

in SA fall under SANSA. Since it formed in 2010 under the 2008 SANSA Act, SANSA has consistently proven their reliability and accuracy in the international space community[10].

\subsubsection{SANSA Space Science}

SANSA Space Science is based in Hermanus and is built upon the former Hermanus Magnetic Observatory, which was established in 1931 and still carries out valuable research today. Considering the impacts that space weather can have on communication, navigation and avionics it is fortunate that South Africa is host to the only regional space weather warning centre in Africa. It operates in connection with the International Space Environment Service (ISES) which has 17 warning centres

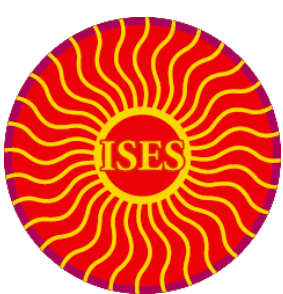

Figure 4.2 Hermanus Space Weather Regional Warning System operates under ISES. worldwide.

In January 2019 SANSA was chosen to be one of two regional centres to provide space weather services, including forecast information across Africa by the International Civil Aviation Organisation (ICAO)[46]. The inauguration has brought renewed attention to the underrated space industry of SA and further funding is being sought to upgrade their facilities further[47]. SANSA's designation as the African regional space weather warning center will inevitably grow the South African STEM (Science Technology Engineering Mathematics) disciplines as well as innovation. These are valuable professions still lacking in $\mathrm{SA}[46]$. 


\subsubsection{SANSA Space Operations}

SANSA's Space Operations facility houses a network of antenna systems that work around the clock, throughout the year to support satellite launches. There are seven full movement TT\&C antennas and there are a range of frequencies available including: L, S, C, Ext C, X, Ku, DBS, Ka and S bands for mobile support. Furthermore other international organisations and companies operate ground station antennas from the SANSA Space Operations facility at Hartebeesthoek. These antennas are maintained on site but operated remotely by companies such as KSAT and MDA or by agencies like ESA and groups like LandSat. So for TT\&C purposes there are ideal local options all housed in the same area and managed by SANSA. This means supporting the Dream Chaser landing will be a simpler task as no new infrastructure needs to be built in preparation of the landing and the experience and proven reliability is already established.

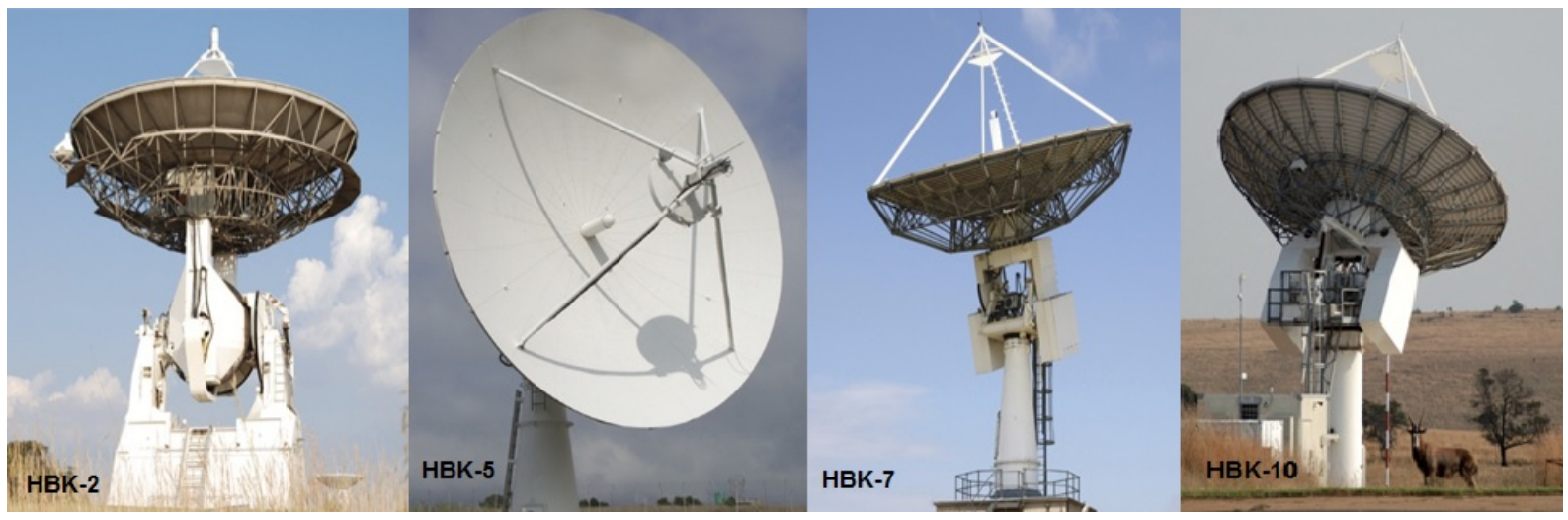

Figure 4.3 A few of the antennas operating at SANSA Space Operations.

\subsection{Overberg Test Range (OTR) and AFB Bredas- dorp}

The Overberg Test Range (OTR), or OTB (Overberg Toetsbaan -Afrikaans for Overberg Test Range), de Hoop Missile Test Range and the Test Flight Development Centre (TFDC) are situated just outside of the small town Bredasdorp, in Overberg, Western Cape. This location is conveniently situated in a sparsely populated region along the Cape Sea Route. The site was first developed for the South African Space programme, when South Africa entered the aerospace industry and has been in operation since 1987. The programme gave rise to sophisticated technical facilities. There were intentions of having a fully-fledged launch facility based there that could launch small satellites into LEO and Sun-synchronous orbits prior to the change of government in 1994. The base was declared an Air Force Base (AFB) in 2004 after an organisational reshuffle and TFDC was moved from Waterkloof AFB to Bredasdorp to utilise the sophisticated facilities. It 
is responsible for all experimental flight testing, research and development of the SA Air Force. Together the companies operating within Overberg service international customers including aerospace organisations and international military. In the secure perimeters of TFDC Bredasdorp are the following:

- flight testing facilities of international standard

- satellite launching facilities (in conjunction with Denel Overberg Test Range)

- missile test range

- secure facilities for military hard and software

The base has large amounts of airspace which it uses during testing and experimentation; this is much of the reason for the AFB being in a beautiful yet remote location.

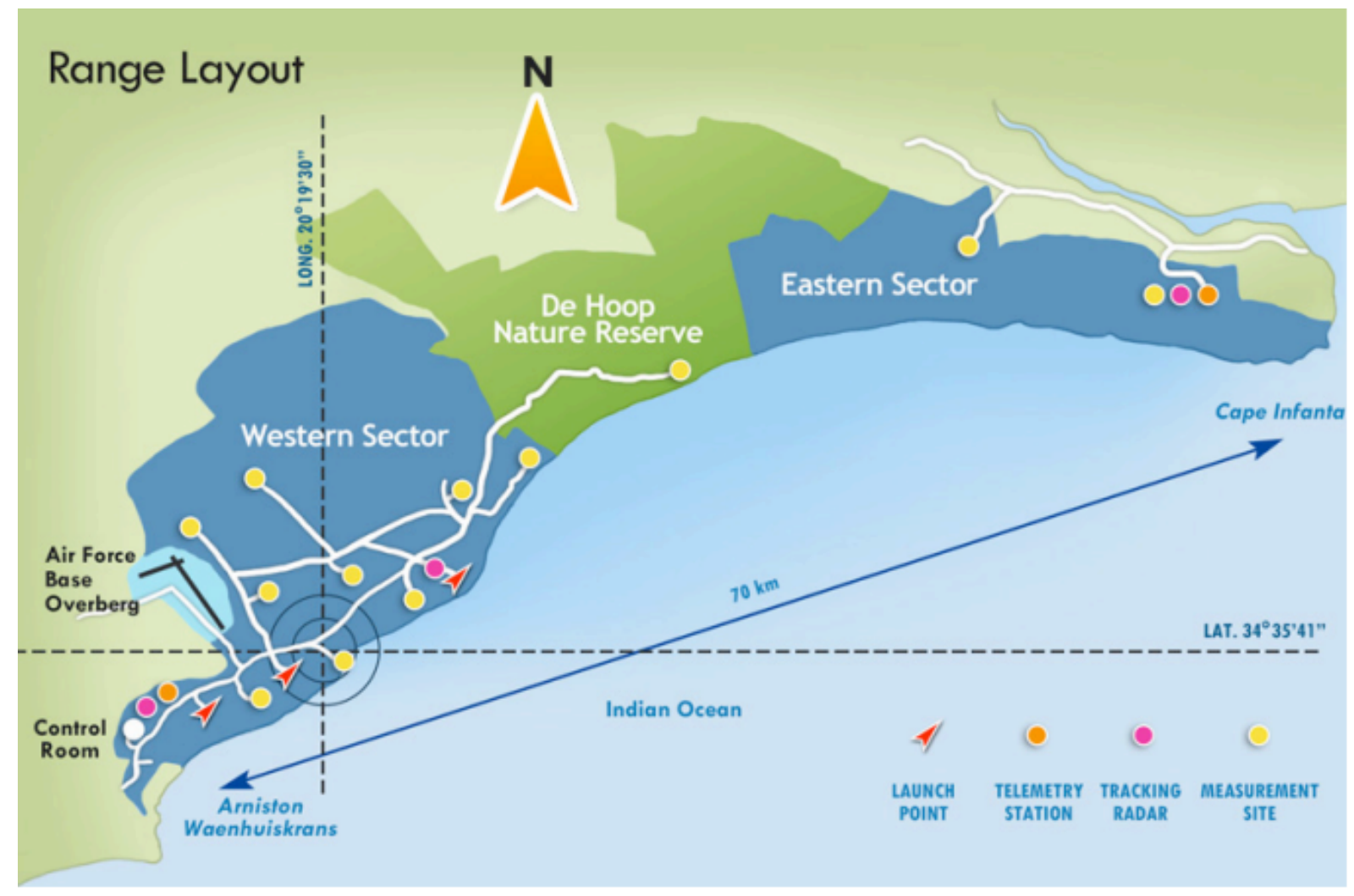

Figure 4.4 Denel OTB Test Range map.

Denel plays a major roll in conducting experimental flight test projects by providing accurate positioning of flying subjects with laser track mounts and Doppler radar as well as visual tracking through cinetheodolites located around the site[48].

The test range has two separate preparation buildings for integration of missiles and payloads with secure laboratories and furnished office spaces. The buildings have fire 
walls, large entry doors and overhead cranes. The larger of the two has integrated hanger space for a helicopter however this could possibly lend itself to securely housing the Dream Chaser between landing and collection for return to the United States. Denel offers clients access to entry for these facilities for high profile projects and equipment. Denel also helps clients with a host of other things such as car hiring and refuelling on site, shuttle services and client accommodation, called The Dunes. The accommodation has conference rooms, training rooms and recreational facilities. Furthermore Denel will assist clients with any additional needs and requirements, such as passenger steps, aircraft taxiing vehicles, etc. [49].

Another business housed at OTR is Incomar Aeronautics a specialised personnel company that operated on site with close relations to the specialised facility to provide support on projects, as complex as required[50].

\subsection{SPACETEQ}

Among the unique facilities in South Africa that make the country an attractive potential landing site for the Dream Chaser is Spaceteq. The facility, formally named Houwteq, was built between 1987 and 1990 specifically in preparation of integrating rocket and satellite technology for South Africa's first space programme. Before such time there had been no ability in South Africa to construct spacecraft according to an investigative news article by Engineering News[51]. Hosting around 500 technical staff working for Armscor, a collective that later became the Denel group.

The facility is only partially occupied now, run by a small team of technical Denel staff under the name Spaceteq that utilise and maintain it. There are specialised products produced and sold such as attitude control systems, flight computers and receivers and importantly Mission Control Software (MCS) designed to link dispersed ground stations and provide consistent communication to users developed through previous missions ${ }^{1}$. The MCS to be used for the Dream Chaser will in all likelihood be developed by SNC, however having experienced personal at Spaceteq familiar with MCS software will be beneficial. Some of the technical facilities available at Spaceteq are: Thermal Vacuum Chambers, Electromagnetic Compatibility (EMC) test facilities and vibration facilities; some of the less technical facilities include: office rooms, conference rooms, clean rooms, laboratories, all boding well for the quick and easy opportunity for science research groups that need access and space to analyse their payloads and experiments soon after landing.

\footnotetext{
${ }^{1}$ https://www.spaceteq.co.za/
} 


\subsection{Square Kilometre Array}

This chapter would not be complete without mentioning the most massive collaborative astronomy project South Africa and the global radio-astronomy community has ever seen. This is the "mega-science project", Square Kilometre Array (SKA). The SKA is run by the not-for-profit SKA organisation that has its headquarters in Jodrell Bank Observatory near Manchester in the United Kingdom although there are 13 "cornerstone" countries and over 100 organisations from 20 different countries working on developing the technology for the SKA.

From a successful bid to host the physical assets, a bulk of Antennas (all High and Midfrequency) have been erected in the Northern Cape, Karoo region of South Africa. While the low-frequency antennas are in the Western Australia Murchison Shire. These locations were chosen as they are some of the most remote areas on Earth and have unrestricted sky view and atmospheric conditions. South Africa also had a bonus piece of legislation, the Astronomy Geographic Advantage (AGA) Act (No.21, 2007) essentially protecting all areas deemed advantageous to Astronomical observation in South Africa. The projects colossal scale has meant its roll-out has been happening in stages. Phase 1 of the project had a budget cap of $£ 650 M$. Beyond the SKA investment the South African government also spends R2 billion on SKA annually and that money is injected back into the local economy, stimulating construction and technical capabilities. The SKA's Associate Director of Science and engineering Professor Justin Jonas says, "For South Africa (...) this represents a new era, where Africa is seen as a science destination and takes its place as an equal peer in global science."[52] This is as important as the financial investment, the intellectual recognition is what South Africa needs to be a global player. The HartRAO and SANSA Space Ops. facilitated the awareness of radio astronomy but it was still a relatively small group of individuals who actively worked with it. A recent announcement on the NRF-SARO website indicated that there would be 38 South African-led scientific research projects which will use the MeerKAT telescopes in the near future. SARAO Managing Director Dr Rob Adam, made this optimistic comment, "a decade ago, such a call for South African-led projects would have resulted in a handful of proposals." But while designing and building MeerKAT, "in parallel we invested in the people, developing a human capital development programme closely tied to the science and engineering of MeerKAT and its associated technologies," says Adam. "This directly accounts for the success we see today, with this large number of young South Africans poised to use one of the world's great research instruments." [53]. This global collaboration with its headquaters in the U.K. and it hardware assets spread across the Southern Hemisphere has lead to more growth in fields relating to STEM than any other space project in the country. Many of these skills learnt from the SKA project are transferable and by the time the SKA is complete scientists will continue to generate research while engineers will look to future marvellous projects to design. 


\subsection{South African Airports}

South Africa has over 460 airfields and landing strips scattered throughout its 9 provinces as listed in the Fallingrain Directory of Airports [54]. It is therefore impractical to go through them all and compare differences and so a pre-screening process must be carried out to narrow the selection of potential Dream Chaser landing sites (refer to Section 6 for more detail on this). Fortunately to help with the selection there is a history in South Africa of relations with the Dream Chaser's best known predecessor, the Space Shuttle. During the Space Shuttle era, NASA made relations with countries all over the world to prepare emergency landing options. This was primarily because the Space Shuttle did not have the same cross-range capabilities of the Dream Chaser, so emergency landing sites were critical for the Space Shuttle to land quickly in contingency situations. Hoedspruit AFB, in the Limpopo province was one such emergency landing site in the global collection of sites[55]. Hoedspruit AFB has a main runway 18/36 of a substantial length 3991x 46 meters. This is substantially longer than the Dream Chaser needs as technical reports suggest runway lengths of $8000 \mathrm{ft}$ or $2400 \mathrm{~m}$ being adequate. Being at an AFB there is also security and hanger space available and all such bases in South Africa will therefore be considered.

South Africa also has 9 international airports that are all run under Airports Company South Africa. These are the airports that comply with the Chicago Convention and are well equipped with facilities and personnel to handle a variety of aircraft. Most of these airports are near cities and often have communities living round them making them potentially unsuitable due to the risk involved with novel space missions. Upington is an airport that has these standards as well as an exceptionally long runway in a vary sparsely populated part of the country. International companies make use of this airports for various reasons. Upington is a large international agricultural trade port, well equipped to handle large aircraft such as the Boeing 747. Furthermore the airport is used to hosting European car companies in the summer months where the likes of Volkswagen and Mercedes-Benz bring their cars to the higher altitudes and heated desert conditions for testing.

Another aerodome distinguishing itself from the rest in the south eastern part of the country widely used by international companies is the Overberg Air Force base. Mentioned in the previous Section, the site is home to the military Test Flight and Development Center (TFDC) as well as the highly technical facility known as the Denel Overberg Test Range (DOTR). The TFDC is a flight test center of international standards and the range is co-located with the OTR missile test range with sophisticated control rooms for the mission control personnel.

For the selection process and feasibility study of appropriate airports and airfields in SA there are going to have to be a limited number of options considered and compared. In 


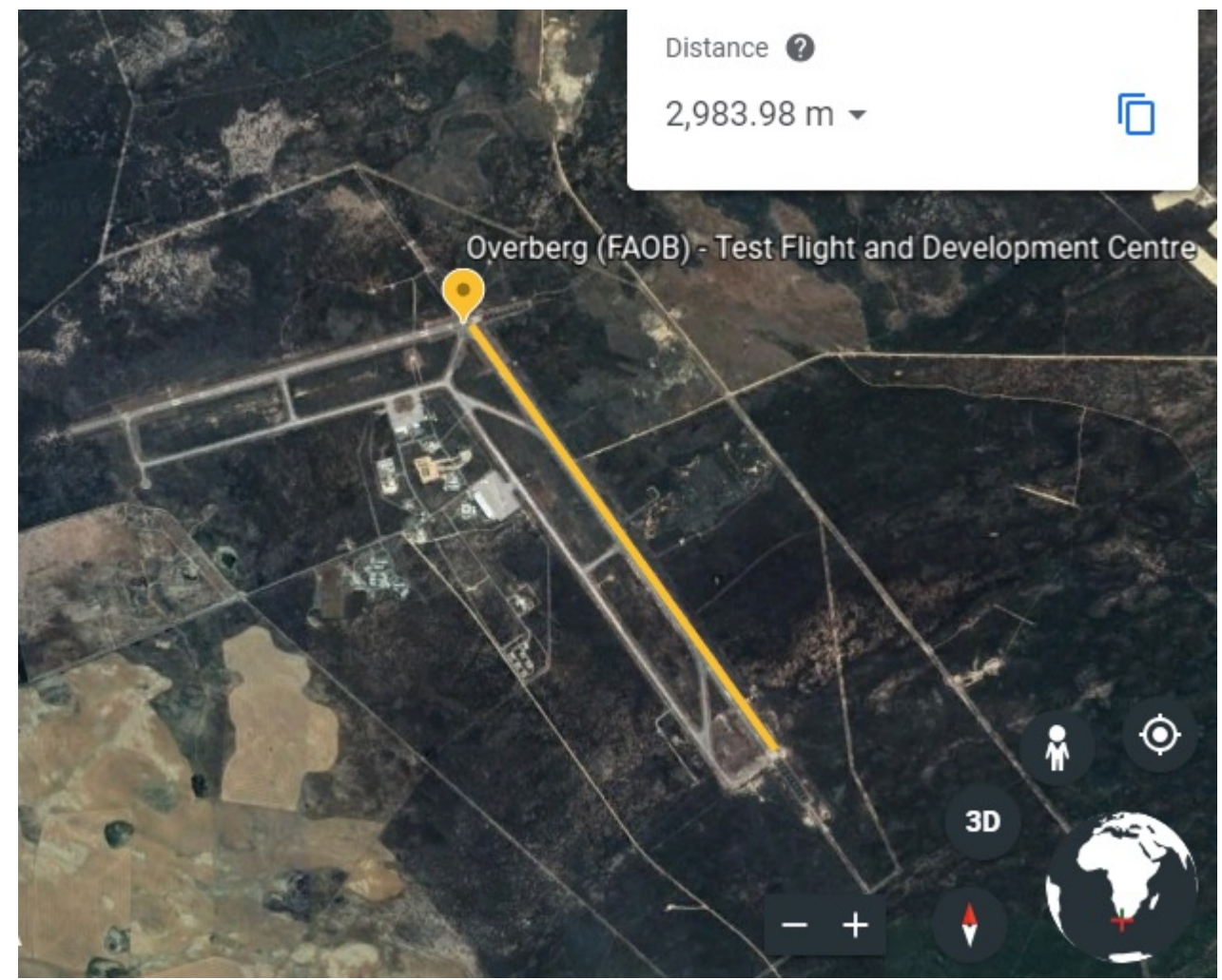

Figure 4.5 Overberg Test Range-Google Earth

order to select airports, certain limiting criteria will be used to narrow down the options. For example, airport runway lengths that are inadequate to land the Dream Chaser on either in structure or length will be immediately ruled out. 


\section{Chapter 5}

\section{Policy \& Regulatory Aspects}

This chapter examines the relevant space and civil aviation policies and regulations that will need to be considered before landing the Dream Chaser in a South African airport. South Africa has ratified four UN treaties governing space activities and the South Africa Civil Aviation Authority aligns itself with the standards and recommended practices of the ICAO. These international obligations will need to be reviewed to determine the national legal implications. In addition there are accompanying principles and guidelines that complement the treaties, standards and practices. Currently at a national level space activities are governed by the Space Affairs Act (No. 84 of 1993). This document will be discussed in context below. Local laws and regulations of governing civil and military aviation activities, licensing and standards will all need to be considered in preparation of the landing and will therefore be brought to light here as well.

With the current lack of legislative guidance concerning activities such as the Dream Chaser mission in South Africa, we look to the South African Space Policy to provide structure and motivation to the industry and discuss the accompanying South African Space Strategy. Through speculation the laws and regulations which these documents will hopefully aid in the making of shall be analysed. This is also in light of the current process under way to replace the 1993 Space Affairs Act with a new Space Affairs Regulating Authority Act. The advantages of finally rectifying these laws will be highlighted.

Ultimately virtually every nation is in a developmental state regarding space policy and regulation due to the global increase in space activity which has led to the increased civilian risk on land, in the air and at sea, astronauts and commercial passengers and crew. This has led some experts to ask if it is not time to create an "ICAO for Space?" [56]. The issue of lacking binding legal regimes, where countries haven't imposed their own hard law derived from international soft law compounds the safety problem. There have been studies conducted revealing capabilities of the ICAO extending their auspices into suborbital orbits (the remaining NAS space) and eventually outer space to provide 
international conventions that protect the global community from trans-atmospheric space activities, as the civil aviation's 'Chicago Convention' has done very successfully. The FAA/AST is already building on their current regulations governing space activity in the USA to include regulation on commercial human space transportation, and have considerable regulatory experience in this field. Worryingly, the FAA/AST has developed independently from the rest of the space fairing world but space is fundamentally owned and used by any space fairing nation, therefore following suit in that regard is counter productive.

There is much to be learnt from the growing body of knowledge on future space regulation being developed internationally, coordinating the collaboration of all the studies and experience gained globally is a challenging prospect. It is the hope that progression will take place with a unified presence of all space fairing nations possibly though a 'Chicago Convention' type document for space. A simplified means of collaboration through common interest may then exist. This also agrees with UNOOSA's ethos which is reflected in the treaties and International Standards and Recommended Practices (SARPs), looking at how developed space nations have adapted their national law to promote and uphold their space programmes. This will be dealt with in Section 5.7 also looking at South African customs of communication to platform the dialogue which will need to take place. In the final section further readings on ways and means for implementation treaties, policies and guidelines will be discussed. Throughout reference to developing space nations methods of implementation will be assessed, emphasising the need for developing space nations to advanced their space law.

\subsection{Background}

It is well known that the South African Space Affairs Act (no. 84 of 1993) and its Amendment Act of 1995 are the primary legislation governing South African Space Affairs. The Act makes provision for a South African Council for Space Affairs under the authority of the Minister of the Department of Trade and Industry (DTI) to exercise regulatory functions and advise the Minister on all space-related matters[57]. The Council is mandated to review all applications on space related activities with reference to the legislation and grant licensing where and when appropriate. Having said that there is currently a lack of supportive legislation regarding space related activities and importantly the guidance thereof, hindering the advancement of capabilities, for example creating a dual-use airport/spaceport which would require extensive supportive legislature in order to be recognised internationally.

To avoid disadvantaging industry by lack of legal infrastructure, legal entities' regimes should forecast commercial development or risk playing catch-up to an outgrown industry. So it is important that South Africa makes a concerted effort to implement necessary 
legislation in order to uphold high standards while promoting growth and development in the space sector. This is not a problem unique to South Africa. In the United States regulating entities must also constantly adapt to industry developments, although they are far better equipped with established groups in place backed by sufficient funding to carry out studies and employ personnel, etc. The Satellite Industry Association (SIA) for instance is the trade association that has been the unified voice of the industry since 1995 on policy, regulation and legislation issues. On August 1st 2019 SIA released an article applauding the Federal Communications Commission (FCC) on actions taken to streamline the applications process required to license certain small satellites. This is an example of incremental improvements countries can take to improve their space sector.

Currently in the United States the FAA/AST is required to licence all non-governmental space activity from launch through operations and landing. However the FAA cannot yet certify launch vehicles or spacecraft and it is therefore up to licensed operators to ensure mission success. The FAA is also not able to ensure passenger safety, so indemnity or informed consent protocol (ICP) is still normal practice. Progressive steps are being taken, however. The 2004 Commercial Space Launch Amendments Act (CSLAA) states that, "... the regulatory standards governing human space flight must evolve as the industry matures so that regulations neither stifle technology development nor expose crew or space flight participants to avoidable risks as the public comes to expect greater safety for crew and space flight participants from the industry."[58].

The challenge now faces the world and not just America as this unique space domain has suddenly gained broader global interest and the safety and utility concerns now transcend borders. A snippet from a Dutch implementation research document sums up the general goal of national space law here, "In short: by means of a national space law a particular state may try to establish precisely that balance between the public interests in space, both of itself and of mankind as reflected by the international space treaties, and those of private entities operating under its jurisdiction, which best fit its political, economic and social philosophies." With that in mind lets proceed onto international space treaties currently informing national space law globally.

\subsection{International Space Law}

The United Nations Committee on the Peaceful Uses of Outer Space (UN COPUOS) is the leading international forum that provides discourse between member states regarding the development and codification of international space law and norms of behaviour around cooperative space activity. Their primary mandate is strengthening the international legal regime governing outer space for improved conditions of expanding international cooperation. The treaties, policies and other supporting documents that arise from this discourse are then implemented by COPUOS member states. The policies work to 
unify the intentional community and make space a safer place for all to operate. The policies become guidelines for member states to implement into their own national policies, strategies, law and other government mechanisms.

\subsubsection{South Africa's International Obligation}

South Africa has ratified 4 out of the 5 Space Treaties negotiated by UNCOPUOS. Under these treaties South Africa is obliged to adhere to their core values and answer to the international community on behalf of space actors acting within the country. Below the highly simplified treaty notes have been developed from the official UNOOSA website[59].

- The Outer Space Treaty (OST)(1967) obliges states to authorise and continuously supervise the activities of private entities of the space sector.

- The Rescue Agreement (1968) elaborates on certain articles in the Outer Space Treaty (Art. $5 \& 8$ ). It states that States shall rescue astronauts promptly and return them to launching States. Also States shall upon request help return space objects that have entered and landed on Earth outside of the Launching State territory.

- The Liability Convention (1972) elaborates on OST Article 7. It provides that Launching States shall be absolutely liable for any damage caused by its space objects on the ground, at sea or in the air. It also describes means of settlement for damage claims.

- The Registration Convention (1975) makes provision for mechanism that provided States with a means to assist in the identification of space objects. The UN Secretary-General was, once again, requested to maintain the Register and ensure full and open access to the information provided by States and international intergovernmental organizations.

\subsubsection{International \& Government Agencies}

The longest standing and possibly the most influential agency is that of the US Government, the National Aeronautics and Space Administration or NASA. The simple mandate set out in its creation in 1958 to "plan, direct, and conduct aeronautical and space activities." The act also specified the agency is required to create and amend rules and regulations that fit best practice and the interest of the nation, its people and international relations. During the cold war years and even into the 1990's NASA has been responsible for controlling almost all American Aeronautic and Astronautic activities and therefore a majority of the world's space traffic as well. Recently however, elements of NASA's operations have been strategically handed over to private commercial companies. 
There are two other international groups worth mentioning when talking about Space safety. The first being a new-comer but one which contributes valuable insight and symbolises global efforts to improve STM and space activities, the International Association for Advancement of Space Safety (IAASS), legally established in the Netherlands on 16 April 2004. Later in 2004 IAASS became a member of the International Astronautical Federation and in 2010 was granted observer status to UNCOPUOS. Their mission is simply to advance the safety of space. One of the ways in which the IAASS has done this was by creating a working group (WG) under its legal and regulatory committee to conduct an in depth study of the ICAO's capability to extend its auspices into the integrated realm of aviation and space. The study was called 'ICAO for Space?' and was later published by Springer with the title The Need for an Integrated Regulatory Regime for Aviation and Space.

The ICAO itself is another international group which is worth reviewing as a major analogues group with much experience in creating a highly successful mass-human-transport regulatory framework that has seen the aviation industry thrive in the decades post World War II through the famed "Chicago Convention". In its own words "The International Civil Aviation Organization is a specialized agency of the United Nations. It codifies the principles and techniques of international air navigation and fosters the planning and development of international air transport to ensure safe and orderly growth" of this sector.

Lastly as a major international producer of air and space traffic regulation is the FAA/AST, a specialised office of the FAA dedicated to Commercial Space Transportation. Established in 1984 as part of the Office of the Secretary of Transportation within the Department of Transportation (DOT). In November 1995, AST was transferred to the Federal Aviation Administration (FAA) as the FAA's only space-related line of business. The Secretary of Transportation's licensing authority is still delegated to the Administrator of the FAA and further assigned to the Associate Administrator for Commercial Space Transportation (AST). It is worth noting their developments and experience in the field. In their own words "The Federal Aviation Administration is a governmental body of the United States with powers to regulate all aspects of civil aviation in that nation as well as over its surrounding international waters. The Federal Aviation Administration is an operating mode of the U.S. Department of Transportation." This leads onto the next major field of interest at the moment, that being Space and Air integrated Traffic Management, as more rockets and Reusable Launch Vehicles (RLVs) pass through NAS there is are growing dangers of accidents that need to be addressed.

\subsubsection{Space Traffic Management}

The global increase in commercial sub-orbital (The region above FL600 and reaching anything from $100-200 \mathrm{~km}$ above msl) space travel and the interest there of has sparked 
the sudden need for establishing a Space Traffic Management (STM) system. The most commonly accepted definition of STM comes from a 2006 study by IAA and goes like this, "...the set of technical and regulatory provisions for promoting safe access into outer space, operations in outer space and return from outer space to Earth free of physical or radio-frequency interference." There are however differing opinions internationally on how this system will be best implemented. Except for the 2016 "Orbital Traffic Management Study - Final report" prepared for NASA which do not contain a definition for STM arguing that "the use of the phrase Space Traffic Management is problematic, in that it implies centralized command and control (...) also creates a direct analog to Air Traffic Management"[60]. The USA therefore proposes the support of nationally implemented system as opposed to an international one. On the other hand Europe has a more common understanding that STM will need to be a global effort as discussed in a series of papers produced from an evaluative study on the implementation of STM in Europe by the German Aerospace Center - Gesellschaft für Raumfahrtanwendungen (DLR -GfR) meaning, Society for Space Application, and its partners on behalf of ESA. The definition of STM in their approach was "Execution of all necessary Managing and Monitoring \& Control Operations (including routine and contingency scenarios) to ensure safe ballistic travel of manned and unmanned Suborbital Space Vehicles (SSVs) and spaceplanes through Near-Earth space and airspace under consideration of the existing European Air Traffic Management System and Infrastructure."[61]

These are considerations for stakeholders of the UNOOSA Dream Chaser mission, although considering SNC has space operations experience the Europeans and the USA will have to agree on details of safety, best practice measures etc. Nonetheless the first mission will almost certainly be launched and landed within the US and if all goes to plan and the mission is a success the practices followed will be validated. One day when the Dream Chaser landing in South Africa takes place it will have to follow similar protocol and spaceport operations and it will be important that legislation is set in practice and well understood by then.

\subsection{South African Space Law}

As already mentioned the South African space legislation is seriously lacking compared to that of the USA, Europe and other developed space nations. In the global market private space companies regularly do business with developed nations as well as with much less developed ones, it is worrying that our capabilities are now advancing through these global relations, therefore possibly outgrowing the regulation and governmental control South Africa currently has.

Since the end of the first South African Space Program in 1994, efforts have been cyclic in repairing and building space programmes, unfortunately as politicians are voted in for 
set terms of power, programmes struggle to lift off the ground. The national space policy outlines the general need for a successful space program aimed at "uplifting the poor, stimulating socio-economic grown and sustained interest and development in the fields of STEM." There is no question that the advancements in space technology locally are also taking off and breakthrough astronomical observations made with the SKA telescope are key in raising awareness and stimulating interest in STEM fields. The national space strategy offers further plans of action for implementing the Policy.

The National Strategy focuses on the key priorities of the country and the directly related user requirements that extend from it. The broader plan has a 10-year first phase implementation followed by a longer term maturity phase aimed at upholding the user interests and national concerns through space related activities and data collected from space[62]. This is discussed further in the next Section 5.3.1.

Worth mentioning is that South Africa has a unique space management situation, unlike the United States and even India where space agencies (NASA and ISRO respectively) report directly to the president, SANSA is an agency of the government formed under the Department of Science and Technology (DST), as seen in Figure 5.1. This is but a fraction of the departments that actually use or benefit from space technology and resources yet SANSA must operate with a fraction of the budget of DST and DTI. This structure heavily restricts the agencies progression. SANSA's separation from the presidency makes it challenging to secure funding and implement changes, further hindering the agency's effectiveness. Some of the many departments linked to space that will likely take interest in South African Space regulation improvements are the: Department of International Relations and Cooperation (DIRCO), Department of Defence (DoD), Department of Telecommunications and Postal Service (DTPS) and so on. Working groups should be set up under each of these departments or a combined working group can address the departments legislative needs tackling one issue at a time.

Currently under-way is the repeal for replacing of the South African Space Affairs Act (No.84 of 1993) by a new Space Affairs Regulation Authority Act. This task is being undertaken by South African Council for Space Affairs (SACSA). The process has been ongoing for over 3 years. The rationale behind the repeal, as provided in a presentation by the portfolio committee of Trade and Industry (20 June 2017) is as follows[63]:

- Increasing involvement of domestic and foreign, public and private sector entities in space activities in South Africa.

- The growth of the commercial space sector locally and internationally since the enactment of the Act.

- To ensure compliance with international legal trends in outer space.

- To align regulatory framework to international space treaties. 
The Presidency

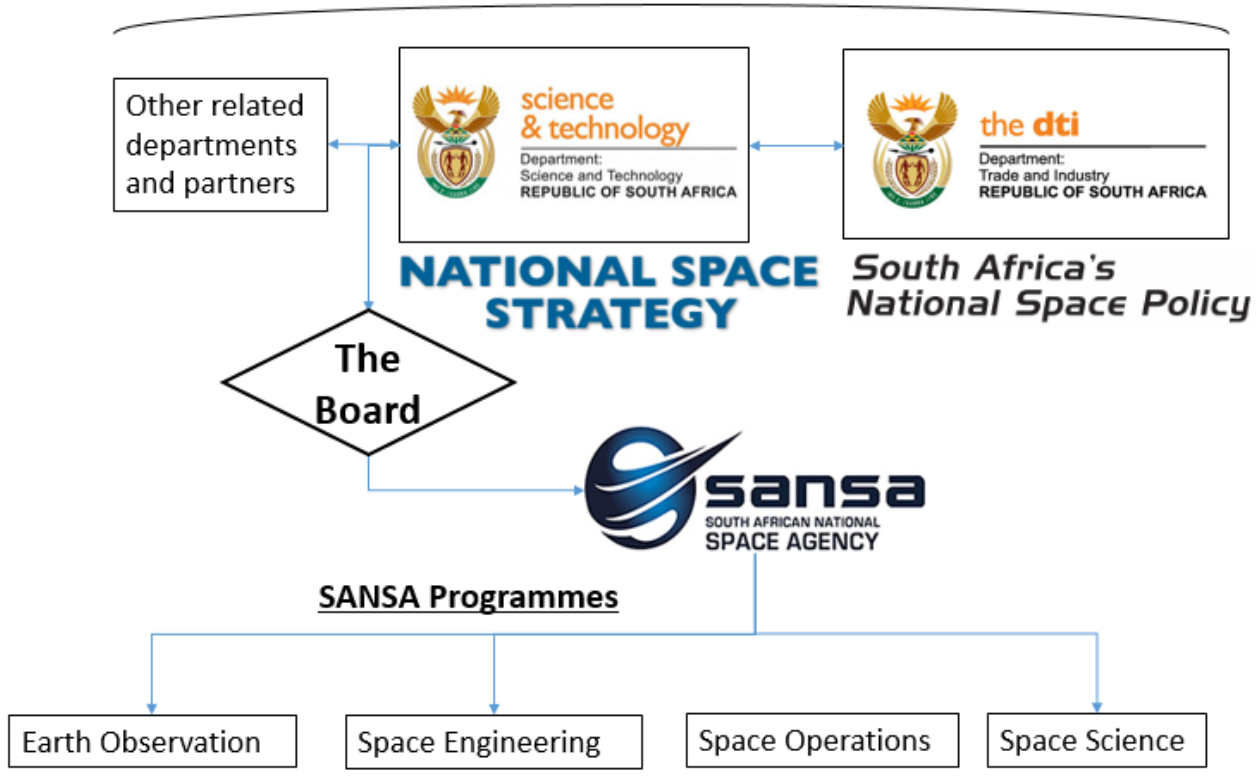

Figure 5.1 The South African space government framework.

- To align to domestic policies \& strategies.

According to the portfolio committee the rationale can be broken down into international obligations and national concerns. On an international front South Africa is a member of UNCOPUOS, a subsidiary body of the UN focusing on international co-operation with 92 member states. South Africa is a signatory of four out of the five UN space treaties, namely: the Outer Space Treaty (1967), The Rescue Agreement (1968), The Liability Convention (1972) and the Registration convention (1976); to which SACSA refers to on space related rulings although most are considered under represented in current South African legislation. On a national front there has been a steady increase in space activities both commercially and governmentally. For example: The National Space Policy was developed by the DTI in 2008, the National Space Strategy was then developed for support and implementation of the policy by DST soon after; the SANSA Act (2008) was passed and SANSA established in 2010; Denel Spaceteq, government enterprise established and so on. A key issue also regarding the need for national legislations updates is that previously space was regarded as a military domain for reconnaissance and warfare however today space has a very different purpose, that of supporting socio-economic growth and sustainable development therefore legislation should update to include previously un-addressed players in the industry while supporting the sustainable commercial growth. Papers on this have been produced by many developed and developing space nations and provide detailed insights as to how countries intend to foster the industry for the benefit of the country.

The Scope of the new Act covers all aspects of space activity in SA: 
- Operation of a space facility;

- Manufacture of space objects;

- Launch of space objects into outer space;

- Operation and control of space objects in orbit;

So developments are under way and South African mindsets are shifting outward to what the space industry can offer if we engage with it. Implementing basic measures to show commitment to the international obligations is a first step in securing our position in the global space industry.

Another important step is protecting our natural advantages and growing the country's capacity with its strengths through dedicated space legislation such as, the South African Astronomy Geography Act -2007. A major reason for South Africa winning a large share of radio telescopes of the SKA is the Astronomy Geography Advantage or AGA Act (2007) Assented by the President in 2008. The Act intends to " intergovernmental cooperation and public consultation on matters concerning nationally significant astronomy advantage areas; and to provide for matters connected therewith." It can't be emphasised enough how powerful steps like this can be for example a national bid to host an intergovernmental collaborative experiments' equipment like the SKA. These are critical areas where policy makers and agencies such as SACSA can have an incredibly positive influence on the economy as we saw with the AGA Act securing the SKA radio telescopes in SA solidifying a long-term intergovernmental relations, further strengthening our capabilities and global presence.

\subsubsection{South African Space Policy and Space Strategy}

South Africa's National Space Policy (NSP) recognises the far reaching and multidisciplinary nature of space activities. There is also considerable recognition of the utility of space in uplifting the economy while supporting and developing the country and its people in a sustainable manor. The policy promotes sustainable use of outer space and the importance of following international best practices and international treaties in all space activities. It mentions the national laws under the Space Affairs Act (No. 84, 1993), which is the only enforceable legislation governing non-spectrum related space activities, updates of which are well behind industry trends. There are sections of the policy that may need to be updated as well to encompass the growing space related activities and international collaborations. Thee need for draft legislation in preparation of a dual use airport/spaceport should also be considered.

The National Space Strategy (NSS) builds on the NSP by providing a practical structure for its implementation by identifying space as a platform for delivering on an array of national priorities around socio-economic development. The strategy identifies three major 
priority areas:

- Environment and Resource Management

- Health Safety and Security

- Innovation and Economic Development

Going further the NSS identifies the requirements expressed by key departments for their own uses of satellites and other space activities in fulfilling their mandates. In order to deliver on these requirements various supporting programmes are required and these are[62]:

- Thematic Programmes: Earth observation, navigation, communication, and space science and exploration.

- Functional Programmes: enabling technologies, mission development, space mission operation and space mission applications.

- Supporting Programmes: human capital development, infrastructure and international partnerships.

The following concluded the NSS, "The strategy is primarily driven by the most urgent user requirements, which is a direct expression of national priorities. These requirements give strategic direction and on the basis of which a number of building blocks are identified. These building blocks form the foundation on which a national space programme will be positioned and indeed provide a measure of success if effectively implemented. The implementation plan for this strategy, which will include work plans in support of the user requirements and associated budgets, will span a 10 year time-frame, as the foundational phase, followed by a longer term maturity phase." Providing a general understanding of the approach.

\subsection{International Spaceport regulations}

South Africa currently has no operational spaceports, so it is not surprising that there is currently no legislation governing spaceports in South Africa. It is therefore instructive to examine the legislation developed in other countries. So looking to the developed space nations such as America which has 10 spaceports registered with the FAA, although the term 'spaceport' is not defined in either U.S. Federal Law or International Law the term is recognised by the FAA to mean 'launch' and 're-entry' sites of 'spacecraft' [64]. Identifying the importance of designating certain areas for launching and sometimes landing rockets and spacecraft has been crucial for the management and control of the commercial space sector. The U.S. Federal spaceports are not governed by the FAA or licensed by them due to the secrecy of missions. Figure 5.2 shows the location of operational spaceports in the U.S. as of 2018.

Other established launch facilities in the world such as those in India and French Guiana, are worth addressing as they both launch rockets on behalf of many other nations as well 


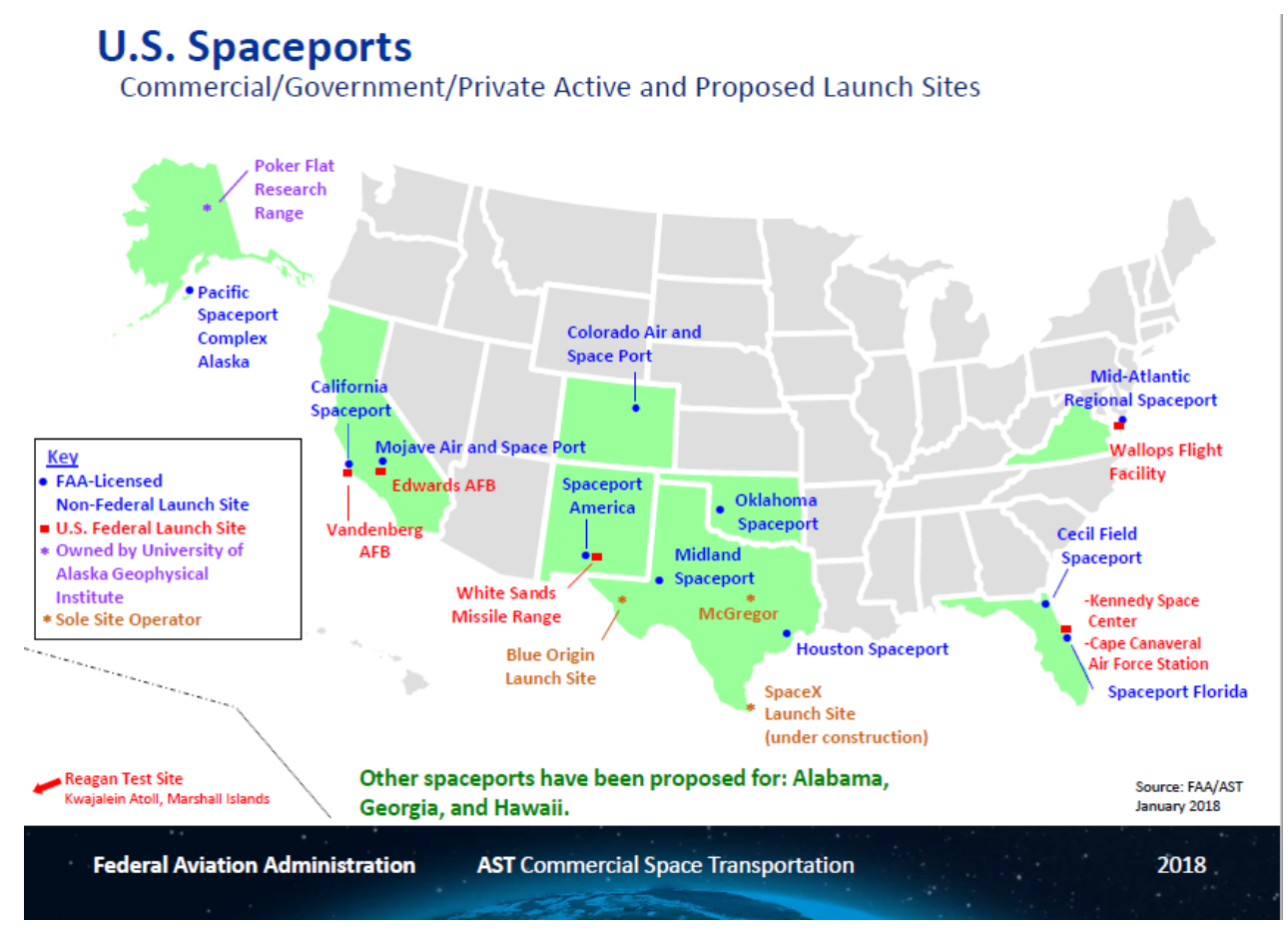

Figure 5.2 U.S. Spaceports. [credits: FAA[65]]

and will therefore have an advanced set of spaceport regulations which will be adaptable if not directly applicable to a South African spaceport context.

The U.K. government is working hard to develop the regulatory framework to allow for commercial space flight operations, particularly launch capabilities from the U.K. After the U.K. Space Industry Act of 2018 was passed independent consultants were commissioned to research health and safety guidelines which a spaceport would need to implement. This was done through studying the ways in which civilian safety may be at risk from the spacecraft flight path[66]. The full document is available on-line and it would greatly benefit the South African regulatory officials to read it. The research specifies that the 2018 U.K. Space Industry Act has a primary purpose of ensuring space operators conduct activities safely and no people are put at any unnecessary risk.

A document of this nature, tailored to build on South African's exceptional constitution, health and safety documentation, would be highly beneficial. Requirements stipulated in terms and conditions of the future UNOOSA-Dream Chaser CFI may require a certified spaceport to already be established in the bidding host country. Spaceports are often multinational endeavours as regular use is critical for financial sustainability. Unless the spaceport is opened for purely strategic reasons, such as landing spaceplanes.

\subsubsection{Launch and Re-entry guidelines}

Issues of launch and re-entry safety will always be a work in progress, as the civil citizens of the world become more expectant of higher safety standards the regulations 
must evolve to meet these expectations. The safest way to avoid risk $100 \%$ is to refrain from the activity entirely, as that is obviously not in the interest of the space mission, or any activity we must proceed with the next best option of assuring risk prevention as best possible. In the United Kingdom the Health and Safety at Work Act (1974) specifies that those who create the risk should control the risk so far as is reasonably practicable (SFAIRP), requiring a key concept of applying common sense when carrying out activities and the prevention of those activities risks. The aim is to get risks as low as is reasonably practicable (ALAIRP)[66].

Looking back at the history of the Space Shuttle, the most practical example we can study of a Reusable (space) Vehicle (RV), there are indications of mission control and planning being the key to success from before guidelines from regulatory bodies were better informed. Foremost the success of the Space Shuttle can be attributed to the NASA Space Shuttle Mission Control Center (MCC) which has a host of scientist, engineers, doctors, technicians and mathematicians all working together creating simulations and preparing to support the mission from take-off to landing. The flight controllers are critical for supporting normal and unexpected events of the Space Shuttle as well as the highly sophisticated technologies that they designed and worked with.

The next most important element of ensuring safety of the Space Shuttle crew, MCC personnel, other staff and employees occupying the premises as well as civilians occupying surrounding areas, is flight planning and prerequisite aviation, waterway and bridge restrictions. There is also an element of weather that determines whether or not the goahead for de-orbit and landing is given. These restrictions prior to take-off and landing were crucial for the Space Shuttle's success, as arrangements could be made in advance to send a message to air traffic control and other civil management to make sure all possible vehicles and craft in the flight path and on the peripheries, once again SFAIRP, are shut down to mitigate interference or collision.

Nowadays in the United States the FAA/AST are far better prepared to manage and licence all space operators, launch and re-entry vehicles as well as launch and landing sites. From the Commercial Space Launch Act (2011) and others like it, through the thorough FAA license process, to Advisory Circulars (AC) published specifically for operators and derived from extensive industry experience, the US has an advanced space regulation system. Being an integrated part of the FAA and using elements of the DOT as well means that planning for cleared airspace during trans-atmospheric stages is well managed as well.

In Europe the general approach appears to be seeking a common understanding that an integrated ATM and STM system needs to be developed and adopted globally in order to ensure safety with regards to the sudden rapid growth of activity and interest in commercial space transportation. Many articles forecast major cities and commercial 
hubs around the world developing means to convert airports into dual-use air/spaceports. This means in the not-too-distant future spaceplanes and other sub-orbital craft may be landing in much more densely populated areas than they have been tested in. The UK passed the Space Industry Act (2018) to allow for the development of their already growing space sector, with the likes of Richard Brandson investing millions of Pounds into Virgin Galactic to realise the dream of commercial space travel. The Act aims to grow the industry and launch capabilities further while ensuring the public is not exposed to health and safety risks they would not usually be exposed to. In the UK's case it is the United Kingdom Space agency (UKSA) and the Civil Aviation Authority (CAA) that is leading the creation of draft legislation.

So what does this mean for South Africa and who's approach do we follow? One might argue that because the Dream Chaser is a U.S. company owned vehicle that the U.S. and the FAA/AST practices should be reflected in South African legislation. This would not be wrong to say although South Africa does not want to alienate itself from European developments either. For this reason it is in the best interest of South Africans that SANSA in collaboration with the SACAA create a working group that can asses the international space industry landscape in context of South Africa's level of development and future space prospects to produce meaningful reports advising the government of what legislation to enact. Furthermore the group can provide ongoing support in the form of $\mathrm{AC}$ to assist operators in ensuring the safety and viability of their practice.

\subsection{Civil Aviation Regulations}

In many respects Civil Aviation Regulations represent the most analogous example of law and guidelines to that of space. Barring a number of technical differences, such as NAS and beyond, this section could have a chapter of its own and be comparable to that of space laws, or what we one day might expect to see as a complete set of laws for space. However, the other major interest for the time-being is specifying where there are overlaps in jurisdiction, such as NAS and duel-use air/spaceports call for coordinated efforts of drafting legislation as sub-orbital space travel particularly (more so than longer range space travel) may be considered an extension of the current air traffic system.

An interesting study carried out by a former student of the SpaceLab, Alexander Gairiseb was that of an integrated air traffic management (ATM) and space traffic management (STM) in a combined SATM [67]. The study looked to analyse the global challenge of a lack of legal framework, adoption of a new treaty regulating STM and advancement in technology to seamlessly integrate STM and ATM. Emphasis was placed on the harmonising of international regulatory regimes in the context of the African space landscape and the implications thereof. It was the finding of Gairiseb that even the "big players" in the African landscape, Nigeria and South Africa were lurking behind with technology 
and regulation related to international integrated ATM and STM. The thesis went on to conduct a detailed SWOT analysis in order to identify the strengths and opportunities, weaknesses and threats of the efforts of an integrated SATM system and its supporting regulatory framework. The SWOT resulted with the following conclusion, "opportunities exist for Africa to integrate SATM, however, the threats that the region faces outweigh any effort to integrate space into ATM in Africa" currently. Further deducing that, "both the current spaceports and the feasibility studies suggest the potential for spaceports in Africa, but the launch activities per annum in the region currently is zero. Thus, why should Africa be concerned about a traffic regime that has not yet kicked off .. If there is any need for integrating space into ATM in Africa, it will be as a result of push effect from the United States and E.U." Further findings and conclusions or Gairiseb's dissertation can be found in Appendix E.

As previously mentioned in the United States the FAA/AST has the responsibility of licensing commercial space activity, including launches, re-entry and operation. This is because the FAA has many years of experience licensing the analogous air traffic system. This is the same for South Africa, the CAA previously the Directorate of Civil Aviation acting under the Department of Transport (DoT) ${ }^{1}$ has been active since 1947, around the beginning of aviation safety concerns in South Africa. As South Africa is a contracting State to the ICAO it is "required in terms of the Convention on International Civil Aviation, commonly known as the Chicago Convention, and its Annexes, to ensure the safety of navigational-aids at international airports. Consequently each contracting state is obliged to provide in its territory airports, radio services, meteorological services and other air navigation facilities to facilitate international air navigation, in accordance with the standards and recommended practices (SARP) established from time to time pursuant to the Convention." [68]. In this regard South Africa abides by the same rule and has the same safety standards imposed on it at its national and international airports as others around the world. In South Africa the Flight Inspection Unit (FIU) a semi-autonomous business unit of the SACAA which services a greater part of the SADC region ensures that navigational aids in South Africa are safe. As an Aviation Operator Certificate (AOC) holder it is authorised to carry out specified operations under its specific ICAO contract. The FIU contributes to the safety and quality control experience available in South Africa.

Until such time as an updated version of the South Africa Space Affairs Act is assented, the civil aviation regulations, protocol and discipline are highly important to ensuring a safe landing of the Dream Chaser. Legislation developed for aircraft operating between certain flight zones as well as autonomous vehicles, vehicle registration and licensing are all dealt with under SACAA and will pertain to the Dream Chaser when landing in South Africa as it currently stands at the time of this dissertation submission.

\footnotetext{
${ }^{1}$ This is the same as the AST as well which developed as an office of the DoT before being transferred to the FAA. This is common to see developing countries following the lead of others and can be highly beneficial to both
} 


\subsection{Benefits of Strong Legislation}

There is no doubt that the AGA Act supported the Astronomy industry, promoted its development and even secured the SKA project with South Africa as a majority shareholder of the telescope assets and infrastructure. So how does this benefit the country and why is it so beneficial?

Legislation, Acts and their amendments published in the Gazette are there to stay, providing guidance while politicians and parties serve set terms bringing their agendas with them before moving on. Legislation and policy is therefore crucial for the medium to long term success of space activities as well as SACSA's rulings and licensing.

To elaborate further, before new legislation is drafted all stakeholders and representatives must be consulted, working groups are established and conventions held. This ensures there is a common narrative between stakeholders covered by the the same or similar value systems aimed at achieving certain goals through their mandates. Ultimately the outcome of all of this is something broadly accepted and sustainable. Strong legislation facilitates authorities and those (in this case all space acting individuals or companies) who fall under it to achieving their goals and those of national priority. Hence legislation is the foundation of a system's success.

\subsection{South Africa fostering international relations}

As a country, deciding to respond to a CFI regarding a landing site has large responsibilities attached, including but not limited to maintaining communication between all stakeholders in a professional manor. There are a few representative examples for guidance to how future collaborations and cooperation on the Dream Chaser mission should proceed in a South African context.

Working together in collaboration fundamentally requires shared interest and a common goal, secondly it requires commitment from both parties and it is always a good incentive if there are benefits for both parties. South Africa is no stranger to hosting foreign countries, our major cities see hundreds of thousands of tourists visiting seasonally, to visit our beautiful beaches and natural wonders such as the Drakensberg, Table mountain or the Vredefort Dome crater. In 2010 South Africa hosted the soccer world cup with few issues. Annually the country hosts international conferences by UNESCO, IEEE and other international organisations. South Africa is recognised internationally as a popular safari destination and there are good things to say for the tourism industry which facilitates the visits of guests. The Minister of International Relations and Cooperation, Ms Naledi Pandor, is very familiar with South African space activities as she previously held the post of Minister of Science and Technology where she was influential in the formation and guidance of SANSA and the SKA project. Ms Pandor was also the minister during the 
time that the South African Space Policy and Strategy were constructed and she had a part to play in both. Ms Pandor attended the UN Climate Summit and the UN General Assembly in New York on the 23rd and 25th September 2019 respectively. The minister ensures that the country remains at peace with all other 193 UN member states and does its part to alleviate climate change while emphasising that first world countries must do more to help transition from coal and other fossil fuels. South Africa is renowned for being a popular holiday destination and has constant dialogue with the global community, so what can be said for these relations benefiting the Dream Chaser dedicated-SDG mission?

Hopefully this research and the benefits of possibly landing the Dream Chaser in South Africa can be that unifying goal. All South Africans can join in welcoming international collaboration and show our government that it is not only holiday makers that can visit but international scientists, engineers and researches too, for this is how a country can develop academically.

According to the article released at the 2014 Space Traffic Management (STM) Conference by SNC (Section 3.0.1), along with the FAA, with whom they regularly liaise, it was explained that a operations manual will be distributed to all contingency landing sites prior to take-off in order to familiarise personnel with the Dream Chasers' operations. When this document is available there will be many more specifications available for the future work on this project. Currently in draft form, a final copy is expected to be ready by the end of 2020. Perhaps more exciting is the decision on landing sites, to be made by the end of 2019 . 


\section{Chapter 6}

\section{Analysis}

This chapter serves to synthesise the findings of the previous chapters, specifically the Dream Chaser and South African Infrastructure Chapters in light of the Legal Chapter. This will be done via an analysis and selection process for suitable airports for the Dream Chaser. A summary of the sites and facilities mentioned in the previous chapters will be tabulated and compared with the specifications and requirements of the Dream Chaser listed previously in Section 3.1.7. But first lets recall the details and specifications of the Dream Chaser from Chapter 3. These are the specifications required for the Dream Chaser and therefore will be used to determine appropriate airports.

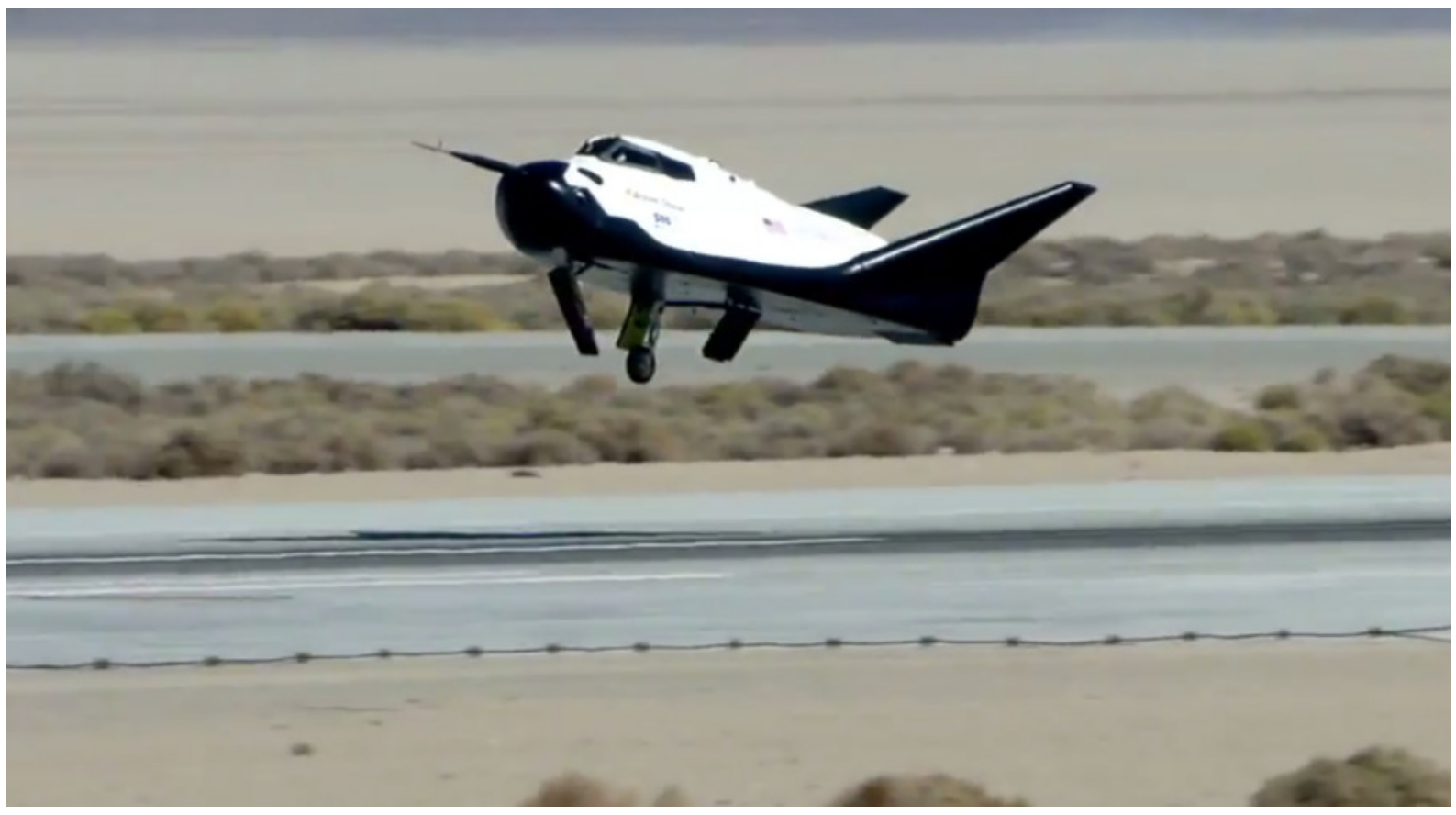

Figure 6.1 Dream Chaser landing at the Dryden Flight Research Center runway in the Mojave Desert. 


\begin{tabular}{|c|c|}
\hline \multicolumn{2}{|c|}{ Dream Chaser Details and Specifications } \\
\hline \multirow[t]{7}{*}{ High Level SNC Specs. } & Lifting-body spacecraft \\
\hline & Autonomous launch, flight and landing capabilities \\
\hline & High reusability, $15+$ times \\
\hline & Low atmospheric entry, at $<2 g^{\prime} s$ \\
\hline & $\begin{array}{l}\text { Gentle runway landing, compatible with all runways } \\
\text { over } 3048 m(10000 \mathrm{ft}) \text {. }\end{array}$ \\
\hline & Immediate access to crew and cargo upon landing \\
\hline & $5500 \mathrm{~kg}$ pressurised and unpressurised cargo it ISS \\
\hline \multicolumn{2}{|l|}{ More detailed Specs } \\
\hline Runway length & $2438-3048 m(8000-10000 \mathrm{ft})$ conditional \\
\hline Runway width & $45,75 \mathrm{~m}(150 \mathrm{ft})$ plus \\
\hline Runway surface & $\begin{array}{l}\text { Any runway capable of handling large aircraft, prefer- } \\
\text { ably concrete. }\end{array}$ \\
\hline \multirow{7}{*}{$\begin{array}{l}\text { Compatibility with } \\
\text { existing airport oper- } \\
\text { ations }\end{array}$} & $\begin{array}{l}\text { Unique airport operations ie. Ability for airport to } \\
\text { accommodate Dream Chaser. }\end{array}$ \\
\hline & Type of airport classification \\
\hline & Existing airport capacity \\
\hline & $\begin{array}{l}\text { Sensitivity of local population (Sonic boom consider- } \\
\text { ations) }\end{array}$ \\
\hline & Geopolitical climate \\
\hline & Unpiloted landing considerations (legal) \\
\hline & $\begin{array}{l}\text { Airport management acceptance of landing space- } \\
\text { craft }\end{array}$ \\
\hline \multirow[t]{4}{*}{$\begin{array}{l}\text { Recommendations } \\
\text { and requirements }\end{array}$} & $\begin{array}{l}\text { Appropriate separation from public runway. In the } \\
\text { case of unvented oxidiser/fuel explosive hazards re- } \\
\text { quire vehicle to be safely away from public areas. }\end{array}$ \\
\hline & Security of temporary parking \\
\hline & Processing hanger \\
\hline & $\begin{array}{l}\text { Ground support equipment (GSE): tug, taxi vehicle, } \\
\text { tow-bar, cooling carts. These facilities will be pre- } \\
\text { verified or temporarily deployed as necessary. }\end{array}$ \\
\hline
\end{tabular}

Table 6.1 Condensed list of Dream Chaser Specifications 
Analysis

\subsection{Potential Dream Chaser Landing Sites}

There are over 400 listed airports and runways in South Africa, spread across all 9 provinces, some of the more ideal ones have already been mentioned in Section 4.5. In order to shorten the list and find higher-potential Dream Chaser landing sites, the list was filtered according to the following two criteria on Excel:

1) Any airports or airfields not registered with an official ICAO four letter code were excluded as these were deemed unfit for such responsibilities as landing the Dream Chaser. 2) The length of the runways remaining was filtered to all runways over $8000 \mathrm{ft}$ or approx. $2400 \mathrm{~m}$.

To be sure these steps were repeated in reverse and they both resulted in a total of 16 runways remaining, as listed in Table 6.2.

\begin{tabular}{|c|c|c|c|c|c|}
\hline Kind & ICAO & IATA & City & Name & Max Runway \\
\hline Medium & FABE & BIY & Bisho & BHISHO & $2444,5 \mathrm{~m}(8020 \mathrm{ft})$ \\
\hline Medium & FABL & $\mathrm{BFN}$ & Bloemfontain & $\begin{array}{l}\text { BLOEMFONTEIN } \\
\text { INTL }\end{array}$ & $2559 m(8396 \mathrm{ft})$ \\
\hline Large & $\mathrm{FACT}$ & $\mathrm{CPT}$ & Cape Town & $\begin{array}{ll}\text { CAPE } & \text { TOWN } \\
\text { INTL } & \\
\end{array}$ & $3201 m(10502 \mathrm{ft})$ \\
\hline Small & FADN & $\bullet$ & Durban & DURBAN INTL & $2440 m(8005 \mathrm{ft})$ \\
\hline Small & FAHS & HDS & Hoedspruit & $\begin{array}{l}\text { HOEDSPRUIT } \\
\text { AFB }\end{array}$ & $3991 m(13095 \mathrm{ft})$ \\
\hline Medium & FALA & HLA & Johannesburg & LANSERIA & $3048 m(10000 \mathrm{ft})$ \\
\hline Large & FAJS & • & Johannesburg & $\begin{array}{l}\text { JOHANNESBURG } \\
\text { INTL }\end{array}$ & $4418 m(14495 \mathrm{ft})$ \\
\hline Medium & FAKM & KIM & Kimberly & KIMBERLY & $3000 m(9843 \mathrm{ft})$ \\
\hline Small & FALM & $\bullet$ & Louis Trichardt & $\begin{array}{l}\text { MAKHANDO } \\
\text { AFB }\end{array}$ & $4020 m(13189 \mathrm{ft})$ \\
\hline Medium & FAMM & $\mathrm{MBO}$ & Mafeking & MAFIKENG & $4560 \mathrm{~m}(14960 \mathrm{ft})$ \\
\hline Medium & FAKN & MQP & Nelspruit & $\begin{array}{l}\text { KRUGER } \\
\text { MPUMALANGA } \\
\text { INTL }\end{array}$ & $3100 m(10171 \mathrm{ft})$ \\
\hline Small & FAOB & OVG & Overberg & OVERBERG & $3115 \mathrm{~m}(10220 \mathrm{ft})$ \\
\hline
\end{tabular}




\begin{tabular}{|c|c|c|c|l|c|}
\hline Medium & FAPP & PTG & Pietersburg & $\begin{array}{l}\text { POLOKWANE } \\
\text { INTL }\end{array}$ & $2560 m(8400 \mathrm{ft})$ \\
\hline Small & FAPN & NTY & Pilansberg & $\begin{array}{l}\text { PILANSBERG } \\
\text { INTL }\end{array}$ & $2682 m(8800 \mathrm{ft})$ \\
\hline Medium & FAWK & WKF & Pretoria & $\begin{array}{l}\text { WATERKLOOF } \\
\text { AFB }\end{array}$ & $3353 m(11001 \mathrm{ft})$ \\
\hline Medium & FAUP & UTN & Upington & UPINGTON & $4900 \mathrm{~m}(16076 \mathrm{ft})$ \\
\hline \hline
\end{tabular}

Table 6.2 Shortened list of SA Airports [Fallinggrain software] reduced with Excel filters.

As can be seen in Table 6.2 a majority of the runways are international (suffixed by INTL) 9 out of the 16 . Therefore the next step of elimination is tactical, based on the fact that safety regulations have not been fully developed yet. So runways located in densely populated areas were ruled out. The options eliminated after this analysis were: OR Tambo International, Waterkloof AFB, Cape Town International, Bloemfontein International, Bhisho, Pilansberg, Kimberly, Mafikeng, Kruger Mpumalanga International and Polokwane, leaving the remaining 6 options as landing sites listed in the Table 6.3. Please see also Appendix $\mathrm{C}$ for images comparing density of population in the surrounding areas for an indication of the bounds of this elimination process.

Going back to Table 6.1 for other obvious elimination criteria we see that a runway may be not only be too short but too narrow as well. After further inspection the Lanseria International airport was found to be only $75 \mathrm{ft}$ wide, half the width required. Lastly runways were double checked via Google Earth and airport websites to make sure they were paved and not gravel. No runways remaining were gravel and so the list was carried forward as is.

Table 6.3 and Table 6.4 below now lists the airports in South Africa best suited for the Dream Chaser mission. The airports are from all corners of the country so maximum flexibility is available to mission planners. In the Table 6.3 below where travel times are provided to Spaceteq facility from far-out airports, the time was taken to fly from the airport to Cape Town International, a further $55 \mathrm{~min}$ must be allowed for drive-time to the facility. There are alternative airports nearer to Spaceteq such as in Hermanus, however they are either too small or currently closed. An explanation and discussion regarding this table will hopefully highlight the advantages while showing the inaccuracies for future work required to be carried out. More details are provided in each airports profile in the following Section 6.1.1. 


\begin{tabular}{|l|l|l|l|l|}
\hline \multicolumn{5}{|c|}{ Chosen Airport Information } \\
\hline \hline $\begin{array}{l}\text { Mission } \\
\text { Landing Site }\end{array}$ & Type & $\begin{array}{l}\text { Airport } \\
\text { Environment }\end{array}$ & $\begin{array}{l}\text { SPACETEQ } \\
\text { Proximity }\end{array}$ & Notes \\
\hline Upington & Int. & $\begin{array}{l}\text { Arid region of the } \\
\text { North West }\end{array}$ & 1hr 20min flight & $\begin{array}{l}\text { Longest runway } \\
\text { in SA }\end{array}$ \\
\hline Hoedspruit & AFB & $\begin{array}{l}\text { Hot interior, } \\
\text { North Eastern } \\
\text { region }\end{array}$ & 2hrs 30min light & $\begin{array}{l}\text { Highly protected, } \\
\text { hardened aircraft } \\
\text { shelters - } \\
\text { Previously Space } \\
\text { Shuttle } \\
\text { contingency } \\
\text { Landing site }\end{array}$ \\
\hline Overberg & AFB & $\begin{array}{l}\text { Temperate } \\
\text { Coastal }\end{array}$ & 1hr 40min drive & $\begin{array}{l}\text { Previous site of } \\
\text { SA Space } \\
\text { Program }\end{array}$ \\
\hline King Shaka Intl & Int. & $\begin{array}{l}\text { Sub-tropical } \\
\text { Coastal }\end{array}$ & 2hrs flight & $\begin{array}{l}\text { New Airport, } \\
\text { ranked 29th best } \\
\text { airport in the } \\
\text { world }\end{array}$ \\
\hline Louis Trichardt & AFB & $\begin{array}{l}\text { Hot interior, far } \\
\text { North Eastern }\end{array}$ & 2hrs 40min flight & \begin{tabular}{l} 
Most modern base \\
\hline
\end{tabular} \\
\hline
\end{tabular}

Table 6.3 Potential Dream Chaser landing sites in South Africa.

\begin{tabular}{|l|l|l|l|l|}
\hline \multicolumn{5}{|c|}{ Chosen Airport Specifications } \\
\hline \hline $\begin{array}{l}\text { Mission Land- } \\
\text { ing Site }\end{array}$ & $\begin{array}{l}\text { Coordinates } \\
\text { South }\end{array}$ & $\begin{array}{l}\text { Coordinates } \\
\text { East }\end{array}$ & $\begin{array}{l}\text { Runway } \\
\text { direct. }\end{array}$ & Elevation \\
\hline Upington & $28^{\circ} 23^{\prime} 57$ & $21^{\circ} 1^{\prime} 37$ & $35 / 17$ & $\begin{array}{l}848 \mathrm{~m}(2782 \mathrm{ft}) \\
\text { AMSL }\end{array}$ \\
\hline Hoedspruit & $24^{\circ} 22^{\prime} 7$ & $31^{\circ} 2^{\prime} 55$ & $36 / 18$ & $\begin{array}{l}531 \mathrm{~m}(1743 \mathrm{ft}) \\
\text { AMSL }\end{array}$ \\
\hline Overberg & $34^{\circ} 33^{\prime} 18$ & $20^{\circ} 15^{\prime} 3$ & $35 / 17$ & $\begin{array}{l}16 \mathrm{~m} \quad(52 \mathrm{ft}) \\
\text { AMSL }\end{array}$ \\
\hline King Shaka Intl & $29^{\circ} 36^{\prime} 52$ & $31^{\circ} 7^{\prime} 11$ & $06 / 24$ & $\begin{array}{l}90 \mathrm{~m} \quad(295 \mathrm{ft}) \\
\text { AMSL }\end{array}$ \\
\hline Louis Trichardt & $23^{\circ} 9^{\prime} 36$ & $29^{\circ} 41^{\prime} 47$ & $28 / 10$ & $\begin{array}{l}935 \mathrm{~m}(3069 \mathrm{ft}) \\
\text { AMSL }\end{array}$ \\
\hline
\end{tabular}

Table 6.4 Potential Dream Chaser landing sites in South Africa. 
Figure 6.2 shows the main commercial flight routes within and entering the country. As an example the AFB Bredasdorp, co-located with OTR, has been roughly pointed out as its air space is not crossed by commercial airlines particularly over the adjacent coast area. This will make licensing the Dream Chaser landing less complicated with an unobstructed approach. This will also become a crucial consideration when considering where to land the Dream Chaser. For purposes of this dissertation no more airports were eliminated due to busy flight routes, although mention of it is made in SWOT analysis.

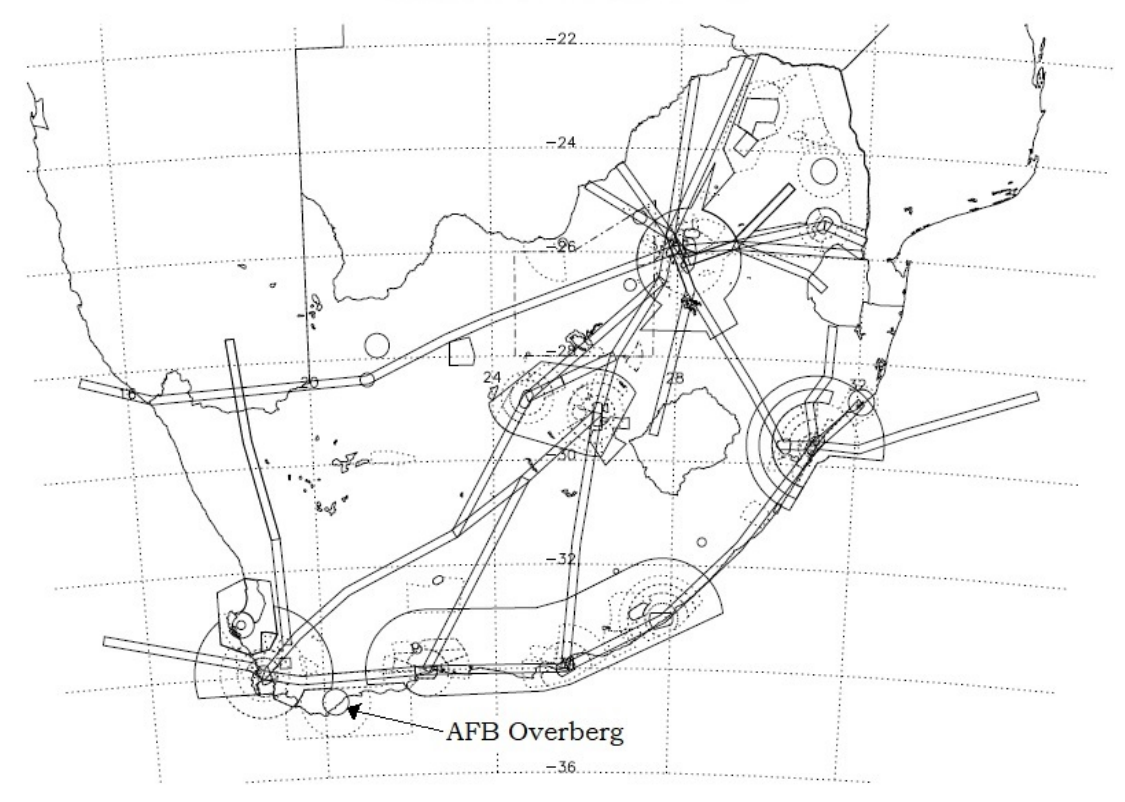

Figure 6.2 South Africa Air Traffic Routes as of 2017 - AFB Overberg labelled.

Figure 6.2 might be used in conjunction with a cohort of statistical models based on previous experience. Such models may appear something like the one in Figure 6.3 which can be visualised in reverse without too much imagination to simulate an approaching spacecraft and break-up points.

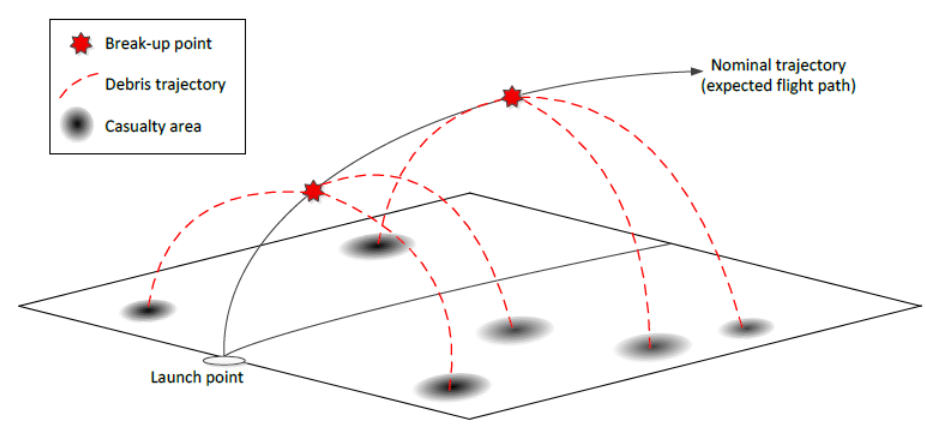

Figure 6.3 Model of debris dispersion from a launch vehicle break-up. 


\subsubsection{Site Profiles and SWOT Analysis}

To sum up the analysis the selected airports or landing sites, a basic SWOT analysis is provided.

\section{Upington}

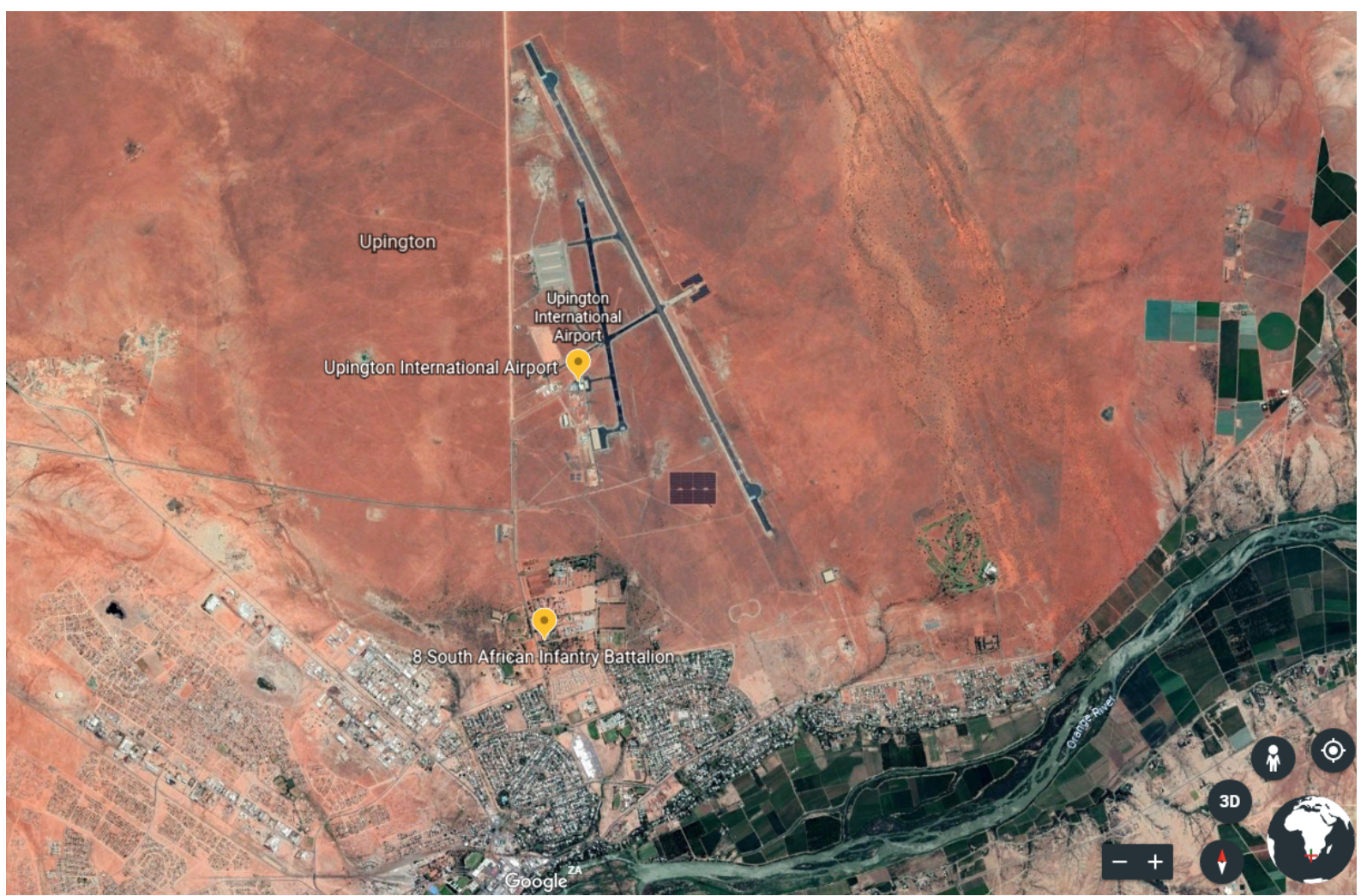

Figure 6.4 Upington International Airport and surrounds

Strengths: As we have seen Upington International Airport has an exceptionally long runway of $16076 \mathrm{ft}$, far longer than any other runway in the country. The runway was rumoured to have been built for providing the Space Shuttle a contingency landing site in South Africa, however this was not the case. Nonetheless, Upington International was built with a purpose of hosting large cargo airlines which distribute South African agricultural produce. There is also the seasonal international guests such as German automotive manufactures who bring cars to test in the hot high altitudes of the Northern Cape. Although the airport is an international one, it has traffic from only two directions as seen in Figure 6.2 this is an advantage when considering logistics of shutting airspace for Dream Chaser decent. 
Weaknesses: Upington is an international airport, so careful planning with the airport management would need to be carried out to make sure there is a clear approach for the Dream Chaser.

Opportunity: Upington in particular is experienced in handling unusual aircraft activity and this will surely provide for furthering that experience. This will be a mutually beneficial experience for Dream Chaser and Upington, South Africa.

Threat: Very hot day-time conditions can be experienced and dust storms can affect airport operations, this season occurrences will need to be considered.

\section{Hoedspruit}

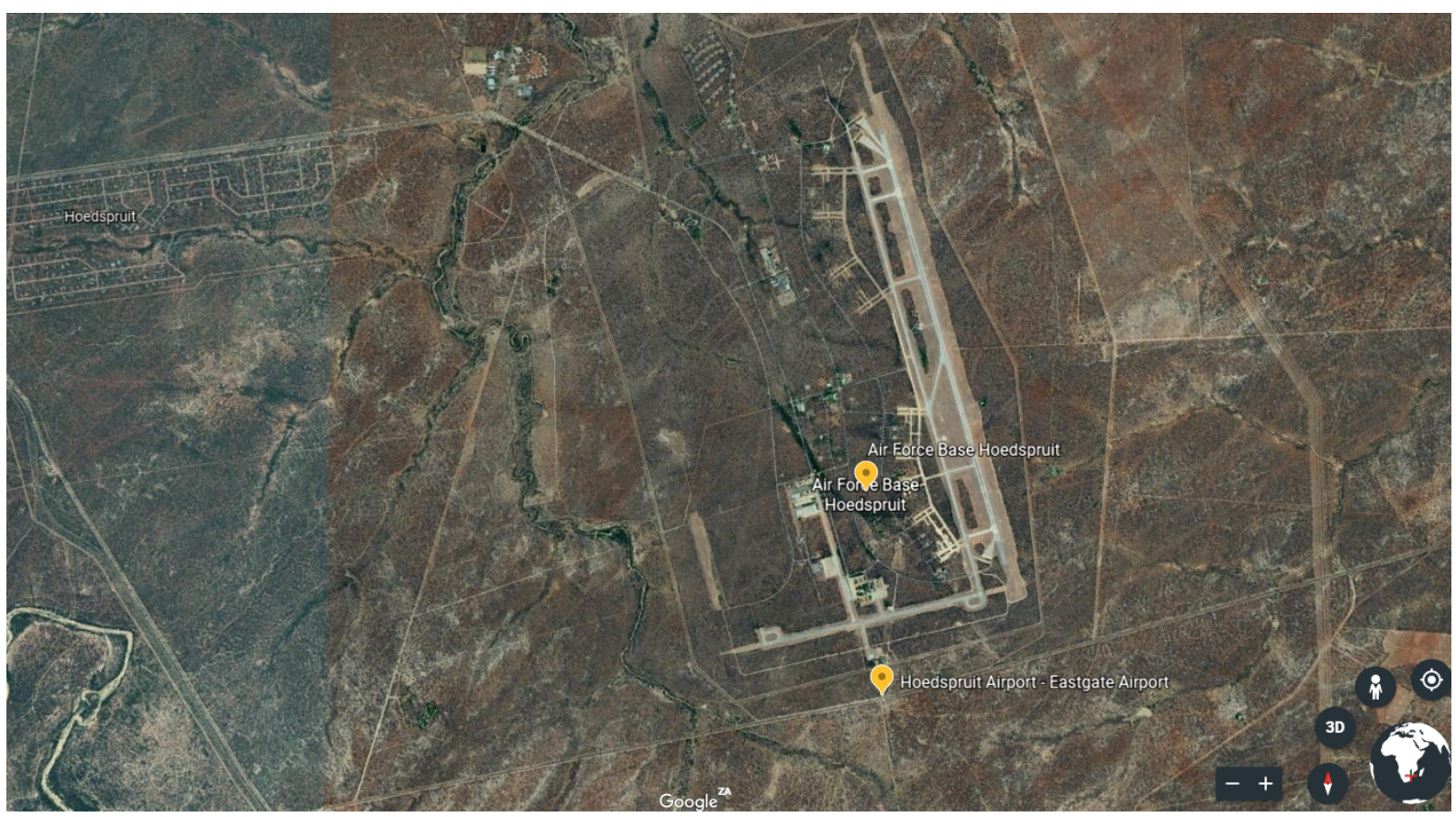

Figure 6.5 Hoedspruit AFB and surrounds.

Strengths: Hoedspruit AFB was the official emergency landing site for the Space Shuttle. Desired for the high security and low air traffic. So the AFB has a history of communication with the U.S. The AFB is situated outside of Hoedspruit, far enough to be a safe landing site of the Dream Chaser and only one lane of air traffic in and out. The AFB has hardened shelters and hanger space for post-processing of the Dream Chaser.

Weaknesses: Hoedspruit is far north in South Africa requiring a minimum of $2 \mathrm{hrs} 30 \mathrm{~min}$ to fly experiments to the Spaceteq facility.

Opportunities: In 2000 the base gained international recognition as the United States Air Force rescue contingency arrived to provide rescue and humanitarian support for 
Mozambiquens after the Cyclone Eline flooding. This mission would be another opportunity for the base to provide international support.

Threats: The AFB is located within a game reserve and animals on the runway can cause issues. There are however 3 cheetahs that keep the area clear. In the past there have also been floods in the area in the rainy season before.

\section{Overberg}

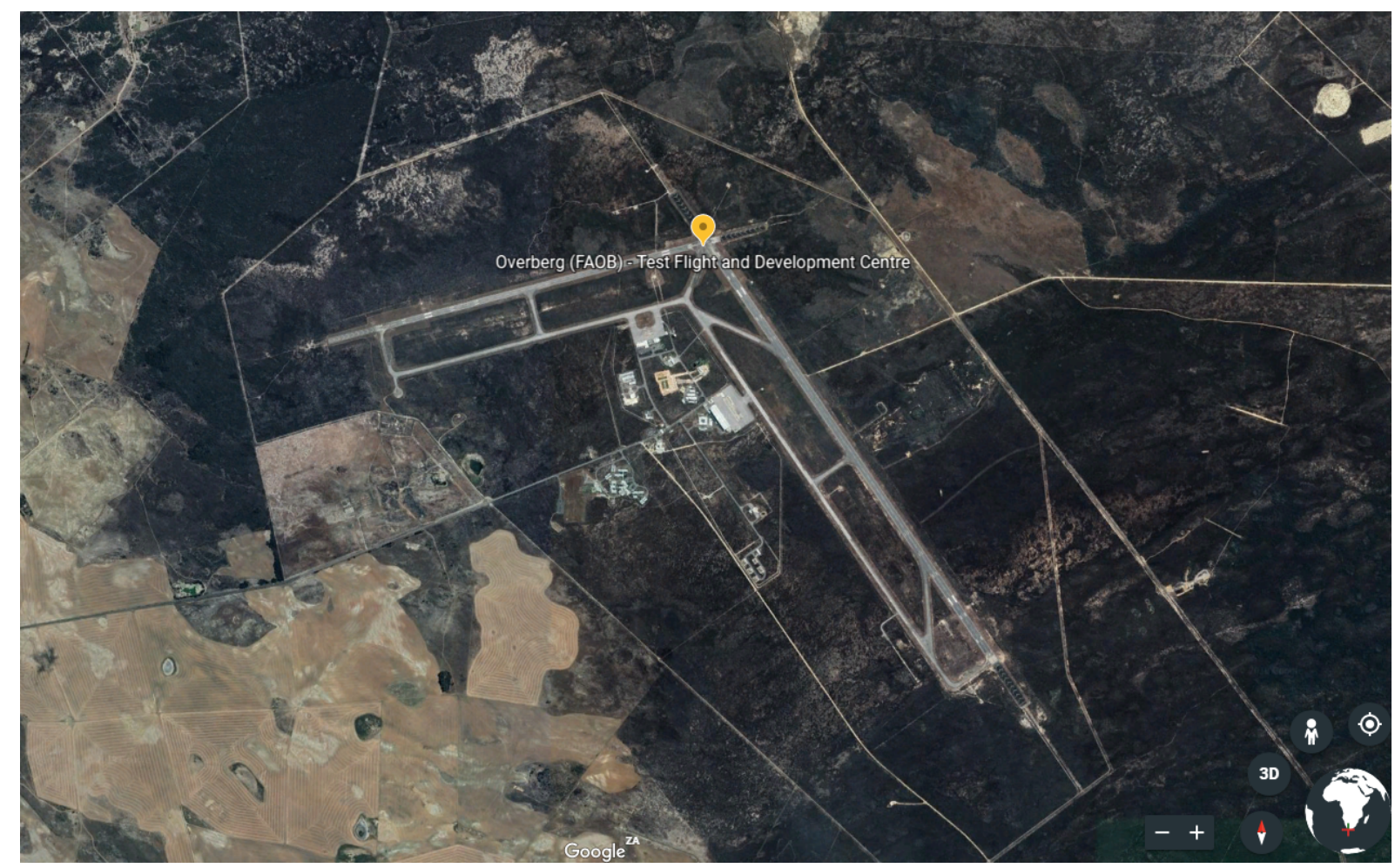

Figure 6.6 TFDC Bredasdorp and surrounds

Strengths: TFDC Bredasdorp has already set itself apart from the rest by having superior flight testing equipment and personnel with the know-how to go with it. The AFB has hosted many international groups wishing to test their integrated fighter jet technologies. The other supporting facilities at the AFB and the potential for a MCC at the base is also promising. Clear airspace as can be seen in Figure 6.2 particularly from the coastal direction is highly advantageous.

Weaknesses: The site is somewhat politicised as Denel is a state-owned entity with a history of mismanagement in recent years. Earlier in this dissertation they were promoted as a potentially useful ally however politics can sometimes ruin these relationships. 
Opportunities: Perhaps more so than the rest, refreshed activity at this AFB may lead to the single greatest push to have a South African Space Programme once more.

Threat: The Western Cape is known for having powerful storms with strong winds in the winter.

\section{King Shaka International}

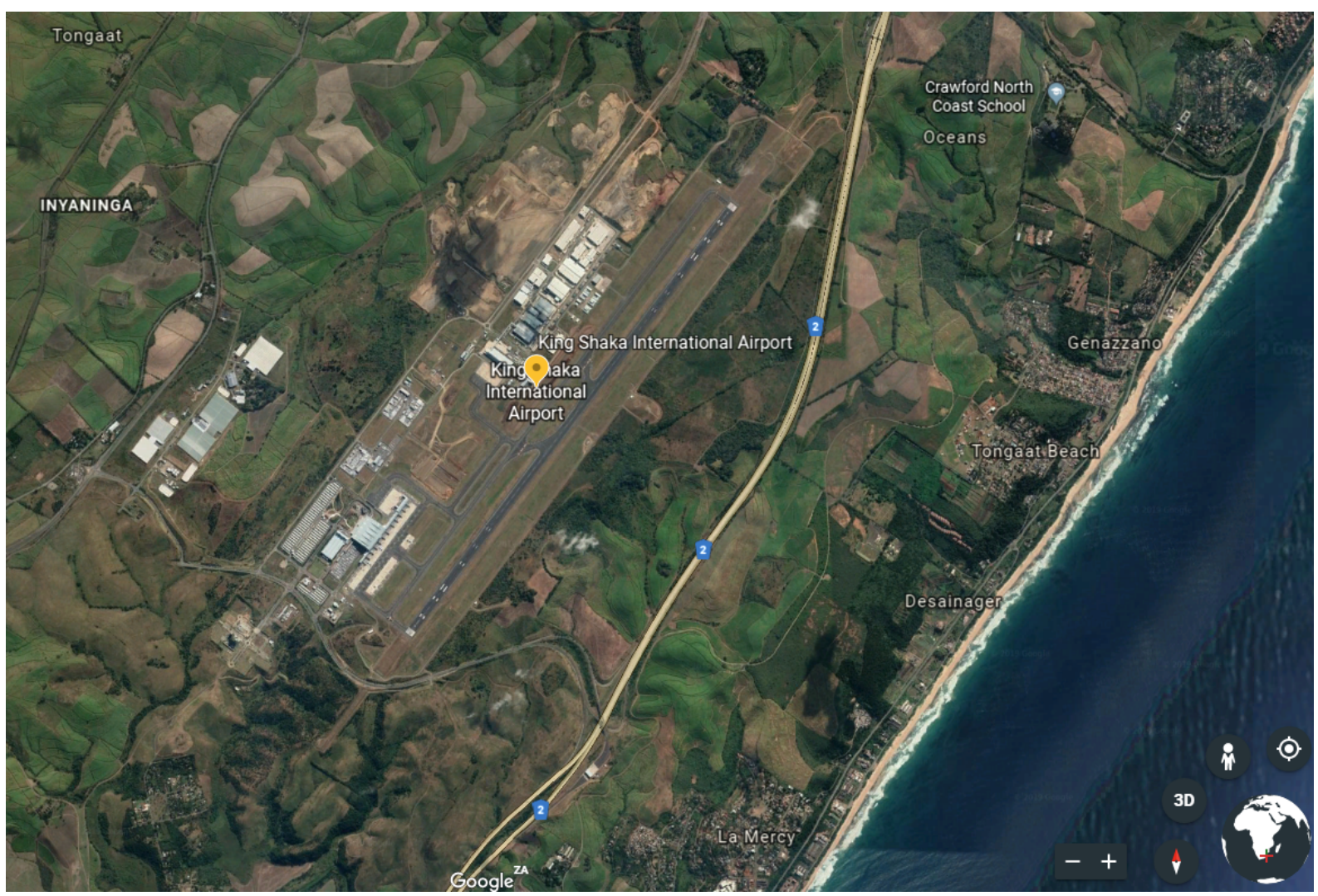

Figure 6.7 King Shaka International Airport and surrounds.

Strengths: This is a relatively new airport with high standards and lots of facilities and personnel. The area is mostly occupied by sugar cane fields. Quick turn around available due to ergonomic single runway running parallel to airport facilities, reduces time to reach the Dream Chaser post-flight.

Weaknesses: As with all international airports there is a lot of air traffic and so careful cooperation and planning is required before landing the Dream Chaser at this airport. There is also only one runway at King Shaka International which means the Dream Chaser landing will have to be scheduled to cause minimal delays in nominal air traffic routine.

Opportunities: Durban has a major trade port, responsible for receiving and distributing goods from all over the world. Managing a port is challenging, experienced logistic 
companies and personnel could be assigned to help planning the landing and distribution of the Dream Chaser and its payloads.

Threats: Sugar cane is periodically burnt (although less so these days) and this can make for poor visibility in the area. Tropical thunder storms occur occasionally in summer.

\section{Louis Trichardt}

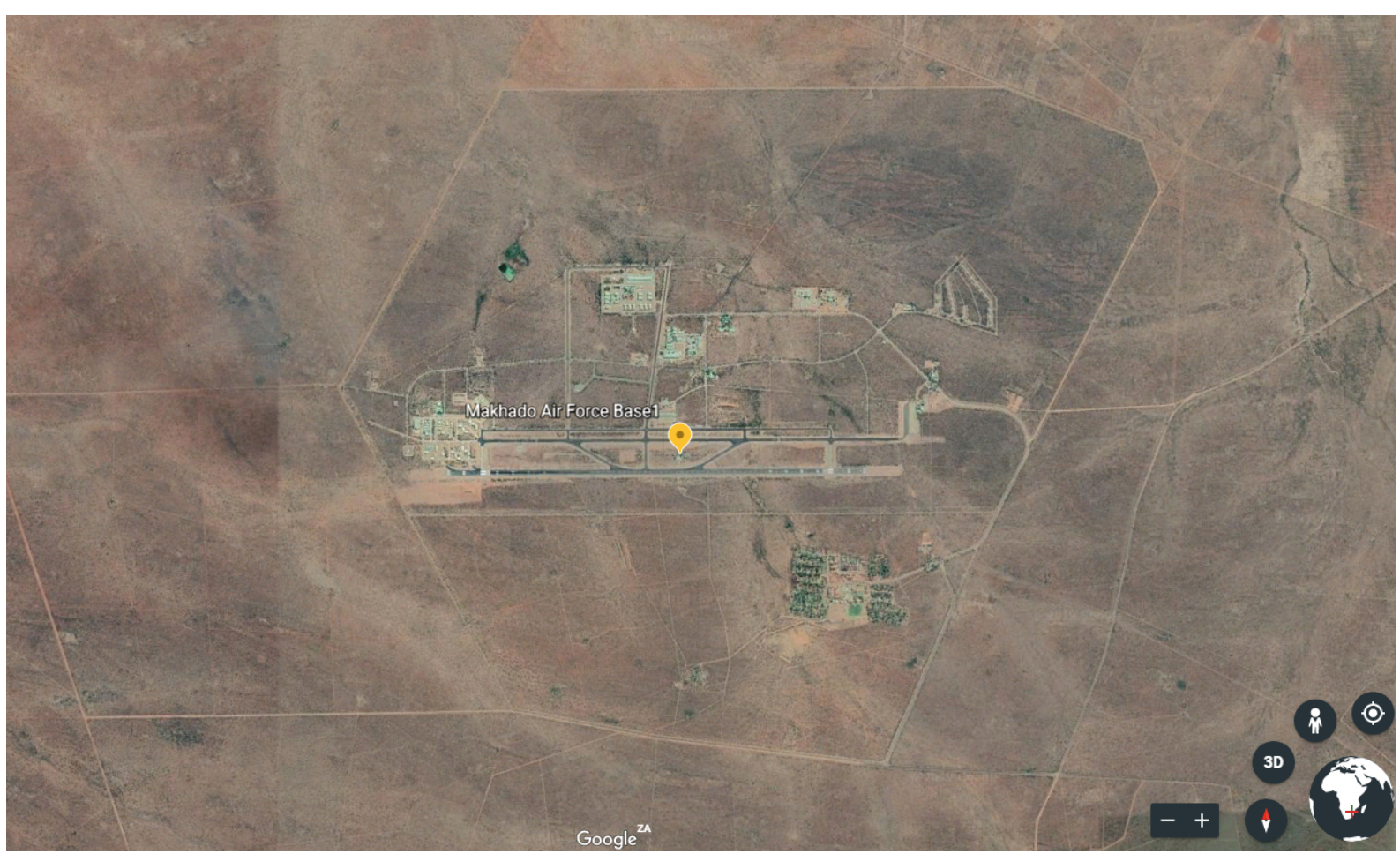

Figure 6.8 Louis Trichardt Airport and surrounds.

Strengths: Louis Trichardt is the newest AFB in the country.

Weaknesses: The base is the furtherest North of any airports in the country.

Opportunity: The base is known unofficially as Fighter Town, it has good protection and is far away from virtually anything, making it probably the safest place to land.

Threats: The AFB is another situated in the far-Northerns region of the country with lots of wild game. There are also international flight routes into the country over the area.

\section{Discussion}

The resulting airports and AFBs have all been strategically selected based on their characteristics, location and facilities. There is still much work to be done on whether these options are in fact viable for the Dream Chaser but this will likely have to happen by or with SNC professional staff who are aware of exactly what the Dream Chaser requires. There have been suggestions in the articles of scholars that Johannesburg is to likely 


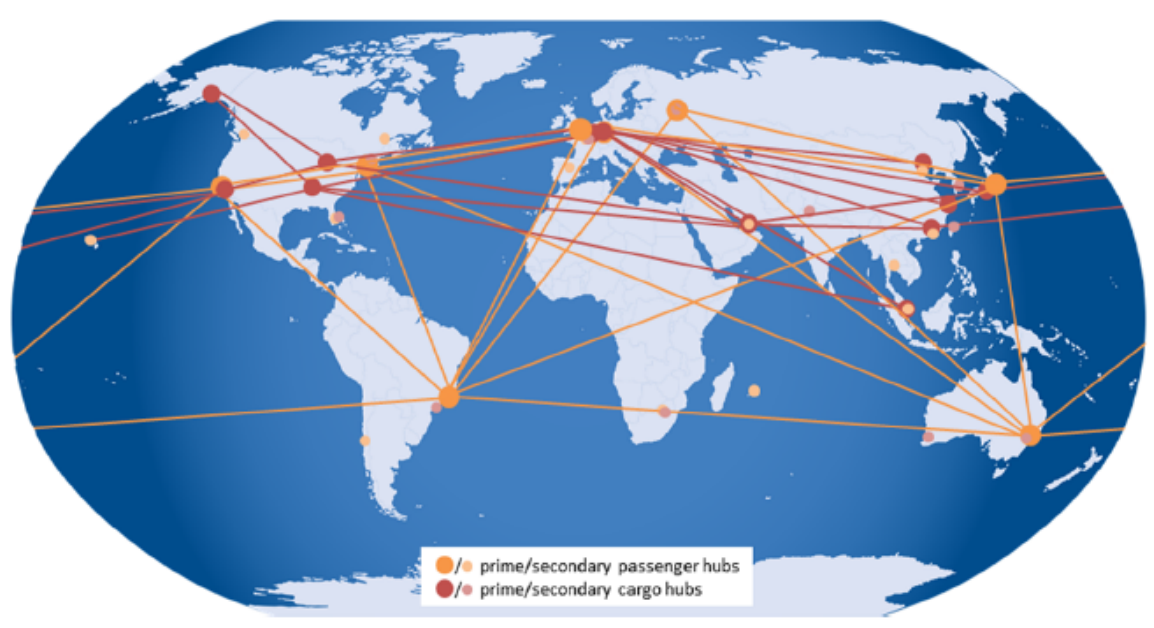

Figure 6.9 Potential suborbital Space Traffic routes for passenger (orange) and cargo transportation (red) [61].

become an international spaceport to host intercontinental-high-speed sub-orbital space vehicles. This is most likely because Johannesburg is a major metropolitan city, known as the commercial hub of the country. This is still many years off however as landing space vehicles with uncharacteristic landing profiles required much consideration and planning, not to mention safety and reliability of the vehicle would need to be proven before landing in a populated area of the country.

\subsubsection{Factors for consideration}

There are always errors related to feasibility studies as predictions can never be perfectly accurate. Therefore it is important to identify as many areas of potential error as possible and discuss the severity of their influence.

Little is known about the overall risk involved in landing the Dream Chaser in South Africa. This dissertation assumes the milestones and other barriers to entry required, including the detailed acceptance criteria and dry-launch of the service vehicle for the Dream Chaser and all NASA contracting companies, will provide adequate standards. Therefore all that can be concerned and should be concerned with in this dissertation are the factors that affect the safety and fulfilment of the Dream Chaser mission landing in South Africa.

Weather and Environment: Important to consider is the seasonal changes in South African weather patterns. On a whole South Africa experiences far less severe or destructive environmental conditions than neighbouring Mozambique or other countries on the far side of the Indian Ocean like Indonesia. Like the rest of the world South Africa is no exception to Climate Change and some areas of the country have been experiencing more intense weather patterns. The East Coast, for example does experience high rainfall 
and lightning during summer months. Last season a terrible flood in the KZN region killed many people and displaced thousands more. In Johannesburg and surrounding areas on the High Veld summer months bring sudden, violent afternoon lightning storms which are fantastic to watch but can be dangerous for smaller aeroplanes and other flying craft. The West Coast of the country is primarily a Mediterranean Climate with higher rainfall during the winter months and increased wind speeds around spring (August-October). In general the Southern parts of the county may experience high wind speeds due to the proximity of the notorious Cape Storms off the South Atlantic Ocean. Otherwise all seasonal weather conditions considered, there are few environmental concerns with landing a space craft in South Africa. Geologically the country is placed well away from any fault lines or continental shelves, rarely experiencing any Earth tremors.

Political: In this regards South Africa fares well against its African counterparts, inspite of the corruption and political in-fighting that has plagued government. South Africa ranked $73 \mathrm{rd}$ out of 180 countries that participated in the 2018 Transparency International (TI) survey, scoring 43 on a scale of zero to 100, with zero being highly corrupt and 100 being very clean. State owned entities continue to make a loss due to mis-management and corruption, these entities are in billions of Rands worth of debt and must be regularly bailed out. Denel, as an example has recently been accused by the Democratic Republic of Chad for not delivering on an order of 40 military Casspirs despite being given a deposit of $R 100$ million. The economic environment is therefore of more concern than the natural one. Having said that, SANSA and the SACAA do have a very good track record of sustainable management practices and embedded policy and prevention plans to mitigate fraud and corruption.

Important to consider is the safe support and turn-around of the Dream Chaser post landing. Much like the Space Shuttle the Dream Chaser will have post-landing procedures (although much simpler and safer than the Shuttle) as well as needing to be taxied off of a runway and be ferried between locations. In this case, the Dream Chaser would need to be flown back to its homeland from the shores of South Africa. Therefore transport planes, the likes of the Shuttle Carrier, will need to land at the same airport as the Dream Chaser, before loading the Dream Chaser internally as opposed to externally like the Space Shuttle and fly back to the United States. The Shuttle Carriers are modified Boeing 747-100 aircraft, their interior has been striped and reinforced, now the vacant interior could easily fit the Dream Chaser which is able to fit in the $5 \mathrm{~m}$ fairing of a rocket. Of course there is the possibility that SNC has its own Dream Chaser carrier with onboard systems to begin readying the Dream Chaser on its way back to the United States. 


\section{Chapter 7}

\section{Conclusions and Recommendations}

As can be seen in the analysis chapter there are a number of potential landing sites available to the Dream Chaser based on the specification and requirements found in literature. As mentioned these would have to be further inspected by SNC to confirm their appropriateness. Beyond the airport and AFB however a variety of other facilities exist in South Africa that will support the Dream Chaser landing and turn-around. OTR was identified as a potential MCC for the personnel needed on the ground in South Africa; Spaceteq is a sophisticated facility with, laboratories, offices, secure wifi and amenities capable of hosting several hundred international guests; the SANSA Space Ops. and Space Science facilities were also brought to light and the advantages of having a local space weather station of international standards in South Africa was discussed. These are many of the advantages of choosing South Africa as a landing site for the Dream Chaser.

Research showed that the South African space industry is poised for growth and development Private players in South Africa are set to grow the industry of space substantially in the following years. The SCS group, Space Advisory and New Space some with entrepreneurs from overseas looking to make the most of the industrious environment of South Africa and capitalise on a market of space related goods and services that can be implemented into satellites all other the world. SANSA particularly is looking to foster international collaboration while making new connections for potential contracts that will span well into the 21st century, therefore it is vital that SACSA and the CAA as well as any other government and none-governmental groups maintain the discussion on improving the South African Space Legislation in promotion and protection of the space industry, to grow our capacity and advance our technology.

In the interest of providing the best legislative environment to promote South Africa as a suitable, no-less attractive landing nation for the Dream Chaser, drafting of legislation that premises at least one strategic landing site in the country being designated a dueluse airport and spaceport should be addressed in the nearest possible future. With the 
current growth in re-usable vehicles, an option to land in South Africa could be attractive to other companies such as SpaceX very soon.

\section{Recommendations}

Throughout this investigation an effort has been made to be thorough in tackling the thematic priorities i.e. the major chapter and section headings. As with most investigations time was limited and the nature of the project meant it was not appropriate to be too investigative at such an early stage but hopefully this report has provided sufficient coverage of all the elements required for landing the Dream Chaser in South Africa. Where possible, depth was provided in areas of expertise, when not hopefully these sections raised enough of the right questions regarding how to move forward effectively through the right means.

Ultimately SNC must be involved in the planning and release of more detailed specifications regarding the Dream Chasers unique requirements. There are clearly more reviews and developments required of legal and policy as well as the major entities, associations, organisations and federations that will help complete a total picture of legal requirements prior to.

A major part of carrying this project forward will be productive collaboration. Collaboration has been a theme underlining this entire dissertation. Details regarding how to manage collaborations were mentioned in the final section of Law and Regulations Chapter 5. Unfortunately this has not been easy to exercise but from the research contained here within there is hopefully sufficient evidence of the need for collaboration.

An adjustment in the form of a careful restructuring of the South African space hierarchy along with an investigation into the current and future beneficiaries, government or private, of space related data and services will place SANSA and SACSA in a more strategic position to implement the progressive steps towards realising South Africa's space potential. The investigation will also inform the budget requirements for SANSA to stimulate the industry and fulfil its mandate. No longer should space in South Africa be a second thought with underwhelming budgets and support. SANSA has a proven record for financial accountability. SANSA also has a budget to which it harnesses maximum potential of student bursaries and scholarships. SANSA supports studies in all four of its programmes (refer back to Figure 5.1) and related fields, providing up to 20 bursaries every year, depending on how many postgraduates and PhD students apply.

Further work It will be necessary to take steps in identifying the actual utility of all the airports and facilities mentioned in this dissertation by professionals who can carry out site visits. Further interviews and proper coordination of all South African stakeholders will be organised before a CFI is completed and submitted. This will also ensure all the documentation and consent from stakeholders is submitted in advance. In terms of steps guiding future work refer to Appendix A point 8. onwards from the SME process. 


\section{References}

[1] S. L. Sacanni, "Sierra nevada corporation and the un/dream chaser® mission." UNOOSA i for Media, February 2018. Most recently accessed: July 2019.

[2] U. Office on Outer Space Affairs, "Unoosa and snc issue cfi for dream chaser mission dedicated to sdgs." UNOOSA i for Media, September 2017. Most recently accessed: July 2019.

[3] U. Office on Outer Space Affairs, "Programme on space aplications: HSTI." Online Information Brochure, UN office Vienna, August 2015. Most recently accessed: July 2019.

[4] U. Nations, "Human space technology inititive." Online Web Page, February 2011.

[5] SNC, "About the dream chaser." Online Web Page, January 2018.

[6] N. Kimberly Schwandt. Sparks, "Unoosa and snc announce first-ever dedicated undream chaser space mission." SNC i News and Resources, September 2017. Most recently accessed: July 2019.

[7] ESA, "Dream Chaser to use Europe's next generation docking station." ESA official web page, April 2017. Most recently accessed: Oct 2020.

[8] "Space supporting the sustainable development goals." unoosa.org. Most recently accessed: Aug 2019.

[9] SANSA, "Facilities - space science." SANSA website, August 2018. Most recently accessed: June 2019.

[10] SANSA, "Sansa history." SANSA official web page, September 2018. Most recently accessed: May 2019.

[11] S. P. Moore P., Collins P., "Hertebeesthoek radio astronomy observatory." ASSA: HartRAO History, May 2015.

[12] S. in Africa, "Over $\$ 3$ billion have been spent in africa since 1998." Africanews.space, May 2018. Most recently accessed: August 2019. 
[13] S. I. Africa, "African space industry annual report, 2019 edition," tech. rep., Space In Africa, 2019. The Authority on News, Data and Market Analysis for the African Space Industry.

[14] Spaceteq, "Spaceteq facilities." spaceteq.co.za/facilities. Most recently accessed: July 2019.

[15] K. S. C. CAASA, "Caasa news: April 2018." CAASA official web page, April 2018. Most recently accessed: June 2019.

[16] A. S. SANSA, "Space industry focus: South africa's bold bid for universal stardom." AfricaOutlook website, March 2019. Most recently accessed: August 2019.

[17] SANSA, "Sansa annual report 2017/2018." SANSA official web page, September 2018. Most recently accessed: May 2019.

[18] N. Kimberly Schwandt. Sparks, "Unoosa and snc issue cfi for dream chaser mission payloads." SNC i News and Resources, September 2017. Most recently accessed: July 2019.

[19] J. J. P. James R. Wertz, David F. Everett, Space Mission Engineering: The New SMAD. Hawthorne, CA: Microcosm Press, 2011.

[20] J. J. P. James R. Wertz, David F. Everett, Space Mission and Design. Hawthorne, CA: Microcosm Press, 1991.

[21] R. B. Scroggs, "Aeroplane - origional documnet," tech. rep., European Patent office, December 1917.

[22] Y. Gibbs, "Past projects: Lifting bodies." nasa.gov/centers/dryden/history, August 2009. Most recently accessed: July 2019.

[23] D. Klingler, "50 years to orbit: Dream chaser's crazy cold war backstory." arstechnica.com/science, September 2012. Most recently accessed: July 2019.

[24] R. D. Reed, Wingless FLight: The Lifting body story, vol. 8 of NASA SP-4220, ch. Introduction. NASA Histroy officel, 1997.

[25] aerospace legacy foundation, "Aviation history: Wingless aircraft." aerospace legacy foundation/gallaries. Most recently accessed: July 2019.

[26] M. Mewhinney, "Nasa, spacedev to collaborate on future space transportation." nasa.gov/centers/ames/news/releases, September 2004. Most recently accessed: July 2019. 
[27] B. J. Fikes, "Spacedev agrees to be acquired." The San Diego Union Tribune, October 2008. Most recently accessed: July 2019.

[28] Y. Gibbs, "Nasa armstrong: Fact sheet lifting bodies." nasa.gov/centers/armstrong/news, February 2014. Most recently accessed: July 2019.

[29] B. J. Fikes, "Spacedev agrees to be acquired." utsandiego, October 2008. Most recently accessed: July 2019.

[30] O. of Audits, "Audit of commercial resupply services to the international space station," tech. rep., Office of Inspector General: Office of Audits, April 2018. IG-18-016.

[31] C. Davenport, "Grounded: Left behind in the contracting race to restore americans to space." Washington Post (online), February 2015. Most recently accessed: July 2019.

[32] B. McDonald, "Snc to introduce dream chaser global project spaceflight program." sncorp¿press release, September 2014. Most recently accessed: August 2019.

[33] Boeing, "Historical snapshot: X-20 dyna-soar space vehicle." Boeing. Most recently accessed: August 2019.

[34] J. Calvin B. Hargis, "The x-20 (dyna-soar) progress report," tech. rep., Aeronautical Systems Devision, U.S. Air Force, 1963.

[35] D. R. Jenkins, American X-Vehicles: An Inventory X-1 to X-50. Monographs in Aerospace history No. 31, 2003.

[36] I. A. V. Lukashevich, "Space wings." buran.ru, 2009. Most recently accessed: July 2019.

[37] A. members. astonautix.com. Most recently accessed: July 2019.

[38] C. I. C. E. BruceJackson, "Preliminary subsonic aerodynamic model for simulation studies of the hl-20 lifting body," tech. rep., NASA Langley Research Center, 1992. Most recently accessed: July 2019.

[39] NASA, "X-37 technology demonstrator: Blazing the trail for the next generation of space transportation systems," tech. rep., Marshall Space Flight Center, September 2003. FS-2003-09-121-MSFC.

[40] U. AF, "X-37b orbital test vehicle." USAF.milatry fact sheets, September 2018. Most recently accessed: July 2019. 
[41] aviation.stackexchange, "What are the advantages of a delta wing over a swept wing." aviation.stackexchange. Most recently accessed: July 2019.

[42] J. Foust, "Dream chaser cleared for full-scale production." SpaceNews.com, December 2018. Most recently accessed: July 2019.

[43] C. L. Frank W. Taylor, Christopher J. Allison, "Challenges and opportunities related to landing the dream chaser reusable space vehicle at a public-use airport," Space Traffic Management Conference, November 2014. Space Traffic Management Program, 2014 Roadmap to the Stars.

[44] J. R. V. Strategy and B. Development, "The dream chaser spacecraft overview," tech. rep., SNC, 2018.

[45] M. J. Tony Whitmore, "Usu researcher develops technology for dream chaser® spacecraft." UtahStateUni - Science and Technology. Most recently accessed: October 2020.

[46] SANSA, "Sa space agency selected as regional space weather centre for the aviation sector." SANSA website-Related news, January 2019. Most recently accessed: June 2019.

[47] R. Campbel, "Sa becomes space weather centre for aviation across africa." Creamer Media's engineering news, January 2019. Most recently accessed: June 2019.

[48] AF, "Afb overberg (tfdc)." af.mil.za bases and units: AFB Overberg, October 2015. Most recently accessed: June 2019.

[49] Denel, "Support services." denel.otr Products Services -Support Services, June 2015. Most recently accessed: June 2019.

[50] unknown, "Incomar aeronautics is an aerospace company with its primary focus on flight testing and logistic support." homepage. Most recently accessed: August 2019.

[51] S. author, "Remebering things past: Sa's first space programme." Creamer Media's Engineering News, June 2000. Most recently accessed: July 2019.

[52] SKA, "Ska q\&a." SAnews.gov.za, May 2012. Most recently accessed: August 2019.

[53] NRF/SARAO, "Vibrant young south african community poised to use meerkat telescope." NRF/SARAO, May 2019. Most recently accessed: August 2019.

[54] unknown, "Directory of airports in south african." spaceteq.co.za/facilities. Most recently accessed: August 2019. 
[55] J. Pike, "Space shuttle emergency landing sites." globalsecurity.org. Most recently accessed: July 2019.

[56] P. S. D. Ram S. Jakhu, Tommaso Sgobba, The need for an integrated regulatory regime for aviation and space: ICAO for space?, vol. 7 of Studies in space policy, ch. Proposal for new regulatory regime, Section 5.2. SpringerWienNewYork, 2011.

[57] P. committee, "Sacsa home." SACSA website. Most recently accessed: July 2019.

[58] FAA/AST, "Commercial space transportation state of the industry unoosa icao symposium." FAA/AST Documents. Most recently accessed: August 2019.

[59] UNOOSA, "Space law treaties and principles." UNOOSA website, Febuary 2018. Most recently accessed: August 2019.

[60] M. G. O. Brown, T. Cottom, "Orbital traffic management study: Final report," $S A I C$, vol. 109, November 2016.

[61] S. B. R. Tüllmann, C. Arbinger, "On the implementation of a european space traffic management system," DLR GfR 2017, vol. v1.0, June 2017.

[62] DST, "National space strategy." dst.gov.

[63] M. P. M. P. c. Ms. Nomfuneko Majaja, "Repeal of the space affairs act no84 of 1993 by the south african outerspace bill." SACSA website. Most recently accessed: July 2019.

[64] M. C. Mineiro, "Law and regulation governing u.s. commercial spaceports:licensing, liability and legal challenges," Journal of Air Law and Commerce, vol. 73, p. 759, 2008.

[65] "Us launch sites and spaceports, commercial/government/private active and proposed sites." faa.gov. Most recently accessed: Aug 2019.

[66] R. MacBeth, "Spaceports: Keeping people safe," tech. rep., HSE's Health and Safety Laboratory, September 2018. Most recently accessed: Aug 2019.

[67] A. Gairiseb, African Perspective on Integrated Space and Air Trafic Management. PhD thesis, SpaceLab, UCT, 2018.

[68] CAA, "Historical background." Site-Flight Inspection. Most recently accessed: July 2019. 
Appendices 



\section{Appendix A}

\section{Tailored SME process for this dissertation}

\section{Define Objectives and Constraints}

1. The Dream Chaser dedicated-SDG mission should be understood overall, where it will take off and land and where the experiments and payloads are coming from.

2. The principal players are UNOOSA and SNC and by default any Member States participating as well.

3. Program timescale begins with successful 2020 Dream Chaser dedicated-SDG mission followed by CFI for alternative landing sites.

4. Needs, requirements and constraints of the Dream Chaser will be brought forward in the dedicated Dream Chaser chapter, Chapter 3.

\section{Define Alternative Mission Concept and Designs}

5. Chapter 4 on the South African space infrastructure will present options suitable for the Dream Chaser program before comparing them.

6. "..."

7. UNOOSA and SNC fulfilling social development obligations while gaining proof of concept in Dream Chaser versatility.

\section{Evaluate the Alternative Mission Concepts}

8. ...

Note. Point 8. onwards deliberately left incomplete, as this is theoretically where future work will continue from with regards to the SME process. 


\section{Appendix B}

\section{Orbital Options}

In this appendix chapter a variety of orbital options are provided as screen-shots from a learning package of STK at the UCT SpaceLab.

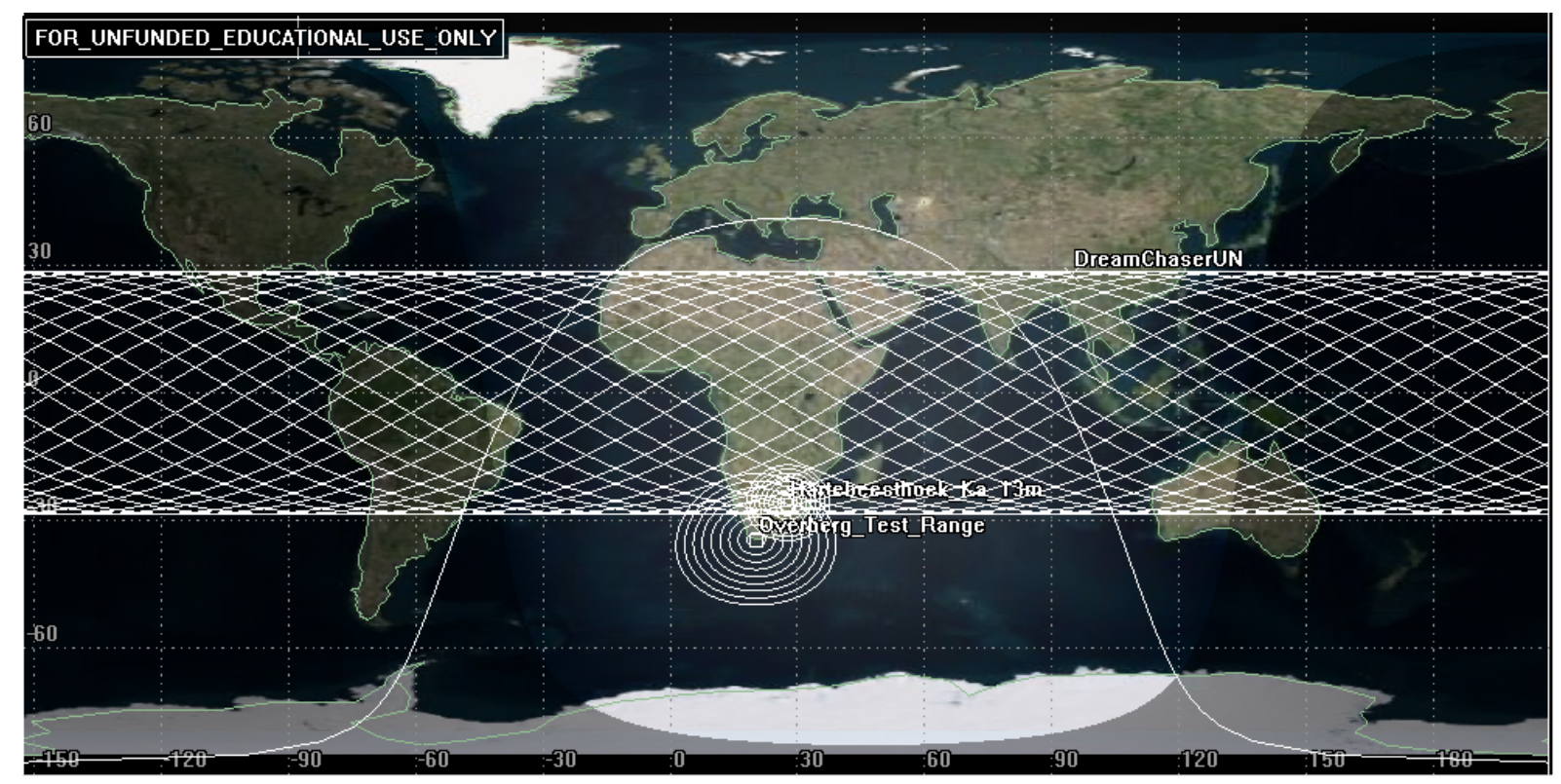

Figure B.1 In this image the DC is in a slightly inclined orbit requiring lower energy and passing over both Florida and South Africa, the take-off and potential landing site respectively. 


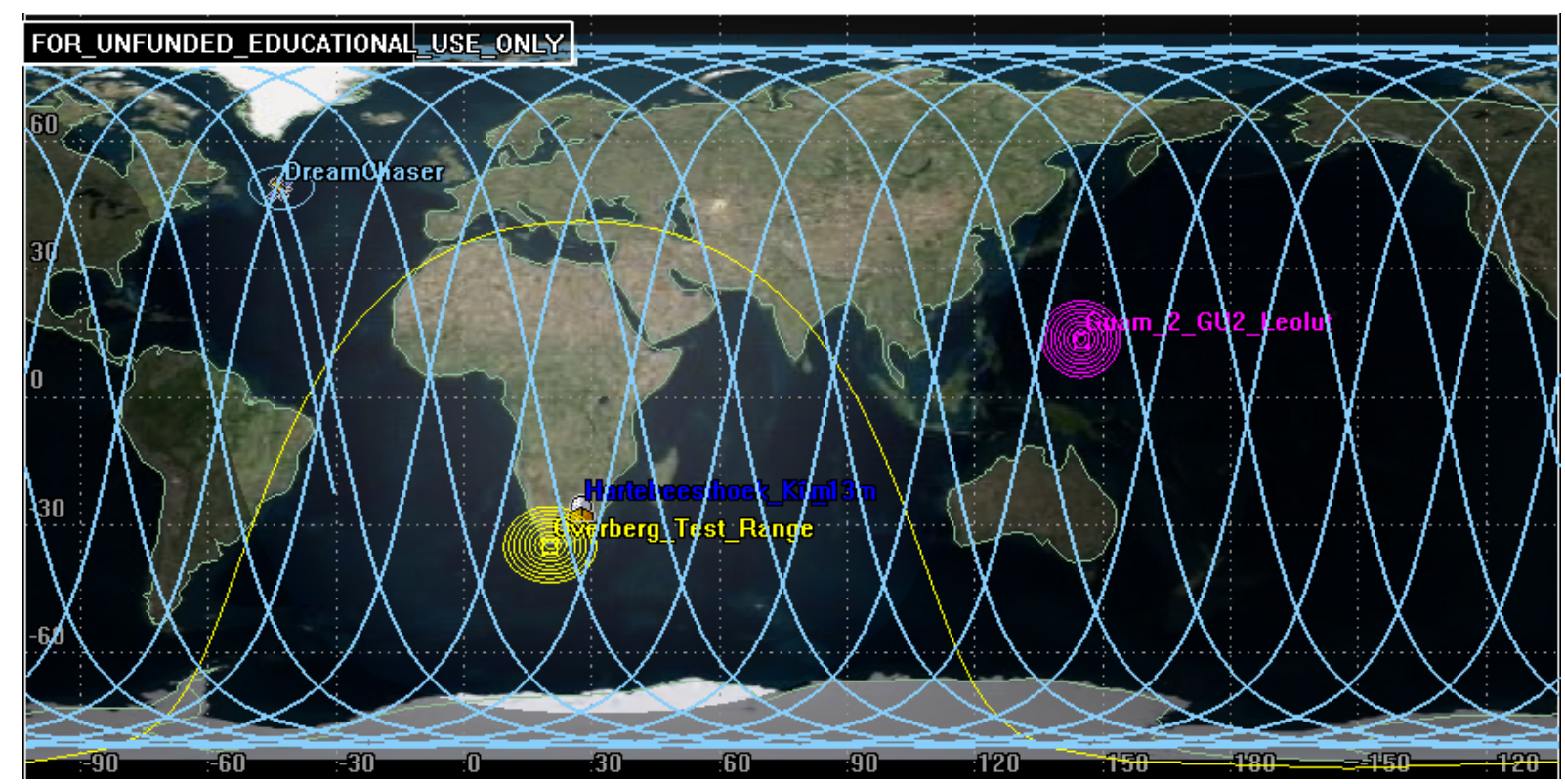

Figure B.2 In this image two potential ground-stations are shown for the Dream Chaser, one in Guam and the other at HartRAO.

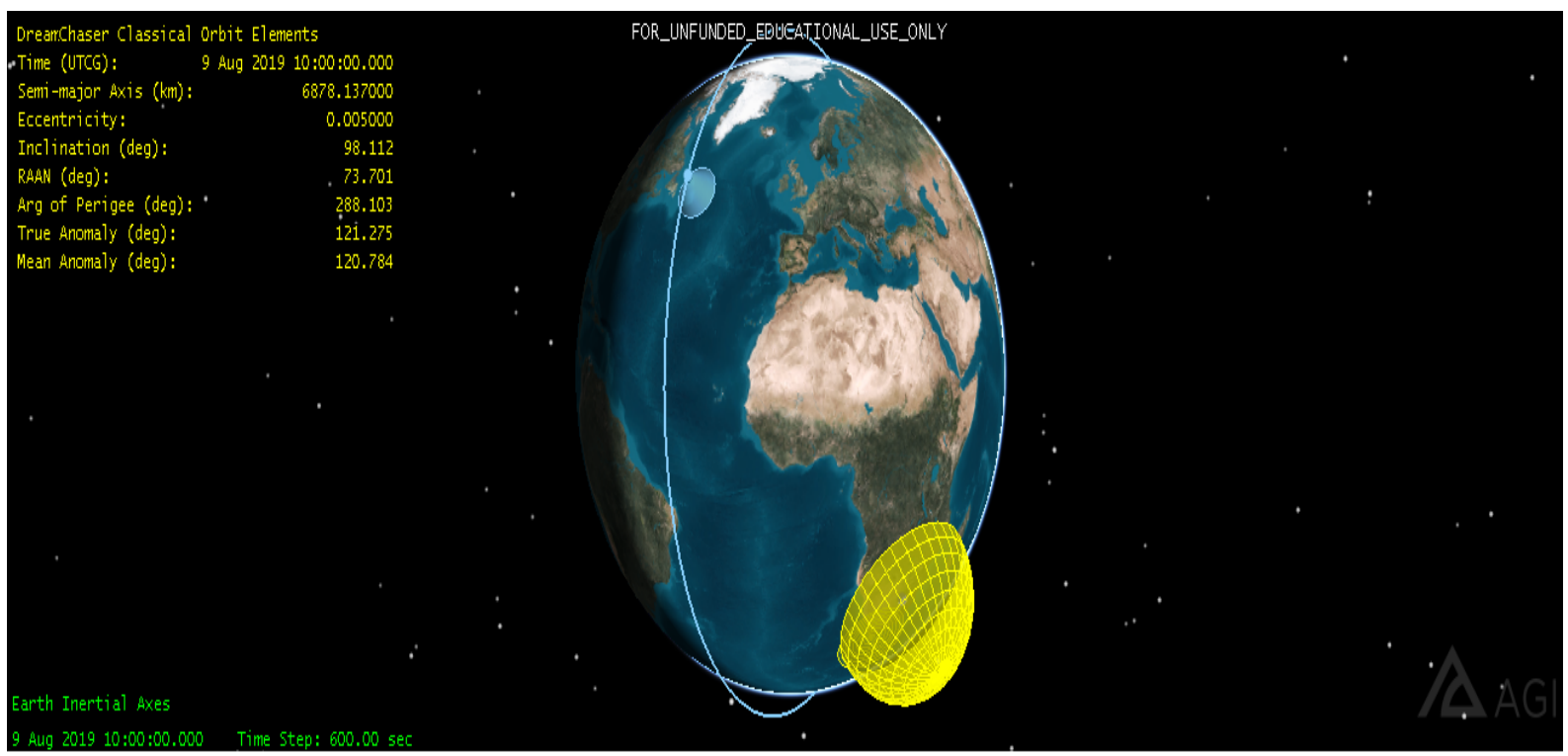

Figure B.3 In this image the Dream Chaser is in a polar orbit, another potentially desirable orbit also covering take-off and landing sites. 


\section{Appendix C}

\section{Density comparison}

Below are a range of airports selected to indicate how airports were distinguished visually as being in too dense a civilian airport, or not.

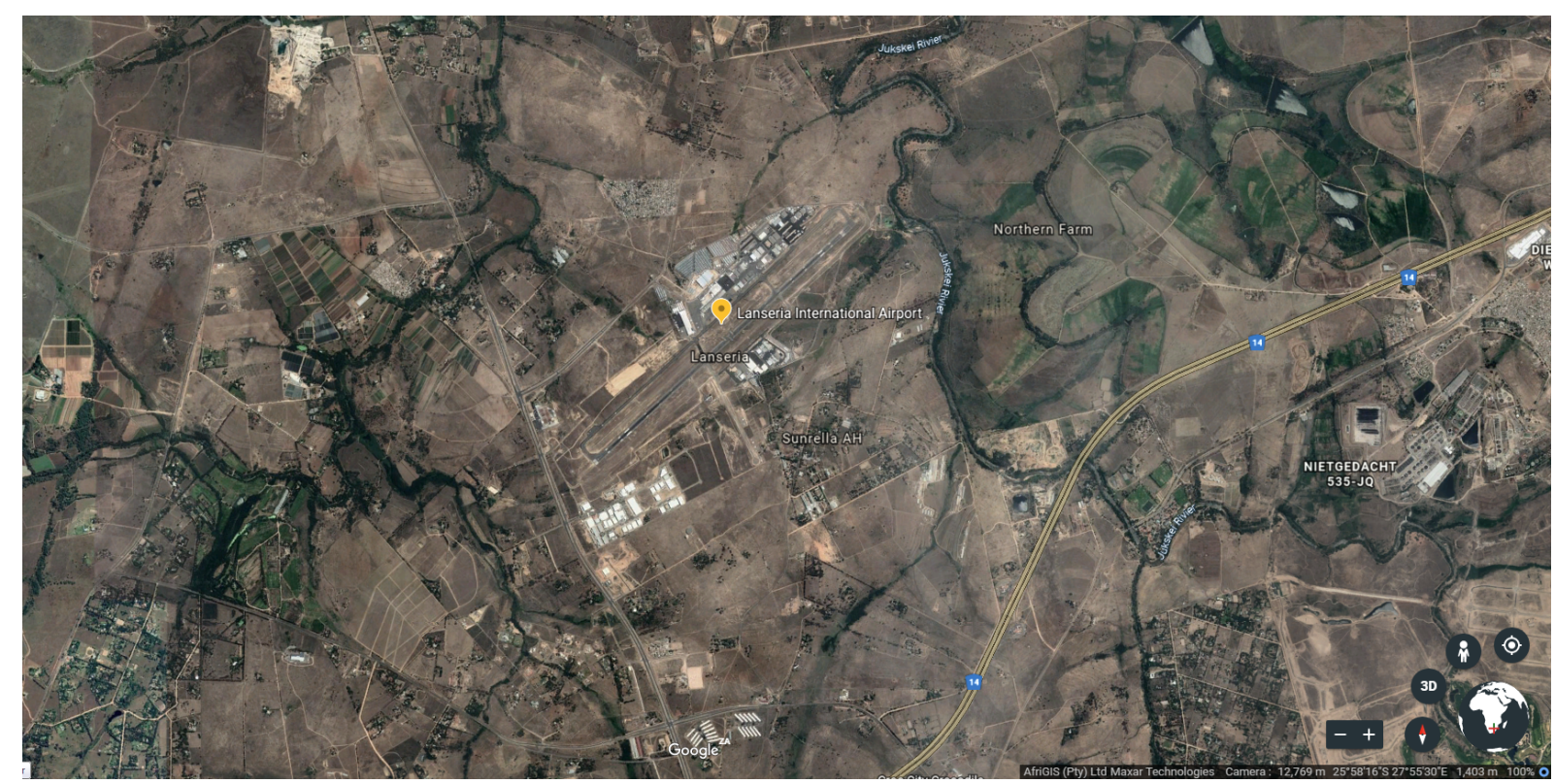

Figure C.1 Lanseria International Airport, NW of Randburg and Sandton surrounded by sparse farmland and owned privately. 


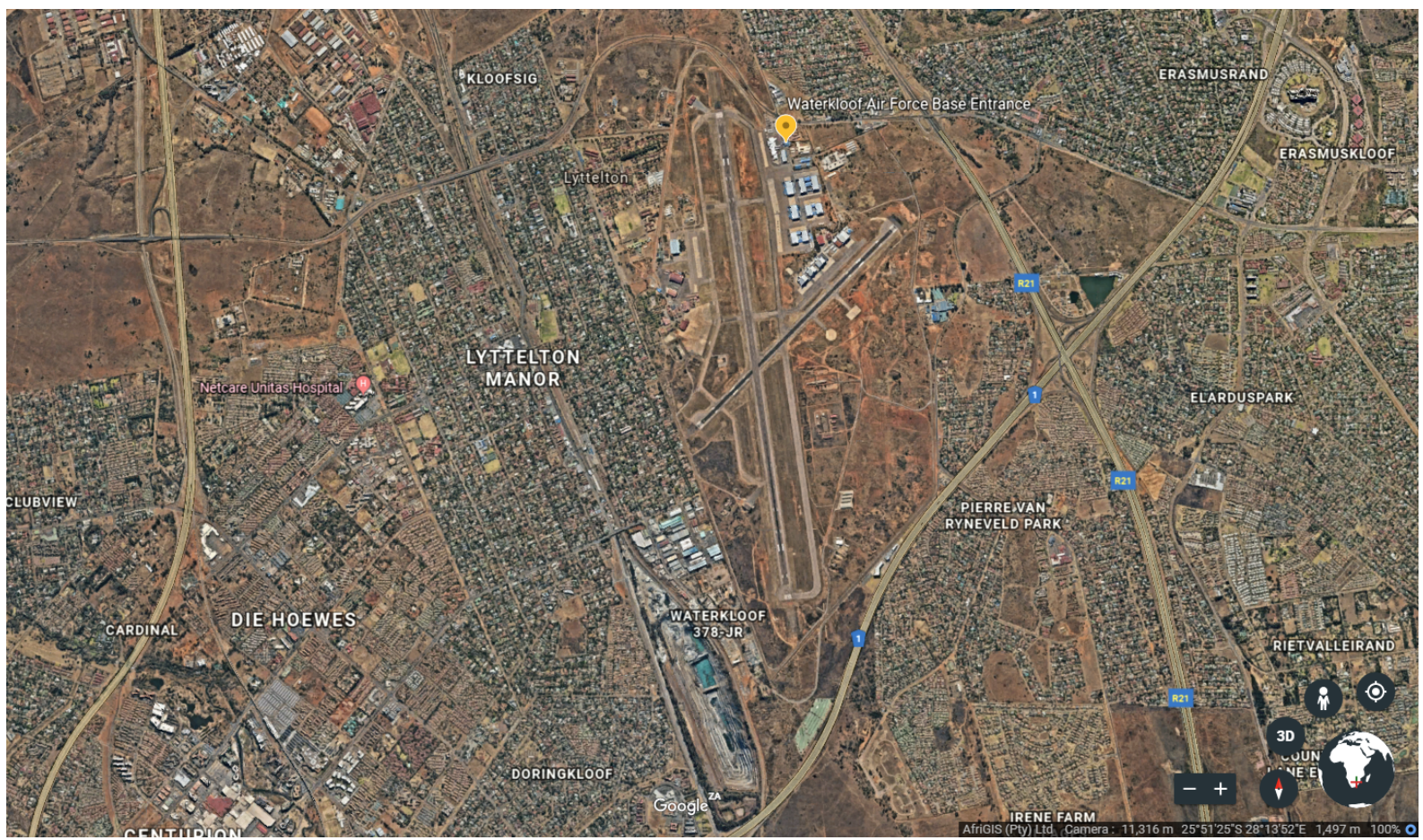

Figure C.2 Waterkloof AFB surrounded by dense civilian population.

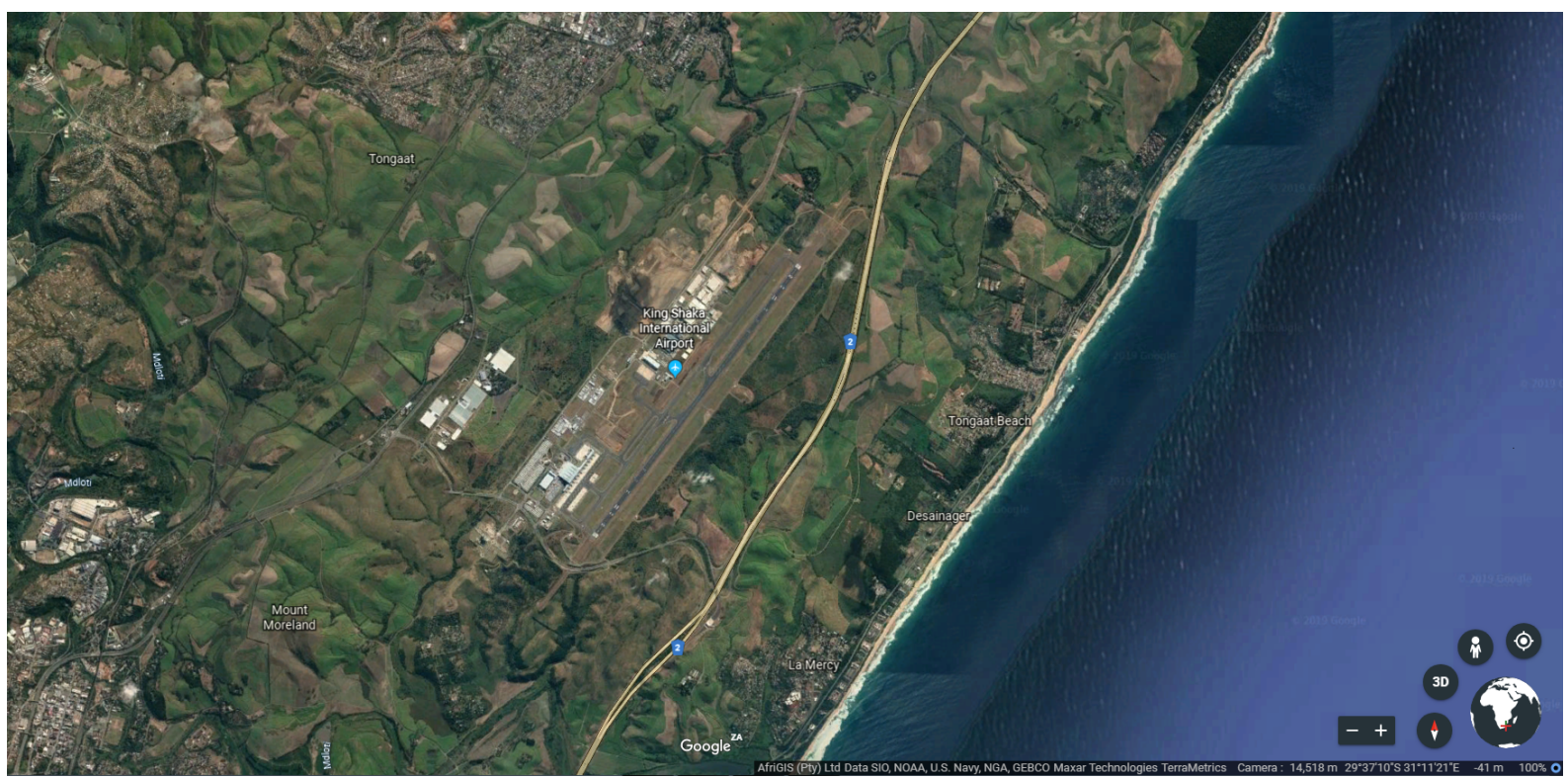

Figure C.3 King Shaka International Airport, surrounded by mostly sugar-cane fields and nucleated settlements. 


\section{Appendix D}

\section{Dream Chaser Mission Overview}

Provided below is a PowerPoint presentation providing an Overview of the Dream Chaser as presented to the delegates at the 2018 UNOOSA briefing. 


\section{MISSION OVERVIEW}

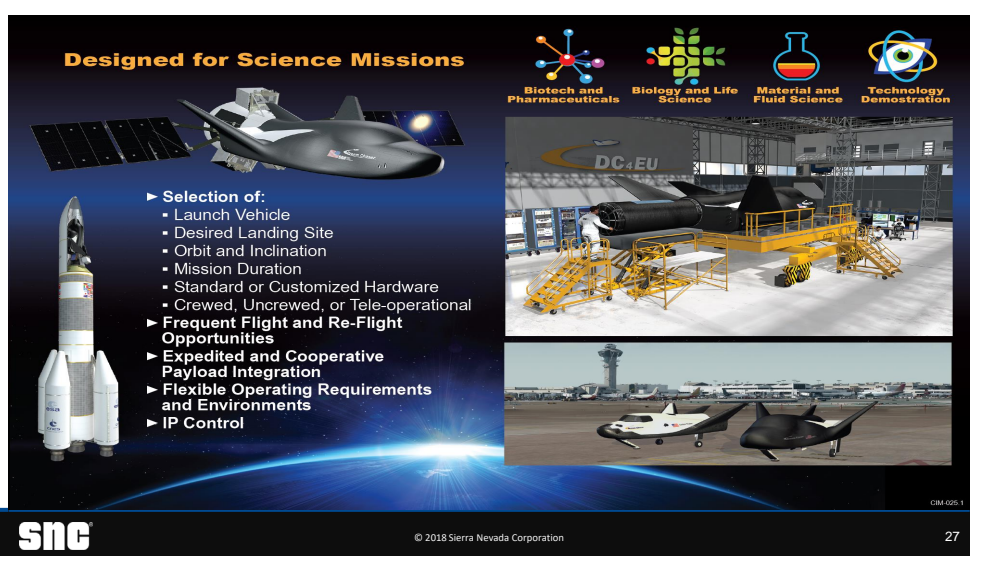

\section{Key Points of the Dream Chaser}

- Increased mission flexibility tailored to smaller set of PI needs

- Driven primarily by payload requirements, not ISS schedule or cargo vehicle manifest Broader orbit possibilities enable more
flexibility in space science mission set

- Minimal risk to payload operations caused by

payload transfer and checkout on ISS

-Mission emphasis on payloads focuses

priorities. Immediate operation enhances
s.

science return

Pay a re rem murcon

Payloads return uncompromised, returning
rapidly to laboratory environment

rapidy to laboratory environment

More flexible interface for Pl either in-person

or via telepresence

SDP

- Payload drives launch and landing requirements

- Lower cycle time speeds results and, if applicable, time to market

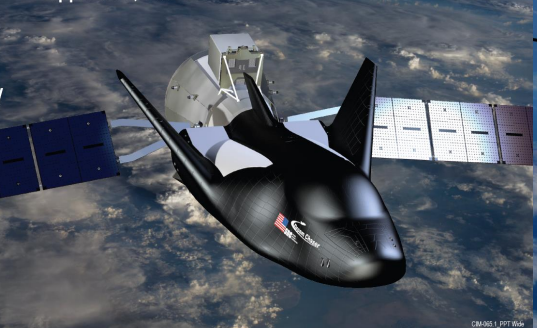
20191 serer neanate corporation
Mission Concept of Operations

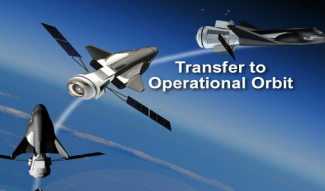

Up to 35 powered payloads operating in orbit

Deploy unpressurized payloads at beginning or end of mission

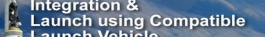

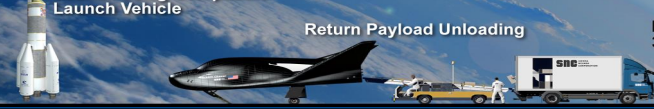
SIA

\section{Mission Assumptions}

- Targeting a $500 \mathrm{~km}$ circular orbit

- Between 0 - 35 degrees inclination

- 3 weeks on orbit

- Some payloads can be supported with late load operations, but the majority of payloads will be integrated weeks/days before launch

- The mission is uncrewed. Payloads will need to be autonomous

- Commands can be sent to the payloads periodically from the ground

- All data will be recorded and downlinked as available

- Launch vehicle and launch site undecided

- Landing site undecided

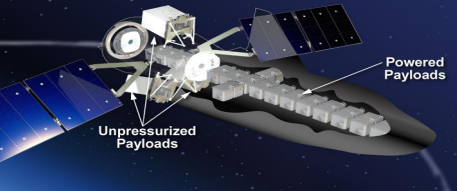




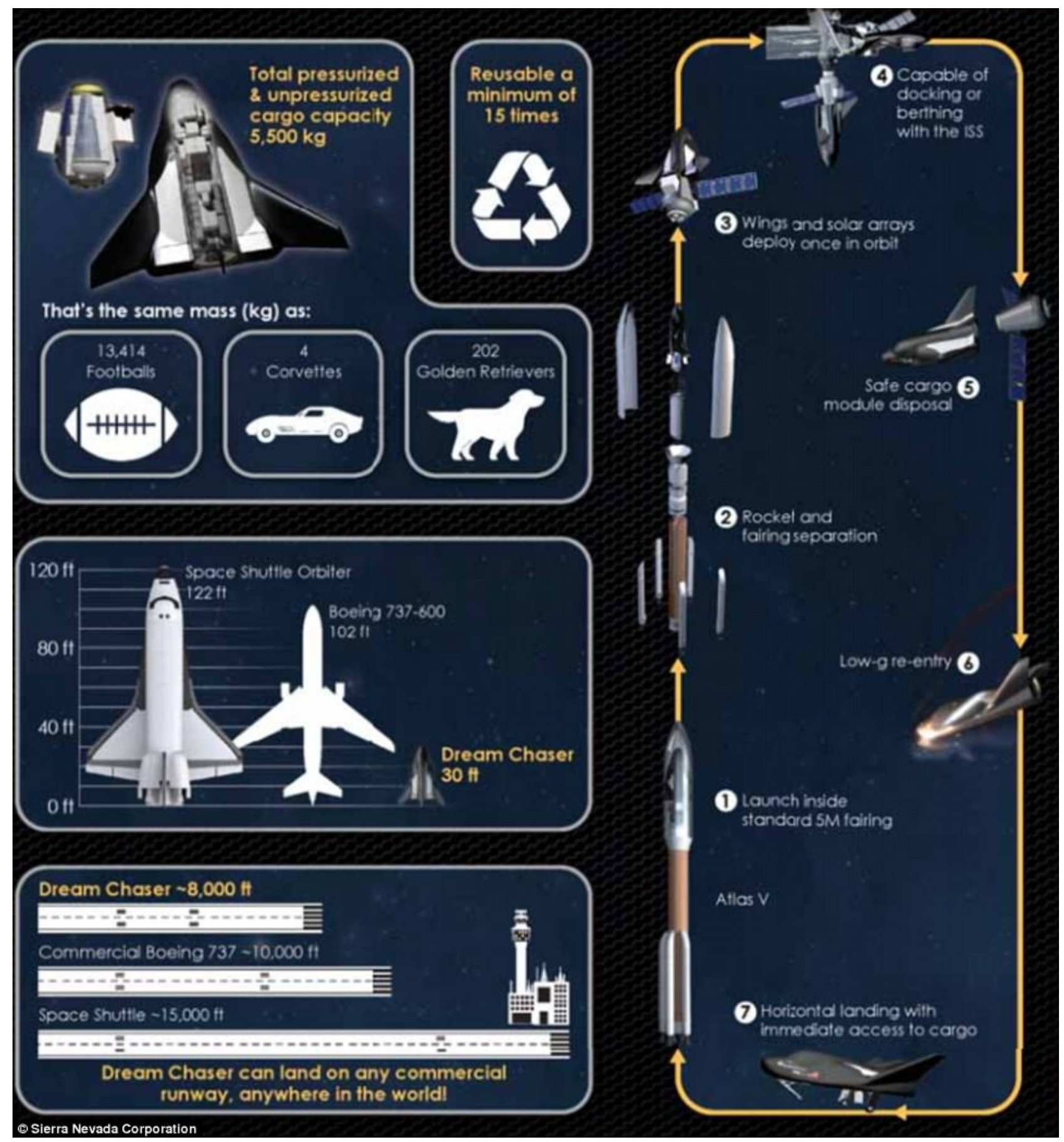

Figure D.1 Comparisons for our common knowledge to help grasp features for the Dream Chaser. 


\section{Appendix E}

\section{African Perspective on Integrated Space and Air Traffic Management}

\section{Conclusion and Recommendations}

(...) But from the African perspective any form of launch, re-entry and sounding rocket operations will go through the traditional process of separating or restricting airspace during a launch or re-entry as opposed to allowing both aircraft and spacecraft to operate simultaneously in the airspace.

Furthermore, the integration of space and air traffic management has raised some legal issues. In particular, should the regulation of space traffic be left to the International Civil Aviation Organisation by way of extending its jurisdiction? If so, this implies that spacecraft will be required to file a flight plans. Moreover, International Standard and Recommended Practices dealing with the rules of the space, spacecraft worthiness and spacecraft maintenance organisations just to mention a few will need to be adopted in the form of new Annexes. In addition, sovereignty is dealt with differently under the aviation law regime and the space law regime, the former recognises territorial sovereignty, whereas the latter does not recognise sovereignty because outer space is not suspect to claims of sovereignty. Consequently, this will be a challenge unless the delimitation between airspace and outer space is defined and agreed internationally in order to determine instances in which the principle of sovereignty will apply or not. In as far as liability is concerned, both regimes address the issue of damages and limitation on liability differently. Another bone of contention is the provision of air traffic services in the protozone. There is a general perception that the protozone is unregulated, however if we invoke the provisions of Annex 11 of the Chicago Convention, a Contracting State can accept the responsibility for providing air traffic services over the high seas or in airspace of undetermined sovereignty and in doing so may apply the SARPs in a manner consistent with that adopted for airspace under its jurisdiction. Consequently, the protozone is not literally 
unregulated; Annex 11 has laid down the foundation for regulation. Therefore, since both aviation law and space law deal with liability and sovereignty concerns differently, and not to mention the lack of delineation of airspace and outer space, a hybrid form of law should be formulated so that these regimes can compliment each other. Thus, aerospace law should be flexible and not static in order to address the legal issues arising from the amalgamation of SATM.

In the final analysis, the following recommendations are made:

- The international community conduct further research before extending the jurisdiction of ICAO to space traffic management in order to address issues such as the rules of the space, spacecraft worthiness, spacecraft maintenance organisation, flight plans for spacecraft;

- The Contracting States to the Chicago Convention should invoke the provisions of Annex 11 - Standard 2.1.2 in order to provide air traffic services in the protozone;

- African States should revive the defunct launch facilities on the continent in order to establish launch capability in the region before we can talk about integrating space traffic into ATM;

- The fragmented organisation of ATM in the region should be harmonised; alternatively African countries could join the ASECNA;

- Africa should implement the Single African Air Market, which will harmonise the provisions of air navigation services in the region and eventually contribute to the integration of SATM in the region;

- More forecasting is required in order to analyse the viability of space tourism in Africa; The international community should clearly demarcate where the airspace ends and where outer space begins;

- Aviation law and space law should be kept flexible in order to complement each other during the integration of SATM.

$\mathrm{S}$

Note. Work here extracted from Reference [63]. 